\title{
EXPLORING THE PARADOXES OF ADDRESSING SUSTAINABILITY IN COMMERCIAL RESEARCH: A STUDY OF SCIENTIST VIEWS
}

By

Mary Ashby

\begin{abstract}
A thesis
Submitted to Victoria University of Wellington

in fulfilment of the requirements for the degree of

Doctor of Philosophy in Management
\end{abstract}

Victoria University of Wellington

2015 


\section{Acknowledgements}

This has been an enriching, intellectually challenging, and rewarding journey made possible through the dedication of my supervisors, Dr Sally Riad and Professor Sally Davenport, Victoria University of Wellington. Their generosity and wisdom is extraordinary, and I am very fortunate that they were willing to supervise my work.

I am also grateful for support received from my former employer, Massey University. I especially thank my friends and former colleagues for their interest and encouragement. Staff and fellow students in the School of Management at Victoria University of Wellington have supported me in numerous ways. I appreciate the contribution they have made to the wonderful experience I have had as a doctoral student.

Without my family's love, patience, and prayers this experience would not have been possible. I thank them all, especially my husband, Rob.

I am very grateful for the financial support received from Industrial Research Limited and Victoria University of Wellington through the award of one of the IRL PhD Scholarships in Business.

The research scientists who took part in this study generously gave of their time and views. I could never feel that I have done full justice to their contribution. 


\begin{abstract}
Research scientists increasingly engage in commercial research as well as face the need to address sustainability by taking into account the social, environmental and economic consequences of development activities. This role often entails addressing contradictory imperatives. Though paradox has pervasive effects on science work and managing for sustainability, it remains underexplored in these contexts. This research is positioned at the novel intersection of three bodies of work: sustainability in the context of science work, commercial research, and paradox in management and organisation. It engages a sensemaking perspective to examine the experiences of research scientists with managing sustainability in commercial research and explicates the tensions they perceive, as well as the ways in which they respond to them.

The study is primarily based on a set of 44 semi-structured interviews conducted with research scientists across four Crown Research Institutes in New Zealand. It offers two sets of findings. First, it identifies three main paradoxes research scientists perceive and elucidates their dynamics. These include the paradoxes of service ethos, role identity, and professional integrity. Second, it explicates perceived responses to these paradoxes, both constraining and productive. The former comprise the practices of opposing, isolating, over-committing, and suppressing. The latter, productive responses, consist of a range of management tactics premised on differentiation or integration. Differentiation tactics include diversification in scope of services, variation in work organisation and responsibilities, and incrementalism. Integration tactics used with external parties comprise identifying financial synergies between public and commercial projects, (re)framing problems and solutions for clients, (re)positioning
\end{abstract}


across roles and identities, as well as harnessing economies of scope by co-authoring with clients.

This research contributes to the literature on research management by casting the emphasis on perceived paradoxes to be navigated when addressing sustainability in commercial research. It also offers a secondary contribution to the literature on paradox in management by contextualising organisational paradoxes and their management in science work. Specifically, it provides new insight into the ways by which scientists' engagement with sustainability cuts across ethos and shapes their views on professional integrity. It also contributes to a nuanced understanding of role identity by focusing on the tensions research scientists at Crown Research Institutes experience in the dual role of advocates of change towards sustainability and allies of business. Altogether, this work extends existing organisational research by offering insights into scientists' experience of paradox and its management when engaging with sustainability in commercial research. 


\section{Contents}

Acknowledgements

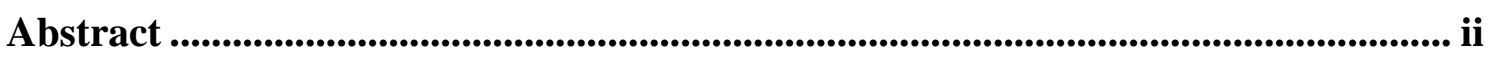

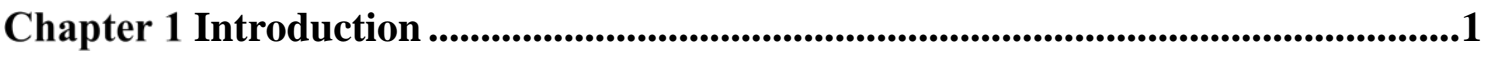

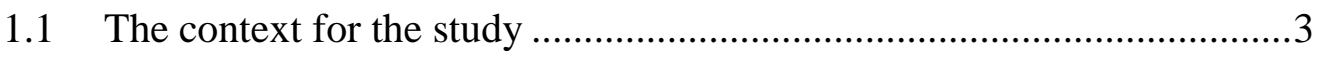

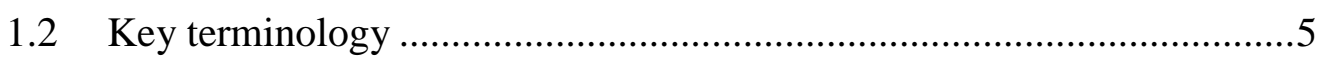

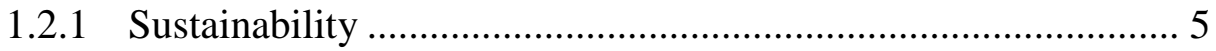

1.2.2 Organisational paradox ......................................................... 7

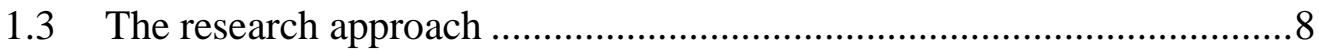

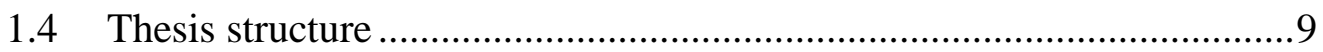

Chapter 2 Literature Review.............................................................................................11

2.1 Background to the study of science work and sustainability................11

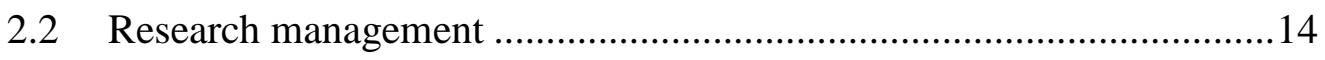

2.2.1 Science work and commercial research................................. 15

2.2.2 Conflictions in science work ............................................... 16

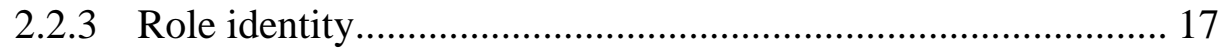

2.3 Sustainability in the context of science work .....................................19

2.3.1 The concept of sustainability ................................................ 19

2.3.2 Sustainability and science work.............................................. 20

2.3.3 Managing external relationships ........................................... 22

2.4 Paradox in management and organisation .........................................23

2.4.1 A paradox perspective ….................................................... 23

2.4.2 Overarching themes on paradox ............................................. 24

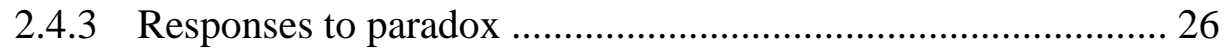

2.5 The literature: A closing overview ................................................28 


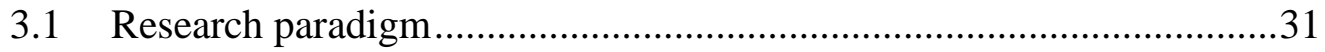

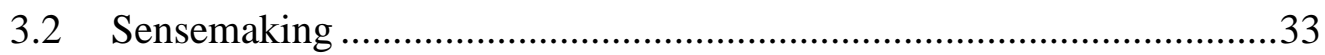

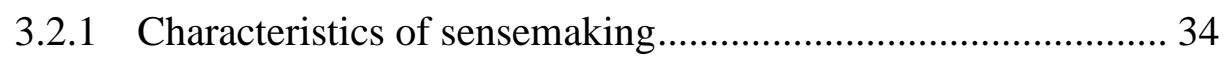

3.2.2 Sensemaking and organisation ............................................... 41

3.2.3 Emerging research on sensemaking and paradox ................... 43

3.3 Crown Research Institutes (CRIs) and their context............................44

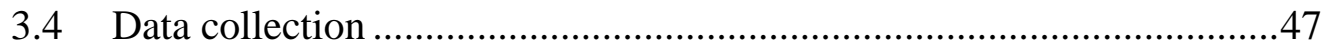

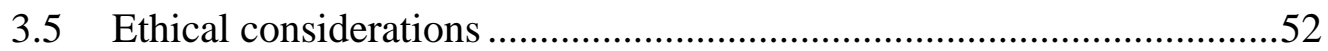

3.6 Data analysis and categorisation .....................................................53

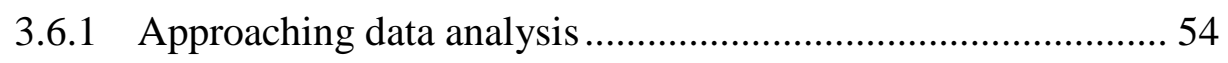

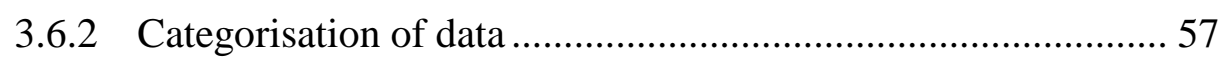

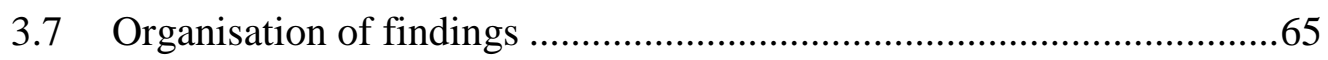

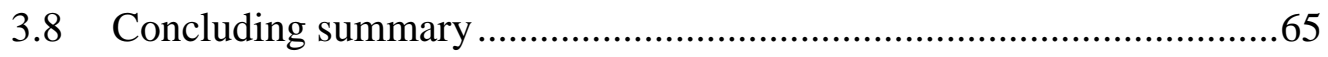

Chapter 4 Performing and the paradox of service ethos ..............................................66

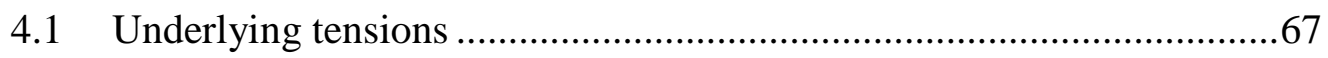

4.2 Defensive responses to the paradox of service ethos............................76

4.3 Managing the paradox of service ethos ..............................................92

Chapter 5 Belonging and the paradox of role identity ........................................103

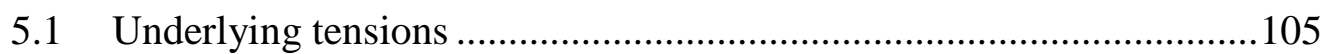

5.2 Defensive responses to the paradox of role identity ..........................111

5.3 Managing the paradox of role identity ..............................................119

Chapter 6 Organising and the paradox of professional integrity ...........................126

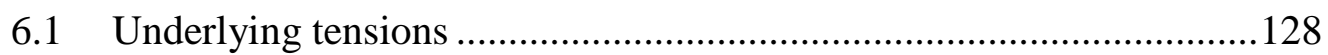

6.2 Defensive responses to the paradox of professional integrity .............138

6.3 Managing the paradox of professional integrity ...............................146 


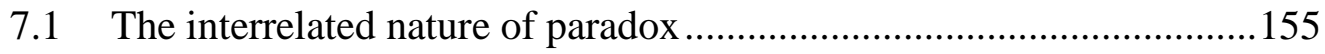

7.2 Developing the capability to engage with paradox ............................157

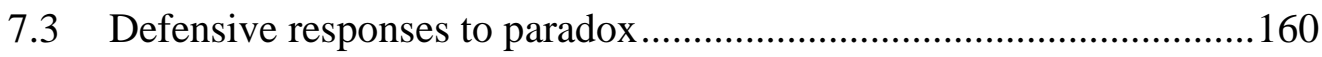

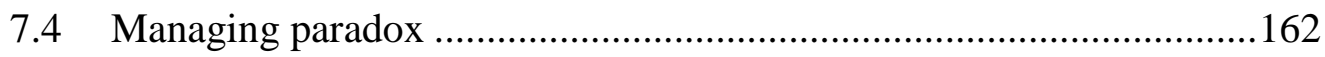

7.4.1 An incremental approach towards addressing sustainability.. 162

7.4.2 The relevance of requisite variety....................................... 164

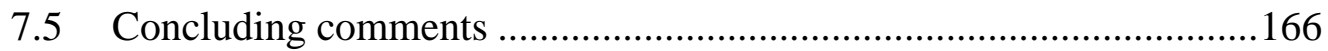

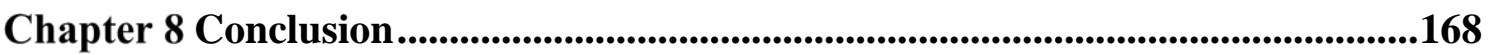

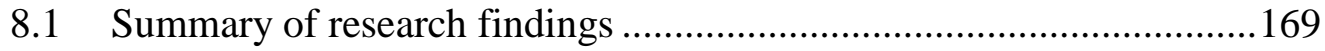

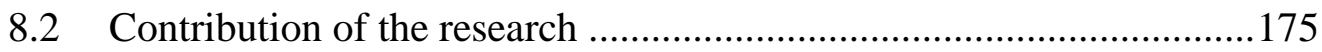

8.2.1 A paradox perspective on research management................... 175

8.2.2 Managing for sustainability in the context of science work ... 176

8.2.3 The paradox perspective in organisational analysis .............. 177

8.2.4 The sensemaking perspective …........................................ 178

8.3 Limitations of the research and avenues for future research ..............179

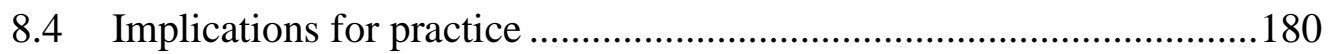

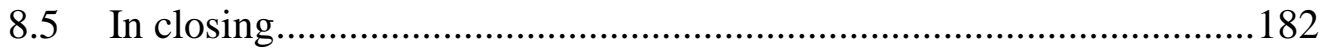

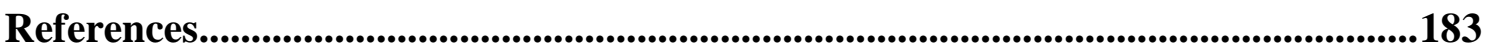

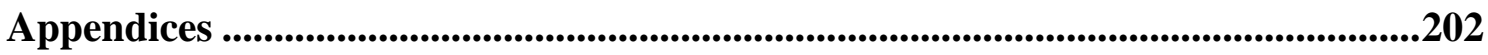

Appendix I Crown Research Institutes Act 1992 (Part 1, Section 5) ...........................203

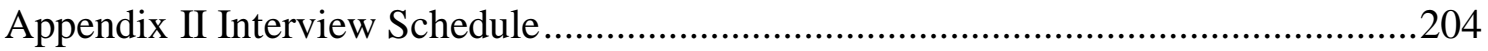

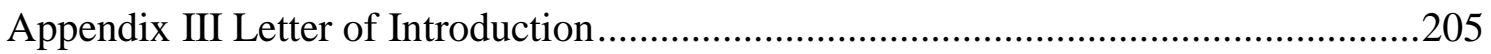

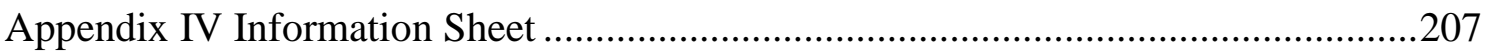

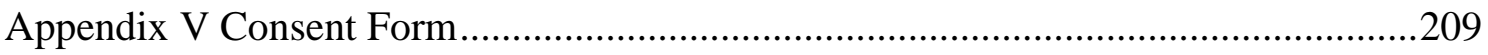




\section{List of Tables}

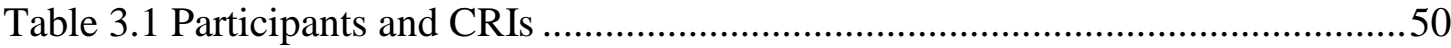

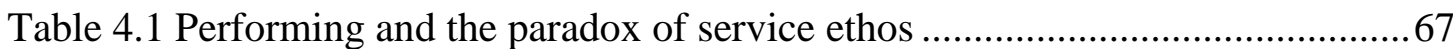

Table 4.2 Defensive responses to the paradox of service ethos .................................77

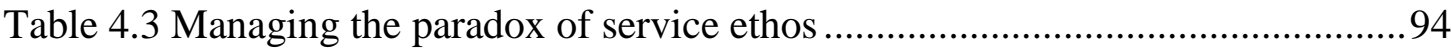

Table 5.1 Belonging and the paradox of role identity ............................................ 104

Table 5.2 Defensive responses to the paradox of role identity.................................112

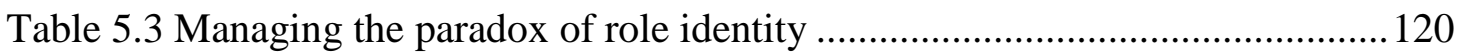

Table 6.1 Organising and the paradox of professional integrity ..............................127

Table 6.2 Defensive responses to the paradox of professional integrity....................139

Table 6.3 Managing the paradox of professional integrity .....................................147

Table 8.1 Paradoxes perceived by research scientists ............................................170

Table 8.2 Perceived defensive responses to paradox ............................................ 172

Table 8.3 Managing paradox through differentiation and integration...................... 174 


\section{Chapter 1}

\section{Introduction}

I'm aware of the range of perceptions [relating to sustainability]. What I do like to do is analyse them and try and find out why people think in a particular way. If you know what their perception is and you can anticipate a response, it does influence the way that you treat that person, approach them and their organisation (Fiona, Science Group Manager, Inspire).

Managing for sustainability entails addressing contradictory imperatives, especially on the part of scientists (Benessia et al., 2012; Ramirez, 2012). As Fiona (pseudonym) explains above, each encounter with a client is different and its challenges include making sense of the ways in which people view sustainability, and responding in ways that facilitate productive engagement. Indeed, prior work points to a range of tensions in science work generally (Hackett, 2005), and specifically in the negotiation of commercial research relationships (Cassiman, Di Guardo, \& Valentini, 2010; Heinze \& Kuhlmann, 2008; Lam, 2007). However, the tensions experienced by research scientists as they engage in commercial research with wider social and ecological implications have rarely been examined.

This study is positioned at the novel intersection of three bodies of work: research management (e.g., Bercovitz \& Feldman, 2008; Glenna, Welsh, Ervin, Lacy, \& Biscotti, 2011), sustainability in the context of science work (e.g. Brandt et al., 2013; Gibbs, 2009; Markard, Raven, \& Truffer, 2012), and paradox in management and organisation (Andriopoulos \& Lewis, 2009; Gotsi, Andriopoulos, Lewis, \& Ingram, 2010). The last, paradox, is a pertinent theoretical approach in this context since understanding the tensions confronting individuals and their organisations enables productive forms of engagement and management (Andriopoulos \& Lewis, 2009; Bednarek, Blumenfeld, \& Riad, 2012; 
Gotsi et al., 2010). The premise is that people in organisations face everyday paradoxes, and that the tensions arising from their contradictory forces should be managed (rather than suppressed) for organisations to thrive (Clegg, Vieira da Cunha, \& Pina e Cunha, 2002; Smith \& Berg, 1987a).

A key message to emerge from the World Summit on Sustainable Development in 2002 was the need for scientists to extend their traditional contribution to sustainability by working more readily with groups to find practical solutions to sustainability problems at the local level (Clark \& Dickson, 2003). Given the role that research scientists play in supporting organisations to engage with sustainability, there is a need for more finegrained analyses of the paradoxes they face as they interact with commercial clients who may prioritise financial imperatives when issues of the environment and social responsibility are at stake. Accordingly, this study draws on a sensemaking perspective (Weick, 1995) to address the following research questions:

What paradoxes do public research scientists perceive when engaging with sustainability in commercial research?

What responses (to paradox) do public research scientists see as constraining or enabling their engagement with sustainability in commercial research?

By drawing on paradox, this research brings a new theoretical approach to the study of research management, and advances the paradox perspective in organisational analysis. Specifically, it contextualises general paradoxes and their management into the environment for science work and sustainability, and affirms the utility of management practices based on differentiation and integration (Andriopoulos \& Lewis, 2009; Gotsi et al., 2010). In doing so, this research sheds light on the experiences of public research scientists, a science group with increasing experience of addressing issues of sustainability in commercial relationships formed with both public and private sector clients. Yet, public 
research scientists' efforts have, until now, received limited attention in the research management literature. The analysis details the contradictory tensions research scientists perceive, and introduces concepts that provide new insight into the ways in which they engage productively or respond defensively when confronted with paradox. By focussing on scientists' sensemaking, the findings also provide a rare glimpse into the reflective practices engaged in by research scientists whose institutionally-determined role requires them to represent the public interest, and to simultaneously generate income from commercial research activities. Underpinning the research scientists' role is the requirement that Crown Research Institutes (CRIs) engage in science research that is excellent, ethical, socially responsible, and relevant (Science New Zealand, 2014). Through this research, CRIs are also expected to maintain their financial viability and benefit New Zealand by producing practical outcomes for clients (Office of the AuditorGeneral, 2013).

In what follows, I provide an overview of the research context and its history, define the key terms used in this thesis, and introduce the methodology. The chapter concludes with an outline of how the thesis is organised.

\subsection{The context for the study}

The data used in this study were primarily based on 44 interviews with public research scientists across four of New Zealand's seven Crown Research Institutes (CRIs). As stipulated in the legislation governing CRIs (CRI Act 1992), their purpose and operating principles include undertaking research for the benefit of New Zealand, and facilitating the sharing of knowledge and technological developments by providing a range of research services to a variety of government, local body, and commercial organisations. 
Each of these state-owned enterprises is aligned with a productive sector of the economy or a grouping of natural resources.

Many research scientists lead global research teams (Crossley, 2013) whose work underpins both local and global policy debates and science-based solutions (Science New Zealand, 2013). CRIs are accountable to shareholding ministers for implementing their government-directed mission, as is the case for government-sponsored enterprises (GSEs) in the US and quasi-autonomous nongovernmental organisations (quangos) in the UK and elsewhere (Andre, 2011). Funding sources include contestable and non-contestable government funds, local and central government agency service contracts, and commercial work. Key strategic relationships include those with the Crown, public-good research funding agencies, and commercial clients. The focus of this study is on the latter: contractual relationships with industry groups and businesses.

Through the relationships CRIs have with businesses, a wide range of privatesector innovation and growth challenges are addressed. Those relevant to sustainability include: the development of fully renewable 'green' products, and technologies and practices that boost productivity while reducing or eliminating harmful environmental impacts; the development of residue-free pest and disease controls, and sustainable production systems; and the development of programmes that allow organisations to measure, manage, and mitigate their greenhouse gas emissions and reduce their impact on the environment (Science Media Centre, 2015). In carrying out these and other applied and basic research activities, as well as in conducting their affairs more generally, CRIs are required to demonstrate a commitment to social responsibility by having regard to the interests of the community while maintaining both their scientific capability and their financial viability (Crown Research Institute Taskforce, 2010). This requirement entails a range of responsibilities including undertaking research that benefits New Zealand, 
endeavouring to accommodate or encourage community interests, complying with ethical standards, promoting and facilitating the application of research results and technological developments, while also generating an adequate rate of return on investment and operating as a successful going concern (Appendix I: Part 1, Section 5 of the CRI Act 1992). Managing in accordance with the terms of the Act confronts research scientists with challenging demands. However, very little academic research has been conducted on how organisations with both public and private characteristics simultaneously engage with commercial imperatives and a social responsibility paradigm (Andre, 2011).

\subsection{Key terminology}

The thesis focuses on the paradoxes confronting public research scientists when seeking to engage with issues of sustainability in commercial research, and the ways in which they respond to paradox. In this section, I clarify the meanings this study assigns to the terms 'sustainability' and 'paradox' by defining and contextualising each.

\subsubsection{Sustainability}

Sustainability is a highly contested concept for which there is, as yet, no universally accepted definition. Rather, its meaning can vary across contexts, and change in accordance with the function that is assigned to it. The following definition of sustainable development produced by the Brundtland Commission in 1987 is widely used as a starting point for other interpretations:

Sustainable development is development that meets the needs of the present without compromising the ability of future generations to meet their own needs (World Commission on Environment and Development, 1987, p. 8).

The Brundtland definition emphasises the concept of 'needs' and alludes to the limited availability of resources in meeting these needs. However, several "parallel but distinct 
discourses around sustainability" have emerged since (Redclift, 2005, p. 225), resulting in various and sometimes conflicting interpretations of related issues (Epstein, 2008). In the policy context, the term 'sustainability' has been used in discourse in strategically ambiguous ways (including as a synonym for 'enduring') in order to promote coherence between conflicting ideologies and goals (Leitch \& Davenport, 2007). From an ecological perspective, an organisation might be described as 'sustainable' if it has adapted its practices to use renewable resources, and is accountable for the environmental impacts of its activities (Capozucca et al., 2009). Social scientists often acknowledge that sustainability has its roots in systems thinking by emphasising the connections between parts; for example, it has been described as the ability of a system to:

maintain its processes, functions, and biological diversity in the long term, with human interactions being seen as an integral part of that ecosystem (Stevens, 2012, p. 589; emphasis in original).

This study draws on the following definition that encompasses a concern for both sustaining the natural environment and embracing notions of social justice:

[Sustainability is] a dynamic state that has the capacity to endure; it is a broad systemslevel concept that transcends entity and national boundaries to embrace notions of equity, equality, and futurity in relation, but not limited to economic, social, and environmental conditions that support life for all. It is simultaneously global and local in orientation (Collins \& Kearins, 2010, p. 500).

By explicitly acknowledging the normative, social, and political dimensions of sustainability, Collins and Kearins's (2010) definition captures the breadth and complexity of the issues research scientists potentially face in linking knowledge to action in the context of commercial enterprise. As Miller (2013) states: 
Sustainability and its problems cut across disciplinary boundaries and defy both problem definition and easy solutions; they challenge not just the analytical tools and approaches of scientists but the usefulness of scientific knowledge (p. 290).

The commercial research context represents one in which research scientists engage across boundaries to potentially address the economic, social, and environmental dimensions of sustainability. This study focuses on their experiences and on the actions they see as desirable and possible to take when interacting with business.

\subsubsection{Organisational paradox}

This research shares the view of other authors that we experience paradox when elements of our actions, thoughts and emotions that appear logical in isolation seem irrational when juxtaposed (Luscher, Lewis, \& Ingram, 2006). Within organisations, there are multiple types of paradox including those embedded in structures, goals, processes, cultures and identities. A key characteristic is the experience of "contradictory yet interrelated elements that exist simultaneously and persist over time" (Smith \& Lewis, 2011, p. 382). These contradictory forces often surface as 'tensions' between, for example, strategies of exploring and exploiting (Andriopoulos \& Lewis, 2009; Papachroni, Heracleous, \& Paroutis; Smith, 2014), financial imperatives and social missions (Battilana, Sengul, Pache, \& Model; Jay, 2013; Michaud, 2013), freedom and constraint in the creative process (Rosso, 2014), and between multiple identities (Gotsi et al., 2010). The term 'tension' encompasses the related, yet distinct, phenomena of contradictions and dilemmas (Michaud, 2013).

A core premise of the paradox perspective is that tensions are inherent in organising and should be worked through (Gotsi et al., 2010; Luscher \& Lewis, 2008). Accordingly, the focus is on understanding, rather than resolving problems so as to bring new possibilities and even greater complexity (Luscher et al., 2006). Acquiring such 
understanding requires paradoxical thinking or the adoption of "a both/and mind-set", a trait that leads to the discovery of the links between opposing forces, and moves organisational research beyond "either/or debates" to delineating focal paradoxes, the range of responses, and ideal outcomes (Lewis \& Smith, 2014, p. 3). Strategies for managing paradox include differentiating and integrating tactics to clarify alternatives and their interrelationships (Andriopoulos \& Lewis, 2009; Smith \& Tushman, 2005). However, there remains a need for further research that enhances our understanding of paradox and organisation. There is also specific need for research that examines the ways in which competing demands can be accommodated in increasingly complex situations (Smith, 2014; Smith \& Lewis, 2011), such as those encountered when engaging with issues of sustainability (Hahn, Pinkse, Preuss, \& Figge, 2015).

\subsection{The research approach}

This research focuses on research scientists' perceptions of, and responses to, paradox. It aligns with an interpretive worldview which holds that individuals actively construct knowledge, and embrace multiple realities according to their membership of different groups (Ramarajan, 2014). Congruent with these assumptions, the study offers contextualised understanding of the realities constructed by research scientists. In doing so, it 'illustrates' rather than seeks to 'prove' a particular perspective or reality by drawing on universal laws or rules (Willis, 2007). Tenets of sensemaking (Weick, 1995) are used to reflect on the proactive role research scientists play in shaping and structuring their realities (Jay, 2013; Weick, Sutcliffe, \& Obstfeld, 2005). Central to sensemaking is the idea of the human subject (with a body, mind, heart, and spirit) living in a time space, moving between a past, present, and a future, anchored in material conditions; yet at the 
same time, the subject is endowed with the capacity to make sense of various phenomena including abstractions, memories, and plans (Dervin, 2003).

As a metatheoretical tool, sensemaking has been found to be particularly useful for understanding the "small-scale, local, sometimes individualized processes by which people make sense", sometimes with profound consequences (Brown, Colville, \& Pye, 2015, p. 273). A useful way in which to view sensemaking is as a series of linkages:

Sense and organizing emerge when a story begins to come together, identities begin to make sense, identities and actions can be given a sense of narrative rationality and we can connect plot and character (Cunliffe \& Coupland, 2012, p.81).

Cunliffe and Coupland's (2012) above definition weaves together various elements of sensemaking (i.e., "sense, organizing, story, identities, actions, making sense, giving sense, narrative rationality, plot, and character") in a way that suggests "beginnings and emergings", and conveys "a sense of ongoing forming and dissolving" (Weick, 2012, p. 147). The premise is that people can be seen as continuously interpreting and actively authoring the situations in which they are embedded (Brown et al., 2015). As Weick (1995, p. 31) states, people produce their environments by acting, ultimately creating "the materials that become the constraints and opportunities they face". Hence, a sensemaking perspective offers the potential to provide insight into the situations research scientists see as paradoxical, and to illuminate the reasoning that underlies their perception of responses that enable or constrain the management of sustainability in commercial research.

\subsection{Thesis structure}

This thesis is organised into eight chapters, three of which (Chapters 4-6) focus on the findings of the study. The contents of each are outlined below. 
Chapter 2 reviews the literature that informs this study. It begins with an overview of the literature on commercial research, and key contributions that address the issue of sustainability in the context of science work. It concludes with an overview of the literature on paradox in management and organisation.

Chapter 3 presents the research methodology, explaining in more detail the selection of an interpretive research design, and the sensemaking approach on which the study is premised. It then offers an overview of the CRI context, the processes of data collection used, and the abductive approach to data analysis adopted.

Chapters 4, 5 and 6 each examine a substantive paradox confronting public research scientists: paradoxes of performing, belonging, and organising, respectively. Each of these chapters also analyses and identifies the responses research scientists see as enabling or constraining their engagement with sustainability in commercial research.

Chapter 7, the Discussion, addresses the research questions by identifying significant themes across all three paradoxes. Finally, the Conclusion, Chapter 8, presents the main contributions of this study. It also summarises the study's theoretical and practical implications. In closing, the thesis poses potential avenues for future research. 


\section{Chapter 2 \\ Literature Review}

This study contributes to knowledge on research organisation and management by entwining three strands of the literature. These include research management (e.g., Bercovitz \& Feldman, 2008; Glenna et al., 2011), sustainability in the context of science work (Benessia et al., 2012; Brandt et al., 2013), and paradox in management and organisation (Andriopoulos \& Lewis, 2009; Gotsi et al., 2010). The focus is on the novel intersection of these bodies of literature, namely the competing demands research scientists face, and the ways in which they respond to them. Together, these strands of the literature both inform the examination of paradoxes that confront research scientists (when addressing sustainability and managing commercial relationships), as well as set the scene for this research.

This chapter begins with an overview of the literature that foregrounds the themes in this study. In the review that follows, the concepts and theoretical insights that inform the work at hand are explored. These are drawn primarily from the management literature, but also include contributions made to other disciplines (e.g., development studies and sustainability science).

\subsection{Background to the study of science work and sustainability}

Around 60 years ago in an article first published in the American Scientist, Kubie (1960) expressed concern at the apparent lack of understanding of the unconscious forces that determine whether or not science work will become both externally productive and internally fulfilling while, at the same time, result in a major contribution to human wisdom. A decade later, when scientists were thrust into the political arena as the 
environmental movement took shape, concerns were raised about the new science and society relations being established and their effect on scientists' ability to maintain the integrity and development of their discipline (Nelkin, 1977). The 1990s witnessed the emergence of the opposing logics of open dissemination of research in the public interest, and suppression of information based on market criteria as industrialised democracies around the world dismantled national science policies and increasingly focussed on the economic benefits to be derived from scientific discovery (Leitch, Motion, Merlot, \& Davenport, 2014). The view of science as a saleable commodity has since been widely contested, as has the impact of an unstable funding system on science outcomes and scientists' careers (Davenport \& Bibby, 2007; Krishna, 2014; Leitch \& Davenport, 2005; Leitch et al., 2014). Though the changing nature of science work continues to capture interest, it is similarly claimed today that understanding new regimes and their consequences for science work remains limited due to the narrow empirical focus of most contributions, and the oversimplified theoretical assumptions often made about the underlying process of change (Lam, 2010).

Studies of science work often focus on changes occurring as a result of the sweeping reforms introduced in New Zealand and, to a lesser extent, other Western countries during the 1980s. For instance, empirical studies highlight the implications of science reforms for public science in terms of the content and conduct of research, and public science's response to external constraints (see, for instance, Cartner \& Bollinger, 1997; Sanz-Menendez \& Cruz-Castro, 2003). The consequences of public participation in the setting of the science research agenda have also been explored (e.g., Cooper, 2009; Goven, 2006; Small \& Mallon, 2007), as has the diversity of institutional contexts within which research scientists operate, and the ways in which they go about engaging with these contexts (e.g., Cooper, 2009; Duberley, Cohen, \& Mallon, 2006; Mallon, Duberley, \& 
Cohen, 2005). At a time when the epistemological superiority of science is increasingly being questioned (Fahy \& Nisbet, 2011), the relationship between public understanding of science and positive attitudes towards science continues to capture interest (Allum, Sturgis, Tabourazi, \& Brunton-Smith, 2008; Evans \& Durant, 1995; Gauchat, 2011).

Scientists' involvement in the management of sustainability increased exponentially after the United Nation's World Commission on Environment and Development (the Brundtland Commission) brought to the fore the sustainability challenges confronting society, and presented sustainable development as a political reality in its 1987 Report "Our Common Future" (Brundtland, 1987). A few years after the release of this Report, the introduction in New Zealand of the Resource Management Act 1991 led to the emergence of a more prominent role for the research scientist in the management of the environment in multiple contexts. In the years since, as science has become more entwined with policy, commercially-driven, and linked with a professional management structure, scientists have increasingly engaged with the private sector in a commercial sense (Crown Research Institute Taskforce, 2010). Their engagement with sustainability comes in many guises but now includes, for example, encouraging industry groups and businesses to balance economic interests with social and ecological interests through the development and integration of cleaner technologies, renewable forms of energy, and production methods that ensure the economic and environmental sustainability of plant and marine-based systems (Office of the Auditor-General, 2013).

As is the case in science-business contexts and elsewhere, achieving the goal of sustainability necessitates a focus on unprecedented and interconnected challenges (Brandt et al., 2013; Geels, 2010), and approaches that "cut across the divides of national sovereignty, of limited strategies for economic gain, and of separated disciplines of science" (Brundtland, 1987, p. 6). An inherent tension is that the parties involved typically 
perceive given problems differently. Hence, a balance is often needed between policy alternatives that satisfice in terms of resolving the issues, and those that garner the support of stakeholders (Gregory \& Keeney, 1994). However, little is known about the everyday exchanges taking place between scientists, business, and other stakeholders in New Zealand or elsewhere as the parties navigate the challenges of sustainable development (Brandt et al., 2013).

The tendency in studies of science work to focus on macro-level norms and structures and their implications for organising (Lam, 2010) results in few contributions to the literature that expressly acknowledge or theorise the everyday challenges scientists face individually (Cohen, Duberley, \& McAuley, 1999). Notable exceptions (to which I return later) include: Zabusky and Barley's (1997) analysis of patterns of identification in science organisations; Mallon, Duberley, and Cohen's (2005) examination of the sensemaking processes employed by scientists when navigating change; and Lam's (2010) analysis of the ways in which academic scientists seek to protect and negotiate their positions, and make sense of their professional role identities. Accordingly, by focusing on the paradoxes research scientists perceive at an individual-level, and on the rationales and perspectives guiding their approaches as they engage with sustainability in commercial research, this study generates new insights that contribute to knowledge on research organisation and management.

\subsection{Research management}

Literature in this area has engaged with science work and commercial research, the conflictions faced in science work, as well as role identity. I review each, in turn. 


\subsubsection{Science work and commercial research}

There is growing interest in understanding the complex dynamics of the commercial relationships forged between scientists and industry due to their salience in enhancing innovation (Bercovitz \& Feldman, 2008; Cohen, Nelson, \& Walsh, 2002; Lam, 2010, 2011). This interest has prompted theorists to address the effects of academic enterprise on the production of scientific research and knowledge (Cooper, 2009; Glenna et al., 2011; Larsen, 2011), barriers to university-industry collaboration, and determinants of scientific entrepreneurship (Bercovitz \& Feldman, 2008; Etzkowitz, 1998; Lam, 2011). Factors seen as central to the success of research commercialisation efforts include trust in the science-business relationship (Daellenbach \& Davenport, 2004; Davenport, Davies, \& Grimes, 1999; Mallon et al., 2005), prior relationships with industry, commitment, communication, and the partner's reputation (Mora-Valentin, Montoro-Sanchez, \& Guerras-Martin, 2004), as well as scientists' interpersonal skills (O'Leary, Gerard, \& Choi, 2012). Organisational identity has also been identified as a significant factor in the quantity and quality of products commercialised, primarily in view of the influence it has on people's interpretation of, and responses to, competing missions and their related demands (Chatterjee \& Sankaran, 2015).

Altogether, there has been considerable discussion of science-industry relationships, and of ways of bridging the gap between the scientists and practitioners (Bansal, Bertels, Ewart, MacConnachie, \& O'Brien, 2012). The focus, however, has largely been on the experience of university academic scientists (Biscotti, Lacy, Glenna, \& Welsh, 2012; Lam, 2011; Welsh, Glenna, Lacy, \& Biscotti, 2008), rather than on the endeavours of their counterparts in public research institutes - the focus in this study. While there are intersections between academic scientists and public research scientists, 
they tend to operate under different funding and regulatory regimes that shape their work and respective relationships. Accordingly, I turn to the literature on the conflictions faced in science work for further insights.

\subsubsection{Conflictions in science work}

Few contributions to the literature on science work focus specifically on the conflictions that arise for scientists in science work generally, or specifically when navigating commercial research relationships. Notable exceptions include Hackett's (2005) examination of the tensions that characterise research groups, and Bartunek and Rynes'(2014) delineation of tensions relevant to the academic-practitioner gap and theorisation of how they might be managed. Tensions that characterise research groups include those experienced when seeking to establish an independent identity and also remain connected to a particular disciplinary field, as well as those that emerge when attempting to direct a group's research efforts while simultaneously allowing autonomy and democratic participation (Hackett, 2005). Though Hackett's (2005) work represents a rare example of empirical research that engages with the tensions experienced by research groups, it does not examine the tensions scientists experience in commercial research contexts or when engaging with issues of sustainability.

Several conflictions have been identified with regard to scientists' navigation of the academic-practitioner gap. These include those that emerge as a result of differing logics, time dimensions, communication practices, interests and incentives, and in relation to matters of rigour and relevance (Bartunek \& Rynes, 2014). Bartunek and Rynes (2014) describe the dialectical forces fostering these conflictions, posing that they are best viewed as needing to be sustained (rather than eliminated) in future research and theorising. Other contributions that focus on the conflictions in science work include those that associate the 
navigation of commercial research relationships with the emergence of different values and career commitments (Box \& Cotgrove, 1996), cultural differences that inspire different approaches to project management (Davenport et al., 1999), and conflictions between open dissemination and commercialisation of scientific knowledge (Biscotti et al., 2012; Welsh et al., 2008). Issues relevant to the negotiation of commercial research relationships can also be found in contributions that focus on issues of role identity. The focus now turns to these.

\subsubsection{Role identity}

A premise of identity is that when roles are socially embedded in valued relational networks, individuals are more likely to find their work meaningful and perform well (Ashforth, Harrison, \& Corley, 2008; Wrzesniewski \& Dutton, 2001). Role identity refers to the internalised expectations individuals bring to their roles, along with the associations they make between it and other positions within their social structure (Stryker \& Burke, 2000). Though identity conflict is widely recognised as a salient tension in science work and, in particular, the negotiation of science-industry relationships (e.g., Empson, 2013; Lam, 2010; Zabusky \& Barley, 1997), few contributions explicitly examine this tension from a paradox perspective. However, important insights are gained from studies that examine the conflictions that emerge between the dual work identities of researcher and practitioner. For example, based on her own experience as an academic, Empson (2013) explains how she came to expand her conceptualisation of academic identity after realising the need for both her academic and practitioner identities to be allowed to coexist in dialectical tension.

Other contributions similarly demonstrate that scientists engaged in commercial work consider the relationship between science and business when conceptualising their 
role identity in a given project. At times they respond by identifying with the project rather than the organisation and manoeuvre their ways between multiple groups in the achievement of outcomes (Zabusky \& Barley, 1997). In some cases, a high degree of continuity and stability contributes to their sense of identity (Lam, 2010), while in other situations they develop rationales for their involvement in commercial work that are congruent with their academic role identity (Jain, George, \& Maltarich, 2009). In the context of a controversial science, senior scientists from a range of public and private sector institutes (including CRIs in New Zealand), draw on multiple scientific and public identities when attempting to legitimate the epistemic and moral authority of science (Motion \& Doolin, 2007). Similarly, in the face of new public management reforms, academic scientists draw on multiple identities when attempting to deal with change and related organisational expectations (Barry, Berg, \& Chandler, 2006).

Studies that focus on the construction of professional identity find that the framing of a professional group's role is associated with alternative institutional discourses that enable the employment of a change frame, on the one hand, and traditional institutional discourses that foster the employment of a continuity frame, on the other (Chreim, Williams, \& Hinings, 2007). A further contribution finds that macro-level traditions (for example, institutional connections, the organisation of science, and the dissemination of knowledge), influence identity construction in New Zealand public science (Simpson \& Hibbert, 2008). At the micro-level, processes that shape and sustain a science group's identity are those that position it within a disciplinary field. This disciplinary positioning can entail, for example, the creation of research technologies that enable the group to continuously produce publishable results in a particular sphere of inquiry (Hackett, 2005).

The contributions summarised in this section underline how scientists develop rationales for their involvement in commercial work, and draw on a variety of identities as 
they move between different contexts. Next, I turn to the literature on sustainability in the context of science work.

\subsection{Sustainability in the context of science work}

Over the last few decades, there has been an explosion of interest in sustainability as firms engage at local, national and global levels in addressing major social, economic and environmental problems (see, for example, Bammer, 2008; Gibbs, 2009). From the vast literature that has evolved, I review a selection of contributions that explore the concept of sustainability, and that explicate both the challenges involved in addressing sustainability in science work, and in managing stakeholder relationships more generally.

\subsubsection{The concept of sustainability}

The term 'sustainability' continues to be used in a growing body of literature focused on the scale of the problems facing society, as well as what is needed to move towards a more sustainable economy (e.g., Gibbs, 2009; Senge, Smith, Kruschwitz, Laur, \& Schley, 2008; Waddock \& McIntosh, 2011). Such a move is perceived to entail a profound shift in thinking (Epstein, 2008; Garud \& Gehman, 2012; Geels, 2010), and the management of interconnected challenges in multi-stakeholder contexts (e.g., Grifoni, Guzzo, \& Ferri, 2014; Sharma \& Kearins, 2010; Whittemore, 2013; Worley, Feyerherm, \& Knudsen, 2010). Yet it has become clear that the meaning ascribed to sustainability tends to vary between groups and across contexts despite numerous attempts to devise universally-accepted definitions.

The lack of a clear definition for sustainability is partly due to a tendency to focus on certain dimensions of sustainability while neglecting others. For instance, physical scientists and engineers have often neglected the social aspects of sustainability, as have 
scholars who devised the 'triple-bottom line' principle in business management; the idea that profitability needs to be balanced with social and environmental sensitivity (Seager, 2008). Though open to interpretation, an understanding of the concept that has been established is that sustainability consists of three equally important dimensions: "the protection of the natural environment, the maintenance of economic vitality, and the observance of specific social considerations" (Steiner \& Posch, 2006, p. 878).

In recent decades, as organisations have begun to engage with sustainability, models have been developed to guide management practice. These models include blueprints for organisations in terms of necessary inputs, outputs, and outcomes for success (e.g., Carroll, 1979; Clarkson, 1995; Epstein, 2008), and process models that focus on teasing out the sustainability character or ethos of an organisation by examining what is thought, said and done in relation to others (see, for instance, Basu \& Palazzo, 2008; Ketola, 2007). The application of a process model is premised on the need for greater understanding of how the integration of different ethical values (utilitarian/egoistic, duty/rights/justice, and virtue) can lead to different discourses and actions (Ketola, 2007).

The contributions in this section help to clarify what sustainability means and entails. However, they do not seek to explicate the paradoxes navigated when addressing sustainability in commercial research or identify practices that may ease the way (AngusLeppan, Benn, \& Young, 2010). In the next sections, I turn to the literature on sustainability and the ways in which it is addressed in science work for relevant insights.

\subsubsection{Sustainability and science work}

Scientists have long questioned humanity's attitude toward the stewardship of the earth and what is needed to achieve sustainability (Rees, 2010), yet their role in this process has received little examination. More recently, some have called for the 
integration of transdisciplinary approaches to sustainability science due to the significant challenges associated with multi-stakeholder collaboration (see Brandt et al., 2013 for a review of transdisciplinary research in sustainability science; Yarime et al., 2012). This call for a transdisciplinary approach coincides with the effort to draw together strands of a vast body of literature under 'sustainability transitions' (Markard et al., 2012) which had previously focussed on the ways in which technical systems define and reproduce daily life (Geels, 2010; Shove \& Walker, 2010). A central premise is that sustainable development entails transformative systemic change (Geels, Hekkert, \& Jacobsson, 2008; Hirsch Hadorn, Bradley, Pohl, Rist, \& Wiesmann, 2006). Though the discussion of the management of sustainability in this literature is also extensive, there remain gaps in understanding due to the predominance of a focus at the macro-level (Geels, 2010). Sustainability science theorists often argue that the very notion of sustainability entails contradiction and paradox (e.g., Benessia et al., 2012; Ramirez, 2012). Specific challenges include conflicting pressures and values when planning for sustainability, and the complexity and uncertainty inherent in crafting strategies that simultaneously address economic, social, and environmental issues (Midgley \& Reynolds, 2004; Valente, 2012). An overarching challenge is that the scale of change necessitates focus on technology, user practices, cultural meanings, policy and markets, and so involves struggles between niches and regimes on multiple levels; such change is enacted by interpretive actors who search, learn, fight, and build coalitions as they engage with sustainability innovation (Geels, 2010). The overall effectiveness of stakeholder management programmes has been evaluated (e.g., Allen, 1997; Allen, Bosch, Kilvington, Oliver, \& Gilbert, 2001; Bellamy, Walker, McDonald, \& Syme, 2001; Fraser, Dougill, Mabee, Reed, \& McAlpine, 2006). In turn, several tensions science groups experience when working on sustainability in multistakeholder contexts have been identified. These tensions include those inherent in 
establishing a coherent terminology and a shared research framework (see, for example, Gibbons, 1999); the challenge of integrating different disciplinary methods that enable learning at the science-society interface (Lawrence \& Despres, 2004); as well as the need to engage with different research process phases and knowledge types, and in knowledge exchange (Brandt et al., 2013).

In order to examine these tensions further, it is useful to examine contributions to the literature on the management of external relationships more generally.

\subsubsection{Managing external relationships}

As organisations have begun to engage with sustainability in a more integrated, sustained, and strategic way (Bansal \& Hoffman, 2010), theorists have sought to explain why, and to what effect, organisations partner to address social issues (Bhattacharya, Korschun, \& Sen, 2008; Jonker \& Nijhof, 2006; Seitanidi, Koufopoulos, \& Palmer, 2010). The conditions that support the development of strategic partnerships between business and non-profits have also been explored (Jamali, Yianni, \& Abdallah, 2011; Le Ber \& Branzei, 2010), and analytic tools or approaches developed for use when establishing or evaluating social partnerships (Rama, Milano, Salas, \& Liu, 2008; Selsky \& Parker, 2011). This research focus coincides with efforts to explain the significant variation in response by firms to social, ecological, and economic issues in relation to the paradigmatic orientation that prevails among their leaders (Gladwin, Kennelly, \& Krause, 1995; Valente, 2012).

A common approach when addressing sustainability is to adopt an instrumental logic (a central premise of which is that firms stand to gain financially by addressing social and environmental concerns), and to accept the primacy of the economic dimension (Hahn et al., 2015). This approach may partially account for the tendency of firms to scale down 
their efforts towards sustainability when confronted with new challenges, such as periods of economic downturn (Andre, 2011). Recently, however, calls have been made for theorists to approach the tensions associated with integrating the economic, social, and environmental dimensions of corporate sustainability into business operations from a paradox perspective (Hahn, Figge, Pinkse, \& Preuss, 2010; Hahn et al., 2015; Van der Byl \& Slawinski, 2015).

As the review in this section shows, though they are salient actors in the global efforts to address sustainability, research scientists and the respective tensions they face have rarely been positioned at the centre of inquiry. Accordingly, the focus now turns to paradox as a fruitful theoretical approach to this study.

\subsection{Paradox in management and organisation}

In the third and final section of this review, I draw on strands of the management literature to explain the core premises of a paradox perspective, along with the ways in which paradox can be managed.

\subsubsection{A paradox perspective}

The value of a focus on paradox in studies of managing and organising has long been recognised (Cameron \& Quinn, 1988; Lewis, 2000; Poole \& Van de Ven, 1989). A core premise of a paradox perspective on organisation is that tensions are inherent within complex systems, and so there is an ongoing need to address "contradictory yet interwoven demands simultaneously” and continuously (Quinn, 1988; Smith \& Lewis, 2011, p. 397). Studies in this area have often drawn on systems theory (Lewis, 2000; Prenkert, 2006; Smith \& Lewis, 2011), viewing industries and firms (as well as teams and human beings) as composed of inter-woven subsystems (Lewis \& Smith, 2014). Others have drawn on 
sensemaking in theorising how individuals construct paradox through self- or social reflection and interaction (Calton \& Payne, 2003; Jay, 2013; Lewis, 2000; Luscher \& Lewis, 2008) and, in doing so, provoke change by talking situations into being (Weick, 1995). As will be discussed in Chapter 3 (section 3.2), Weick's (1995) articulation of sensemaking also informs this study.

A paradox approach to management research explicates inherent tensions and considers their relevance and implications, rather than seeks to eliminate them (Bloodgood \& Bongsug, 2010; Cameron \& Quinn, 1988). The idea is that when an either/or choice is made, the suppressed challenges may go underground and perpetuate (Lewis, 2000; Lewis \& Smith, 2014). Such premature closure can also lead the organisation to neglect forfeited options, which later return with a vengeance under new sets of circumstances (Smith \& Berg, 1987a; Smith \& Lewis, 2011). Accordingly, studies of paradox emphasise the need for both/and thinking, and the futility of seeking to eliminate tension when confronted with competing goals (Andriopoulos \& Lewis, 2009; Luscher \& Lewis, 2008). Put simply, the extremes of a paradox are too pervasive to be willed away, and so attention needs to be accorded to the bi-directional relationships between the two poles (Bloodgood \& Bongsug, 2010; Clegg et al., 2002). Doing so, generates new possibilities for organisations to deal with their challenges constructively (Clegg et al., 2002; Luscher et al., 2006; Smith \& Lewis, 2011).

\subsubsection{Overarching themes on paradox}

The literature on management and organisation identifies overarching themes on paradox, including paradoxes of performing, belonging and organising (Bartunek \& Rynes, 2014; Jarzabkowski, Le, \& Van de Ven, 2013; Luscher et al., 2006; Smith \& Lewis, 2011). Paradoxes of performing consider the ways in which roles fluctuate during 
change in expectations or structure thereby facing the person with apparently contradictory demands (e.g. lower costs and enhanced services) (Luscher et al., 2006). Recent contributions to the paradox literature have theorised, and occasionally explicated, the competing strategies and goals organisations find themselves confronted with when they focus on both commercial and social goals (Jay, 2013; Margolis \& Walsh, 2003; Tracey, Phillips, \& Jarvis, 2011). The competing demands these organisations face often stem from the plurality of stakeholders that need to be taken into account. This situation has been linked to tensions due to conflict over goals and a lack of clarity around organisational outcomes (Jay, 2013; Pache \& Santos, 2010). Paradoxes of performing have also been examined in the context of mergers and organisational restructuring (Bednarek et al., 2012; Seo, Putnam, \& Bartunek, 2004). In such situations, tensions are perceived to emerge when new goals and relationships leave people with blurred roles and no blueprint to follow (Luscher \& Lewis, 2008).

Paradoxes of belonging revolve around the relationship between the individual and the group or collective (Jarzabkowski et al., 2013; Lewis, 2000; Smith \& Berg, 1987a). They examine shifting social relations that foster tensions as people identify themselves in relation to various fluctuating groups and their competing values and roles (Smith \& Berg, 1987b). Challenges of belonging arise because people strive for self-expression as well as collective affiliation (Lewis, 2000; Luscher et al., 2006), and are often experienced as 'double-binds' or the sense of being stuck (Smith \& Berg, 1987a; Tracy, 2004). Individuals may experience multiple, seemingly conflicting identities when they internalise disparate role expectations (Stryker \& Burke, 2000). For instance, prior research finds that creatives may see themselves as both artists and consultants (Gotsi et al., 2010). It has also been found that the ongoing success of an orchestra can depend 
upon the ability of musicians to identify with both their orchestra's artistic and economic identities (Glynn, 2000).

Paradoxes of organising consider the ways by which various participants in the organising process enact contradictory practices in meeting the demands of their role (e.g., increasing employee participation through the conflicting but simultaneous practices of empowerment and control). They are embedded within changing systems (Luscher \& Lewis, 2008), and can also be experienced as systemic contradictions between, for example, structure and order or flexibility and improvisation (Luscher et al., 2006). A paradox of organising has been presented as the tension that exists between differentiation and integration in complex organisations (Lawrence \& Lorsch, 1967). Particularly salient paradoxes of organising are those experienced by project teams when interacting with external parties. For instance, there is the experience of finding that clients face manufacturing and distribution constraints, for example, when opportunities to create frame-breaking products are identified by teams (Andriopoulos \& Lewis, 2010). It is likely that research scientists experience similar tensions when seeking opportunities to exploit their knowledge of sustainable technologies when interacting with clients. All three paradox categories (i.e., performing, belonging, and organising) are addressed in this study.

\subsubsection{Responses to paradox}

The experience of paradox can be discomforting (Vince \& Broussine, 1996) and provoke both defensive and strategic responses (Lewis, 2000; Lewis \& Smith, 2014). The term 'defensive' is used in the paradox literature (Lewis, 2000; Smith \& Lewis, 2011) since these responses involve avoidance tactics, rather than finding ways of working through paradox (Jarzabkowski et al., 2013). Defensive responses, which include clinging 
to the pole that supports one's preferred priorities while opposing or ignoring lesspreferred imperatives (Clegg et al., 2002; Smith \& Lewis, 2011), can trigger unintended and sometimes harmful consequences (Jarzabkowski et al., 2013; Smith \& Berg, 1987a; Tracey et al., 2011). The search for unity and the resolution of tension through making ‘either-or' decisions (Bartunek \& Rynes, 2014; Lewis, 2000) has long been reflected in firms' application of the 'if-then' insights enabled by a contingency perspective (Lewis \& Smith, 2014). However, in the past decade, researchers have increasingly realised that seemingly opposing demands are often interrelated, and that an acceptance of paradox and the pursuit of 'both-and' expectations can enhance organisation (Andriopoulos \& Lewis, 2009; Jay, 2013).

Though often theorised, few empirical studies elucidate the everyday activities that constitute enabling or constraining responses to paradox. Exceptions include those that identify how the defensive acts of opposing, splitting, and suppressing constrain performance (Jarzabkowski et al., 2013; Lewis, 2000; Poole \& Van de Ven, 1989), and others that explicate how engaging strategically with competing forces enables greater complexity (Andriopoulos \& Lewis, 2010; Lewis, 2000). For instance, 'framing' is sometimes used as a tactic (Jay, 2013; Putnam, Myers, \& Gailliard, 2013) in an attempt to 'recalibrate' competing demands so that the value of each becomes apparent (Quinn \& Cameron, 1988). It has been found that when people are encouraged to critique their existing frames, they may engage with higher levels of abstraction in searching for links between opposing demands (Luscher \& Lewis, 2008). Consequently, synergies may be found when polarities join in self-reinforcing tensions, driving performance to higher levels (Quinn \& Cameron, 1988).

Some authors argue for the confluence of approaches premised on differentiation and integration as an effective means of managing paradox (Lewis, 2000; Poole \& Van de 
Ven, 1989). 'Differentiation' refers to the process of recognising and articulating distinctions, as well as directing efforts at addressing each of the seemingly contradictory elements. Examples include temporal and/or spatial differentiation through diversification of projects and work portfolios, variety within teams, roles and identities as well as across workspaces (Gotsi et al., 2010). Meanwhile, 'integration' focuses on the interdependence between apparent opposites and deploys tactics that embrace them as synergistic (Clegg et al., 2002). Examples include an organisational meta-identity that embraces paradox, as well as processes of socialisation, including teamwork and mentoring (Andriopoulos \& Lewis, 2009, 2010; Gotsi et al., 2010; Smith \& Lewis, 2011; Smith \& Tushman, 2005). The premise is that through the supportive tactics deployed by managers (for example), individuals will come to accept both elements of the paradox and draw on them explicitly, rather than engage in counterproductive responses such as the futile pursuit of internal consistency (Gotsi et al., 2010).

\subsection{The literature: A closing overview}

This review has underlined tensions in management and organisation as a pertinent theme across the literatures on research management and sustainability in the context of science work. In the case of the former literatures (those on science work and commercial research, conflictions in science work, and role identity), there has been considerable debate around the tensions academic scientists experience as they engage in research commercialisation activities. This debate has included whether their science should actually be 'sold', and if it bears relevance to practice.

Several contributions offer insights into the nature of conflictions scientists face when interacting with business (e.g., communication barriers and other relational issues, differing logics and time frames). Conflictions in role identity have also been identified, 
leading theorists to pose that scientists sometimes draw on multiple identities when they engage in commercial work. However, the focus has generally been on the macro-level issues universities and science groups face, rather than on the tensions scientists experience individually. The literatures pertinent to sustainability in the context of science work (i.e., the concept of sustainability, sustainability in science work, and addressing sustainability), draw attention to the significant challenges entailed in managing for sustainability. Contributions that focus on the ways by which organisations and science groups partner to address sustainability in multi-stakeholder contexts offer insights by identifying several sources of tensions with which groups have to contend (e.g., communication issues, and difficulties in integrating different disciplinary methods, research process phases, and knowledge types). However, once again, the focus tends to be on the challenges faced by organisations and science groups, rather than those experienced by academic scientists or research scientists as they interact with clients in the context of commercial research.

Rarely are the tensions identified in contributions to the literature on research management and sustainability in the context of science work addressed from a paradox perspective. Yet, the argument is often made in the literature on paradox in management and organisation that a paradox perspective has much to offer since tensions are inherent within complex systems, and that there is a need to engage with them productively. Several works pose the value of a management approach premised on differentiation and integration. However, few contributions focus on the ways in which tensions are experienced by individuals during their everyday work activities, or on their responses.

Altogether, this review reveals a need for further research that explicates the ways in which research scientists view, and respond to, paradox when seeking to engage with sustainability in commercial research. 


\section{Chapter 3 \\ Research Context and Methodology}

The scientist needs to search for information that supports opposing explanations of an observed event. The event itself probably contains properties such that both explanations may appear to be valid at one time or another, even though they are opposed (Weick, 1979, p. 30, italics in original).

This study examines the paradoxes research scientists perceive, as well as the ways in which they respond to tensions when addressing sustainability in commercial research. The central questions underlying this study are as follows:

What paradoxes do public research scientists perceive when engaging with sustainability in commercial research?

What responses (to paradox) do public research scientists see as constraining or enabling their engagement with sustainability in commercial research?

The focus is on research scientists' experiences of, and responses to, paradox which indicates the need for a research design that emphasises the importance of "the small, the relational, the oral, the particular, and the momentary" (Weick et al., 2005, p. 410). Accordingly, whereas previous studies of the tensions experienced in science work (e.g., Hackett, 2005; Thompson, Gilding, \& Spurling, 2011) and sustainability (Benessia et al., 2012; Hahn et al., 2015) have tended to remain at the strategic or institutional level, this study focuses on the ways in which paradox is experienced at the individual level. It does this through qualitative inquiry and, in particular, by focusing on research scientists' sensemaking (Weick, 1995) as a means of capturing the dynamics of the paradoxes they perceive, the ways in which they respond, and the reasoning underlying their actions. 
This chapter begins by introducing the research philosophy underpinning this study. Here, the basic tenets of a constructionist ontology and an interpretivist epistemology are addressed as they pertain to this study. Thereafter, it outlines how Karl Weick's (1995) articulation of sensemaking informs the theoretical framework, before introducing the research strategy which addresses the research questions. Next, the chapter presents an overview of the CRI context and the rationale for its selection as the setting for this study. The methods of data collection and analysis follow. The chapter concludes with a summary of the steps taken to ensure the integrity of the study.

\subsection{Research paradigm}

Underlying the development of any cohesive research design are the arguments, criticisms and debates that represent one's ontology or view of the world. As Wisker (2008) explains, how we experience and perceive ourselves in the world influences our selection of research practices. The focus of this research on explicating scientists' construction of paradoxes faced in the commercial research context and the ways in which they respond to them aligns with an interpretive epistemology, one that holds that meaning-making is a social process involving the co-creation of knowledge within a particular context using such tools and traditions as language (Willis, 2007). Interpretivism is one of three dominant research paradigms alongside postpositivism and critical theory in the social sciences.

The assumption that there are multiple realities - a basic tenet of the constructivist ontology - underlies the interpretive research journey (Denzin \& Lincoln, 1994). These sometimes conflicting realities which take the form of intangible, socially- and experientially-based, mental constructions are dependent on the individuals or groups holding the constructions (Guba \& Lincoln, 1994). Knowledge consists of those 
constructions about which there is relative consensus among people who interpret the substance of the construction (Guba \& Lincoln, 1994). Those "competent to interpret" are individuals with relevant experience of the context or phenomena studied; that is, interpretive research recognises interviewees as "autonomous, intentional, active, goal directed" beings capable of construing, constructing, and interpreting their own behaviour and that of others (Schwandt, 1994, p. 120).

The prevailing interpretations which individuals generate are provisional, serve the practical needs at hand, and rely upon "delimited cultural categories that are diversely and artfully articulated with, and attached to, experience" (Holstein \& Gubrium, 1994, p. 268). It should not be assumed from this depiction of knowledge as 'transient' that interpretive research cannot arrive at a particular position or that its findings are relevant only to a particular context. A core premise is that the wider application of research findings is a reflexive process that involves the consideration of context, practice, and multiple perspectives on a topic (Willis, 2007). The overarching goal is to contribute to understanding the paradoxes perceived in a specific context and, through the provision of vicarious experience (i.e., articulation of the dynamics that occur in the commercial research context), to influence both the questions asked and the subsequent interpretation of data by researchers in other contexts. That is, interpretive research is not concerned with prediction and control, and instead seeks to offer "a consensus construction that is more informed and sophisticated than any of the predecessor constructions" (Guba \& Lincoln, 1994, p. 111). The focus in doing so is on generating idiographic or contextualised understanding that better reflects how individuals both influence and are influenced by the groups they belong to (Willis, 2007). The "heuristic generalisations" produced are then open to further specification in other studies (Sandberg \& Tsoukas, 2011, p. 353) or can be applied by knowledge 'consumers' to their own context (Rasche \& 
Behnam, 2009). Hence, theories developed are both useful to other researchers and relevant to practice; this quality is not generally attained when detached modes of engagement are adopted in management research (Bartunek, Rynes, \& Ireland, 2006; Sandberg \& Tsoukas, 2011; Weick, 2007).

\subsection{Sensemaking}

Sensemaking offers a means of capturing aspects of logic and richness of practice by providing a framework for reflecting on the proactive role people play in shaping and structuring their realities. Specifically, the focus of inquiry in studies that draw on sensemaking is on establishing the meanings people make, the reasoning underlying their interpretations, and the effects of the sense that is made. This entails looking for instances of labelling, categorizing, and the creation of plausible stories (Humphreys, Ucbasaran, \& Lockett, 2012; Weick, 1995; Weick et al., 2005). Accordingly, the use of sensemaking may be explained as going beyond interpretations to examine the ways in which people contextualise their experience "in the context of a learnt frame, narrative or category" (Holt \& Cornelissen, 2014, p. 525). As Goffman explains, these people then draw on this frame "to locate, perceive, identify, and label occurrences" in their lives and world (1974, as cited in Snow, Rochford, Worden, \& Benfold, 1986, p. 464).

As a metatheory derived primarily from pragmatism and symbolic interactionism (Dervin, 2003; Weick, 1995), sensemaking fuses the theoretical insights presented in various literatures. Symbolic interactionism, as originally theorised by American philosopher and social theorist George Mead (1863-1931) and further developed and articulated by Herbert Blumer (1969), rests on three premises: first, people act towards objects in their environment and each other in accordance with the meaning they attach to them; second, these meanings are derived from the social interactions people have with 
one another; and third, the meanings taken are established and modified through an interpretive process, then used and revised as instruments to guide action (Schwandt, 1994). Although the label 'sensemaking' was applied for the first time in 1983, its development as a metatheoretical tool began in 1972 when theorised by Dervin and colleagues as a useful approach to the study of communication (Dervin, 2003). Another turning point in its development was Meryl Louis's (1980) conceptualisation of sensemaking as a thinking process triggered by surprise.

More recently, sensemaking has been portrayed as "the experience of being thrown into an ongoing, unknowable, unpredictable streaming of experience in search of answers to the question, 'what's the story?"' (Weick et al., 2005, p. 410). Given the ambiguity and complexity inherent in addressing sustainability in commercial research (due to the highlycontested nature of sustainable development (Redclift, 2005) and the tentative nature of science), it is conceivable that research scientists may almost continuously engage in the subtle, social, ongoing and easily taken for granted process of sensemaking when interacting with clients. This engagement can involve drawing reasons from various frameworks including “institutional constraints, organizational premises, plans, expectations, acceptable justifications, and traditions inherited from predecessors" that allow the resumption of interrupted activity (Weick et al., 2005, p. 409).

\subsubsection{Characteristics of sensemaking}

Sensemaking has several key properties or characteristics (i.e., identity construction, retrospective of experience, enactive of sensible environments, social, ongoing, extracted cues, and plausibility), and is a process that unfolds as people continuously construct, enact and modify provisional understandings (Maitlis \& 
Christianson, 2014; Weick, 1995; Weick et al., 2005). These characteristics are introduced, in turn, and their relevance to this study explained in the section below.

\section{Identity construction}

Identity is central to sensemaking since who we think we are (identity) shapes how we construct the world (Weber \& Glynn, 2006). In turn, the image we project and through which we seek to maintain a positive self-conception affects how we are perceived and treated (Cunliffe \& Coupland, 2012; Maclean, Harvey, \& Chia, 2012). Our need for selfenhancement, self-efficacy, and self-consistency is such that our construction of self evolves as we continually seek to conform to a greater or lesser degree with the expectations of others, particularly when the salience of their expectations is high (Cornelissen, 2012; Pratt, Rockmann, \& Kaufmann, 2006; Weick, 1995). Purposeful sensemaking is triggered by a failure to validate one's self in the eyes of others, and a desire to maintain a consistent, positive self-conception (Dutton, Dukerich, \& Harquail, 1994; Weick, 1995). So, the focus in sensemaking is on the processes through which people interpret actions and identities, rather than on the content of these interpretations (Grant, Dutton, \& Rosso, 2008).

When considered in relation to this study, the above assumptions imply that the identities research scientists assume as they interact with their various constituents will have more to do with the meanings they derive about their role and related responsibilities, than the 'actual' situations faced. These identities will not be static, but evolve as they proactively and reactively engage in the construction of the selves they see as appropriate. This identity construction process may include efforts to embody role-related goals, values, beliefs, and norms (Ashforth et al., 2008), as well as the codes and conventions of the clients and others with whom they interact and see themselves as accountable to for their actions (Cornelissen, 2012). 


\section{Retrospective (of experience)}

The creation of meaning through retrospect or by glancing back in time is a key premise of sensemaking. Due to the breadth of experience people usually have, their elapsed experience is often equivocal in that it makes many different and, sometimes, contradictory kinds of sense (Weick, 1995). Accordingly, many possible meanings may be synthesised (Alvesson, 2003). Here, clarity as to what is important (i.e., values and priorities) in elapsed experience facilitates sensemaking, rather than engagement with even more information (Weick, 1995).

Research scientists typically engage in multiple projects simultaneously, and have a plethora of possible meanings to synthesise. The depiction of retrospect given above implies that research scientists will sometimes talk a situation into being, rather than plan an act before the fact. In looking back on an interaction with a client, for example, they will retrospectively address the reasoning that informed their action (i.e., construct meaning). This reflection begins in the present, and the values, beliefs, and feelings held, along with the projects underway at the time will affect the attention that is given to that lived experience, and what is seen (Weick et al., 2005). Should the act in question come to be viewed as a mistake, for instance, it is in hindsight (Paget, 1988, cited in Weick et al., 2005). That is, the act itself is not mistaken as it unfolds; it becomes a mistake when constructed that way subsequent to the activity.

\section{Enactive of sensible environments}

Weick's (1995) theory of enactment downplays the importance of objective environments and instead gives primacy to the interpreting mind by suggesting that people construct reality through their acts (Maitlis \& Sonenshein, 2010). To emphasise this point, Weick (1995) argues that people enact laws, take undefined time and space, establish categories, and develop labels, for example, that then characterise a particular 
environment. In this way, they enact the environments they face. Relevant here, are the ways in which research scientists interpret and enact the purpose and operating principles of the legislation governing CRIs (CRI Act 1992) and, in particular, the dual requirement that they exhibit a sense of social responsibility by having regard to the interests of the community while also maintaining their institution's financial viability.

Drawing on the 1924 work of Follett, Weick emphasises the need to think of sensemaking as "relating", and to talk about "confronting the activity of the environment", rather than resisting change $(1995$, p. 33). The premise is that a conceptualisation of people as enacting sensible environments will steer researchers away from a blinkered view of how people deal with the environment and from premature judgements, towards a deeper appreciation of the notion that people receive stimuli as a consequence of their own activity (Barry \& Meisiek, 2010).

\section{Social}

Central to sensemaking is the social context within which meaning is constructed through processes of interaction (Weick \& Roberts, 1993). An important part of conceptualising sensemaking as a social, rather than solitary activity, is an awareness of the various forms social influence can take. Drawing on a case of sensemaking in a medical context, Weick et al., (2005) explain that as knowledge about a correct treatment gradually unfolds, it is located not just in the minds of nurses and their immediate contacts, but distributed across the healthcare system to converge on patients as much through processes of scheduling as through the appearance of a nurse or physician at the bedside. Thus, the locus is system-wide, and realised via processes of coordination and distribution among interdependent healthcare workers (Weick et al., 2005).

The transdisciplinary and multi-stakeholder nature of commercial research is such that research scientists are likely to influence and be influenced by various social factors 
including past mentoring, structures in place, as well as discussions with other scientists, industry groups, clients, and community groups. From a sensemaking perspective, the relational manner in which thinking and behaviour are said to occur is such that even when a research scientist thinks, or engages in an internally-directed monologue, an audience is presumed. In social contexts such as this, it is likely that there will be disparate views on ambiguous issues of sustainability.

\section{Ongoing}

Integral to an understanding of sensemaking is the need to appreciate that it is part of an ongoing flow of activity that never starts nor stops, leaving us always in the midst of events or projects (Weick, 1995). So sensemaking begins when the flow of action becomes unintelligible in some way, and entails chopping moments out of this "undifferentiated flux of raw experience" (Chia, 2000, p. 517) in order to extract cues for closer attention (Weick et al., 2005). Emotions affect sensemaking because they prompt the recollection of previous events when similar emotions were experienced (Maitlis, Vogus, \& Lawrence, 2013). These recollections are then reconstructed by individuals in explaining the present circumstances as they feel, rather than look, the same (Weick, 1995). However, this process of recollection and reconstruction makes sensemaking more difficult as in attempting to apply a "feeling-based memory" in resolving a "current cognitive puzzle", the sensemaker is in effect seeking to "mate two very different forms of evidence" (Weick, 1995, p. 49).

In the commercial research context, when research scientists or their clients become aware of, and provoked by 'interruptions' (e.g., opposing views of contractual obligations) and begin to search for their source, they may experience negative emotions if the interruption is unexpected and perceived to be harmful or detrimental. The depiction of sensemaking as ongoing suggests that research scientists' sensemaking accounts would 
be inspired by both their recollection of past events (irrespective of their different characteristics), and their recollection of more immediate circumstances.

\section{Extracted cues}

Sensemaking tends to be swift and effortless, making end products, rather than processes, more readily apparent (Weick, 1995). Accordingly, it is useful to focus on how people deal with prolonged puzzles (e.g., paradoxes and dilemmas) that make sensemaking more challenging (Weick, 1995). What the researcher looks for in doing so are the acts of noticing, or contextualising of, cues or experiences in the context of learnt frames, narratives or categories (i.e. conceptual templates) through which interpretation is enabled (Holt \& Cornelissen, 2014). Specifically, the focus is on the ways in which people construct meaning by presenting moments of experience and embellishing them by relating them to frames and categories that reflect their past experience (or more general ideas). As Weick explains:

The content of sensemaking is to be found in the frames and categories that summarize past experience, in the cues and labels that snare specifics in the present experience, and in the ways these two settings of experience are connected (1995, p. 111).

This study focuses on how research scientists see themselves dealing with paradoxes, and the experiences they note, and draw from, in making sense of situations. In doing so, the cycle of activity this research focuses on is scientists' association of specific observations in the present with more general ideas acquired through past experiences.

\section{Plausibility}

In studies of sensemaking, "accuracy is nice, but not necessary" (Weick, 1995, p. 56). This statement is premised on the assumption that the sorts of situations that provoke sensemaking (e.g., ambiguous, uncertain, or paradoxical), are such that the 'truth' is never able to be fully established, and that overcoming inertia by acting (even if erroneously) 
will propel meaning-making and, potentially, positive outcomes (Abolafia, 2010). So sensemaking is more concerned with "plausibility, pragmatics, coherence, reasonableness, creation, invention, and instrumentality", than with accuracy and objectivity (Weick, 1995, p. 57).

The commercial research context is one in which there may be considerable ambiguity and uncertainty. It is also an environment in which people are required to address complex issues within very tight timeframes. Though they may be trained in the pursuit of objectivity or "global accuracy" (Weick, 1995, p. 58), it is likely that research scientists will be required to rely on plausible interpretations in the interests of moving forward in a way that is productive when interacting with clients. The study's focus on "circumscribed accuracy" (understanding the dynamics of specific encounters within an identified context), offers the potential to generate insights that clarify the ways by which research scientists seek to engage with organisational aims in a world infused with equivocality, ambiguity, and conflicting interests.

Altogether, the above summary presents sensemaking as a process of retrospective meaning making inextricably tied up with language, values and beliefs, through which we come to understand our identities as we engage with others in the enactment of sensible environments. Weick (1995) sums up this multi-faceted process:

Once people begin to act (enactment), they generate tangible outcomes (cues) in some context (social), and this helps them discover (retrospect) what is occurring (ongoing), what needs to be explained (plausibility), and what should be done next (identity enhancement) (p. 55).

The following sections discuss sensemaking in organisational studies and its relevance for paradox. 


\subsubsection{Sensemaking and organisation}

In recent decades, sensemaking has been studied in a variety of organisational contexts and in methodologically diverse ways. One key theme is that organisational sensemaking is concerned with language (Brown et al., 2015; Maitlis \& Christianson, 2014; Weick, 1995). Accordingly, it has been used to examine what is said by focusing on discourse, narratives or stories (e.g., Bolander \& Sandberg, 2013; Brown, Stacey, \& Nandhakumar, 2008; Humphries \& Brown, 2002). For instance, studies have explored the ways in which people inside organisations author versions of their realities and identities in their performance of work tasks (Karreman \& Alvesson, 2001), sometimes seeking to impose this 'reality' on others (Sonenshein, 2010). Research has also examined how business leaders, groups and individuals seek to protect their interests and justify their position to themselves and others by managing meaning through discourse and storytelling (Maclean et al., 2012; Zilber, 2007), seeking to interpret and justify change in conversations with internal and external audiences (Gioia \& Chittipeddi, 1991; Rouleau, 2005).

Studies have also made visible the power struggles that occur as parties compete to shape meanings of, and within, organisations (Currie \& Brown, 2003; Mantere, Schildt, \& Sillince, 2012; Sonenshein, 2010). As awareness of the role of values has increased, so has the relevance of ethical and moral considerations as a research topic. In recent years, studies have examined ways by which to integrate moral sensemaking into undergraduate training in business (Elmes \& King, 2012) and in the biological and social sciences (Mumford et al., 2008). This research focus coincides with growing interest in the use of sensemaking to explore the ways in which people in organisations construct their own reality around social issues in management and, in particular, the social processes 
underlying their engagement with corporate social responsibility (Cramer, Jonker, \& van der Heijden, 2004; Fassin \& Van Rossem, 2009; Sharma \& Good, 2013) and corporate sustainability (Angus-Leppan et al., 2010; Hahn, Preuss, Pinkse, \& Figge, 2014).

Specific to this study, theorists argue that organisations are both "antecedent to, and emergent from, sensemaking processes" (Weber \& Glynn, 2006, p. 1642), and that they are best conceived of as fluid, dynamic entities (Gioia, Schultz, \& Corley, 2000). Within organisations, the content of "ideologies, third-order controls, paradigms, theories of action, traditions, and stories" passed on through training, work, and life experience tends to colour people's interpretations (Weick, 1995, p. 132), and shape the situations, environments, and organisations they talk into existence (Weick et al., 2005). Some of the content derived from external sources is also influential. For instance, the pressure exerted on organisations by the media, professions, interest groups, and government agencies can compel individuals to conform with the expectations of these groups (DiMaggio \& Powell, 1983). This is likely to be the case in the CRI context where multiple stakeholders exist, and government has a significant role in shaping a CRI's overall organisational focus.

When the expectations imposed on organisations by external sources are institutionalised to the point of being taken for granted, the normalised expectations can constrain sensemaking, making it less varied and more stable (Weber \& Glynn, 2006). Such extremes can stifle personal development, and overwhelm an identifiable sense of self (Maclean et al., 2012). Accordingly, the context in which meaning is constructed is relevant (Cornelissen, 2012). Weick et al., (2005) suggest that questions of power over sensemaking may be addressed by examining such issues as "proffered identities, criteria for plausible stories, actions permitted and disallowed, and histories and retrospect that are singled out” (p. 418). As Weick (1995, p. 132) explains, complex relationships are formed between vocabularies drawn from a variety of sources (i.e., ideologies at a societal 
level, third-order controls at an organisational level, paradigms of occupations, theories-ofaction of individuals, traditions as the vocabularies of predecessors, and stories as the vocabularies of sequence and experience), with meaning varying as "a function of the content and the connection".

Whereas this study is concerned with the meanings research scientists construct through sensemaking, other work also discusses 'sensebreaking' and 'sensegiving'. The former, sensebreaking, refers to the process of exposing knowledge gaps in such a way

that a void is created, thereby, prompting identity exploration (Ashforth et al., 2008). The latter, sensegiving, entails the construction and articulation of organisationally-sanctioned ways of making sense of the world that individuals may draw on in seeking answers to questions of identity (Maitlis \& Lawrence, 2007).

\subsubsection{Emerging research on sensemaking and paradox}

Some studies have drawn on sensemaking to examine paradox (Calton \& Payne, 2003; Hahn et al., 2015; Jay, 2013; Luscher \& Lewis, 2008). For instance, Luscher and Lewis (2008) explain how through researcher facilitation of sparring sessions, managers come to critique their frames and subsequently negotiate more meaningful and actionable understandings when dealing with messy paradoxical situations. Similarly, Jay’s (2013) case study of a hybrid organisation illustrates the importance of framing realities in ways that prompt organisational members' active reflection on paradoxes whereby they may engage in more behaviourally complex and generative ways of working amid competing logics. Calton and Payne (2003) cast the focus on external networks, arguing that paradoxes can be addressed through multi-stakeholder learning dialogues. Hahn et al. (2015) develop two alternative cognitive frames (a business case frame and a paradoxical frame), posing that the adoption of a business case frame directs decision-making towards 
economic objectives and the pursuit of narrow but workable responses based on existing routines and practices, whereas a paradoxical frame leads to more ambivalent interpretations of corporate sustainability and more comprehensive, albeit cautious, responses.

As this overview shows, sensemaking is congruent with a relativistic perspective, and also aligns with the interpretive epistemological positioning that meaning-making is a social process involving the co-creation of knowledge through language. Whereas few contributions to the literature to date draw on sensemaking to examine paradox, those that do show that sensemaking and paradox sit together comfortably. Specifically, their congruence is apparent in the focus of sensemaking on the meanings that materialise in paradoxical situations that "inform and constrain identity and action" (Weick et al., 2005, p. 409). Sensemaking thus offers a useful perspective on which to base this study.

\subsection{Crown Research Institutes (CRIs) and their context}

The study was carried out in New Zealand CRIs, a context well-suited to a sensemaking approach and the study of the paradox for several reasons. First, research scientists are exposed to a variety of relevant experiences and expectations that provide fertile ground for sensemaking. CRIs are collectively the largest dedicated providers of science research in New Zealand, and are often also the largest integrated providers in their sectors in the world (Science New Zealand, 2013). Their research scientists engage in both blue-sky and applied science and technology research and development (R\&D) to address critical economic, environmental, and social issues. Under the Crown Research Institutes Act 1992, CRIs are required to pursue excellence in delivering benefit to New Zealand, while remaining financially viable in a highly competitive environment. A CRI is also required to operate in a socially responsible manner "by having regard to the 
interests of the community in which it operates and by endeavouring to accommodate or encourage those interests when able to do so" (Appendix I: Part 1, Section 5 of the CRI Act 1992). In short, research scientists are expected to engage in a range of activities that both create value for their institution through commercial enterprise, and generate value for New Zealand through the achievement of public good outcomes. The experience of being confronted with competing demands both polarises people (Bartunek, 1988) and offers a salient context for sensemaking (Luscher \& Lewis, 2008).

Second, research scientists' engagement with the social, economic, and environmental dimensions of sustainability situates them in commercial research contexts where they may be confronted with conflicting ideologies and divergent interests. The potential for conflict to arise when dealing with complexity, ambiguity, and commercial pressures in social settings stimulates the need to justify actions through sensemaking (Cunliffe \& Coupland, 2012). The external parties with whom research scientists are likely to interact and to whom they may be accountable include representatives of central and local government agencies, industry groups and businesses, local iwi, local communities, environmental protection groups, and professional bodies. Within relationship-rich contexts, such as these, the social processes of sensemaking can be particularly significant and visible (Maitlis, 2005) in the accounts of individuals who seek to build goodwill and legitimacy for their organisations through communication (Cornelissen, 2012). Such accounts may contain "retrospective sensemaking of puzzling or unfamiliar situations, including how in those situations they gave sense to relevant internal and external stakeholders" (Cornelissen, 2012, p. 120).

Third, the context of institutional change in which research scientists operate represents an important context for sensemaking. CRIs were formed in 1992 from existing government-owned research bodies, the largest of which was the Department of Scientific 
\& Industrial Research (DSIR), established in 1926. The formation of New Zealand's CRIs followed a period of radical economic and structural transformation beginning in the 1980s when first a Labour government and then a National government led the rapid transition to a neoliberal, free-market economy (Davenport \& Bibby, 2007; Roper \& SchoenbergerOrgad, 2011). Though the newly formed CRIs retained the DSIR's original purpose of conducting research in the national interest, their discipline-based, input-driven structure became market-oriented and output-based with corporatisation (Simpson \& Hibbert, 2008). At the time, this move was widely criticised by the science community who saw the changes implemented as destroying the career prospects and morale of scientists in New Zealand (Roche, 1993).

In the decades since, there has been fierce competition between CRIs and other public- and private-sector organisations for public funding available from contestable sources. Originally, the main public funding source was the Public Good Science Fund administered by the Foundation for Research, Science and Technology (established as a Crown entity in 1990). The size of this funding pool and its priorities and, hence, the research conducted by the State, were determined by the Ministry of Research, Science and Technology (Kelsey, 1997). These agencies have since been disestablished and their policy and investment functions taken over by the Ministry of Science and Innovation formed in 2011. However, the limited public funding available, along with a customer base with limited capacity or incentive to invest in $R \& D$ due to its high composition of business enterprises employing fewer than 20 people (Cartner \& Bollinger, 1997; Davenport \& Bibby, 2007), means that there is ongoing uncertainty for research scientists (Science New Zealand, 2012).

For CRIs, the requirement to serve the 'public interest' puts corporate social responsibility obligations on an equal footing with financial objectives (Crown Ownership 
Monitoring Unit, 2012). However, frequent job losses, a loss of organisational capability, and constantly changing rules of engagement since their formation in 1992, have led to considerable disquiet among scientists about the role of CRIs and the future of science in New Zealand (The New Zealand Association of Scientists, 2005). For instance, it has been suggested that in their struggle to remain financially viable, CRIs may not have the incentive to work primarily in the public interest, and that their public good roles are being compromised by the requirement to generate income from private sector clients who may be unconcerned with public good outcomes (The New Zealand Association of Scientists, 2005).

A climate of change prevails in CRIs as a series of recommendations contained in the 2010 Report of the CRI Taskforce are actioned with a view to benefiting New Zealand by changing "the attitudes and behaviours of CRIs through streamlined funding processes, strengthened governance structures and clarified goals for each CRI" (Crown Research Institute Taskforce, 2010, p. 3). Given the changes occurring, it is apparent that the CRI context represents one in which scientists' sensemaking accounts will be influenced by a raft of social pressures to align with or accommodate the priorities mandated by government, as well as the expectations of various others. Contexts of change are useful sites for examining the plausible meanings used to rationalise what people are doing (Maitlis \& Sonenshein, 2010). Altogether, the CRI context represents a setting that brings salient paradoxes to the foreground, and so offers the opportunity for their explication (Bednarek et al., 2012; Jarzabkowski et al., 2013; Luscher \& Lewis, 2008).

\subsection{Data collection}

In recent years, studies have drawn on qualitative methods to examine research collaboration generally (e.g. Bammer, 2008) and, more specifically, research management 
(e.g. Etzkowitz, 1998; Jain et al., 2009; Welsh et al., 2008). To gain insight into the phenomena central to this investigation, in-depth interviewing was used to generate vivid and informative accounts of the experiences of research scientists who engage with sustainability in commercial research. In-depth interviewing is a suitable choice when drawing on an interpretive orientation that sees human action as meaningful and historically contingent (Bevir \& Kedar, 2008). It allows the researcher to capture participants' experience, especially when the approach adopted during interviews is one of narrator and listener: with the interviewer as 'listener' inviting specific stories, rather than asking participants to generalise about their experiences (Chase, 2011).

The principal data source was a set of 44 semi structured interviews with research scientists. These in-depth interviews were conducted in four CRIs (eleven interviews each) over a nine-month period from February to October in 2011, and encompassed five different geographical regions across New Zealand. The sample size of 44 participants allowed a range of perceptions to be identified and meaningful categories to be developed. No further interviews were conducted beyond this point as "diminishing returns" on data gathered suggested that theoretical saturation had largely been achieved (Given, 2008, p. 196).

The CRIs were assigned the pseudonyms Discover, Innovate, Create, and Inspire (Table 3.1 Participants and CRIs). The environment in which CRI research scientists operate is relatively fluid. Some scientists move between CRIs, other scientists work across CRIs in multi-disciplinary project teams, and CRIs have repeatedly restructured. Furthermore, as government-owned organisations, CRIs are bound by the same operating rules and regulations, and often face similar challenges in conducting their affairs. Therefore, the data gathered across the CRIs was intended to gauge a variety of views, rather than seek to compare organisations. Archival data were also collected in the months 
leading up to, and during the interview period. These included a range of reports and publications produced by each CRI, articles in the popular press, government publications, and information presented on websites.

Though this study focuses on a specific time and context, the insights offered through thick description may resonate with scientists and others similarly engaging with pressing sustainability issues in other contexts. The theoretical contribution this study stands to make lies in its ability to extend or refine pre-existing theoretical and conceptual formulations and to detect new concepts or theoretical constructs by examining them in the context of science work and sustainability (Ridder, Hoon, \& McCandless Baluch, 2014). As will be outlined in Section 3.6.1 (Approaching data analysis), this entails iterating between data-based theorizing and making conceptual leaps (Klag \& Langley, 2013). So, it is in the positioning of its findings alongside existing works that this research will signify its distinct contribution to theory, a contribution to be evaluated on both its theoretical relevance to literature and practice as well as its "sensegiving potential to the wider audiences" (Corley \& Gioia, 2011, p. 29).

All participants were scientists with direct experience of the phenomenon of interest (i.e., commercially-funded research of direct or indirect relevance to an issue of sustainability). As shown in Table 3.1, the majority of participants held senior positions, and had experience of managing science groups or teams. Participants represented a range of disciplines and areas of science, and had an average length of service 16.5 years. 
Table 3.1

Participants and CRIs

\begin{tabular}{lccccccc}
\hline CRIs & Interviews & Male & Female & $\begin{array}{c}\text { Science } \\
\text { group } \\
\text { managers* }\end{array}$ & $\begin{array}{c}\text { Team } \\
\text { leaders }\end{array}$ & $\begin{array}{c}\text { Senior } \\
\text { research } \\
\text { scientists }\end{array}$ & $\begin{array}{c}\text { Research } \\
\text { scientists }\end{array}$ \\
\hline Innovate & 11 & 8 & 3 & 3 & 3 & 3 & 2 \\
\hline Discover & 11 & 6 & 5 & 4 & 2 & 2 & 3 \\
\hline Create & 11 & 8 & 3 & 3 & 2 & 4 & 2 \\
\hline Inspire & 11 & 6 & 5 & 3 & 3 & 2 & 3 \\
\hline Total & 44 & 28 & 16 & 13 & 10 & 11 & 10 \\
\hline Average length of service of participants: 16.5 years & & & \\
\hline
\end{tabular}

Access to the organisations was gained by discussing the proposed research with a senior manager at each of the four CRIs (either over the telephone or in person), providing them with a Letter of Introduction (Appendix III), and requesting access. Participants were recruited in four ways. First, a senior staff member within each CRI emailed an outline of the study to all staff. This paved the way for the direct approaches subsequently made. Second, a senior staff member at each CRI provided the names of individuals with relevant experience (i.e., engagement in commercially-funded research of direct or indirect relevance to an issue of sustainability). Third, scientists with relevant experience were identified through a search of publicly available information (i.e., articles in the popular press, corporate websites, and videos profiling the work of scientists on the YouTube channel). Fourth, participants were invited to offer the names of others with relevant experience at the conclusion of each interview (i.e., using 'snowballing' (Patton, 2002). 
The aim was to include variety across gender, position, and experience in the sample chosen for the analysis of relatively novel phenomenon, rather than distinct differences for the purpose of comparison.

Interviews typically took one-hour, and were organised to allow participants to reflect on their experiences. The majority of interviewees (38 of 44) opted to be interviewed in their private work space. Other arrangements included cafés, sailing club rooms, a private residence, and a university office. At the start of each interview, participants were asked about their role and relevant experience, including any personal or professional links with external groups with an interest in sustainability. The conversation that started using these preliminary questions enabled an understanding of context from which to individualise subsequent questions. As each interview progressed, participants were invited to focus on the challenges they had experienced in addressing sustainability in the context of commercial research, and the ways in which they tended to respond to these challenges. Active approaches to questioning align with a constructivist perspective that views the interview as an interpretive process through which meaning is jointly constructed (Cassell, 2005). Though questions were used to trigger reflection on relevant issues, the flow of discussion varied according to the issues that were relevant and meaningful to each interviewee. Flexible, interactive approaches to questioning are needed when seeking to explore complex interactions and tacit perceptions (Patton, 2002). At the same time, from a sensemaking perspective, it was important not to interrupt the flow of speech with too much questioning. As Cornelissen (2012, p. 121) explains, frequent breaks through questioning can prompt unwanted "turns in the sensemaking or rhetorical moves such as summarizing and contrast”.

An interview schedule with key questions and topic prompts helped to ensure that ideas derived from the literature and newly evolving ideas were addressed during 
interviews (Appendix II). However, the focus was primarily on following scientists' stories, rather than on structuring interviews around the schedule. There is a need to be open to the multitude of meanings that may emerge during empirical investigation (Dubois \& Gadde, 2002). While ideas derived from the literatures on research management (e.g., Biscotti et al., 2012; Jain et al., 2009; Lam, 2010, 2011), sustainability in the context of science work (e.g., Epstein, 2008; Geels, 2010; Worley et al., 2010), and paradox (Gotsi et al., 2010; Lewis, 2000; Smith \& Lewis, 2011) were examined in more depth as the data collection progressed, this theory-checking was done discretely in that the use of the terms 'paradox' 'tension' and 'contradiction' was avoided. Instead, participants were invited to talk about the highlights and challenges of their role generally, and specifically in their engagement with clients and sustainability in commercial research. The mention of tensions, paradoxes, and their respective sources emerged spontaneously in scientists' discussions.

All interviews were recorded and transcribed verbatim (with the permission of participants). Shorthand notes of relevant points were also taken and used as a quick reference during interviews. An aggregated summary of the main findings was sent to participants and the senior managers who had authorised access. Feedback received confirmed that the report accurately reflected participants' overall experiences.

\subsection{Ethical considerations}

Issues of confidentiality and anonymity can arise due to the personal interactions required by the methodology (Guba \& Lincoln, 1994). Prior to conducting this research, these issues were addressed in an application submitted to and subsequently approved by Victoria University of Wellington's Human Ethics Committee. Procedures documented in this application and in the Human Ethics Committee's Policy and Guidelines were then 
complied with throughout the project. Specifically, the intention and scope of the study was openly and honestly discussed with senior managers at each organisation, and approval obtained to conduct research on their premises. Some project details were also set out in a Letter of Introduction prior to gaining access (Appendix III). Other matters pertinent to the integrity of the study discussed with managers included how participants would be recruited, whether and how policy and other relevant documentation could be accessed, the need for anonymity and confidentiality, and verification and release of information.

At the start of each interview, participants were given an Information Sheet (Appendix IV), and reminded that their participation was voluntary. They were also advised that they could refuse to answer any questions asked, and/or withdraw from the study at any time prior to the completion of data gathering in their organisation. A Consent Form towards participation in research was used (Appendix V). Participants were also advised that although they would not be identified in the reporting, it was possible that their past or present profile within the organisation could allow information given to be linked to them. Anonymity was maintained during and after the data gathering. Neither the organisations' names nor the participants' names are used in the reporting; pseudonyms are used instead.

\subsection{Data analysis and categorisation}

Making the conceptual leap involves bridging the gap between empirical data and theory: moving from the mass of words and other data (the world of the field), through and beyond the mechanics of analysis to an abstract and explicit set of concepts, relations and explanations that have meaning and relevance beyond the specific context of their development (the world of ideas) (Klag \& Langley, 2013, p. 150). 
The research was abductive, involving iteration between the literature and the interview material (Dubois \& Gadde, 2002; Van Maanen, Sorensen, \& Mitchell, 2007), and an increasing emphasis on dovetailing particular findings with theorisation on paradox. Abductive reasoning processes entail the search for alternative explanations when the flow of experience (or ongoing observations) is interrupted by the emergence of doubt or punctuated with uncertainty and ambiguity (Alvesson \& Karreman, 2007; Klag \& Langley, 2013). The abductive strategy aligns with an interpretive epistemology and the use of sensemaking in that it shares the same assumptions regarding the creation of knowledge (i.e., knowledge is co-created through the use of language, and derived from everyday concepts and meanings) (Blaikie, 2007). Hence, the focus of the researcher is on understanding the knowledge and skills employed by people in constructing and reconstructing their lives, and on producing social accounts from them (Ong, 2012).

\subsubsection{Approaching data analysis}

Following Klag and Langley's (2013) theorisation of the analytical processes involved in making conceptual leaps, the analysis was approached as entailing the negotiation of a series of dialetical tensions (i.e., deliberation and serendipity, engagement and detachment, knowing and not knowing, and social connection and self-expression). Deliberation included examining ideas drawn from the literature alongside metatheoretical categories derived from Weick's (1995) articulation of the characteristics of sensemaking. Doing so added variety and deepened my engagement with emerging theoretical understandings by prompting consideration of issues of control, identity, plausibility, and retrospect. As others claim, the use of heuristics in theorising stimulates more holistic thinking (McIntyre, 1998) by adding variety or more diverse conjectures (Klag \& Langley, 2013; Weick, 1989). 
In contrast to the purposeful process of deliberation, moments of serendipitous discovery entailed the sudden realisation of new explanations or categories that captured the essence of certain realities (as perceived by research scientists) not immediately apparent in the data. Though seemingly effortless, these discoveries occurred in a context of preparedness after having first engaged with the data, the field, and theory, as well as reading widely (Klag \& Langley, 2013). Moments of serendipitous discovery in theorising are often seen as no more than a lucky accident (Weisenfled, 2009). However, drawing on the open systems concept of Ashby's law of requisite variety which stipulates that the variety within a system must be at least as great as the variety it is attempting to control in its environment (Lewis \& Stewart, 2003), Weick (1979) explains that the diversity in the phenomenon needs to be matched by the same diversity in the enquirer for the phenomenon to be comprehended and made sensible.

Purposefully engaging with the data initially entailed systematically identifying main themes and their interrelationships. My use of the term 'engagement' in the context of theorising refers to the exercising of data to seed ideas (Klag \& Langley, 2013), drawing on coding procedures of constant comparison and theoretical questioning (Strauss \& Corbin, 1994). Given the need for clarity around procedures applied in moving towards insight, the next section (3.6.2 Categorisation of data) discusses in some depth my engagement with the analytical process. In contrast to periods of close engagement with the data, there were periods of detachment that entailed creating time for the gestation of ideas. As Klag and Langley (2013) explain, there is a need for both logic and creativity in theorising, and taking a break may be equally as evocative as the purposeful engagement that precedes it.

'Knowing' in relation to this study entailed considerable substantive and theoretical knowledge acquired through life events and experience of different work trajectories. 
Specifics on which I drew for insight included career experiences (through which I gained an understanding of the sorts of issues confronting people in organisations), and prior research activities (which provided me with an understanding of the logistics of planning, conducting, writing-up, and reporting on qualitative research). The value of such knowledge and experience lies in its ability to enhance one's theoretical sensitivity or capacity to make conceptual leaps (Klag \& Langley, 2013; Strauss \& Corbin, 1994). Paradoxically, knowledge and experience can also be a liability since too much knowledge and experience can stimulate banality, rather than creativity in theorising (Klag \& Langley, 2013). In my case, 'not knowing' triggered the need to find answers. As others have noted, embracing the tension that can accompany 'not knowing' by pursuing hunches, guesses, or problematising, can stimulate the creativity needed to provoke the theoretically-relevant insights that contribute to a discipline (Locke, Golden-Biddle, \& Feldman, 2008).

The fourth and final dialectic concerns the seemingly contradictory need to generate insight through individual identity and personal engagement, as well as though social connectedness. Making sense of the research findings was a highly personal experience that entailed attempting to stimulate variety, grow ideas, and draw on past experiences. Throughout, I was aware that the agency I enjoyed as a researcher meant that my own philosophical, methodological, and ideological viewpoints were influential in shaping the knowledge generated. At the same time, making sense also included maintaining connections with others through processes of peer review and by attending seminars and conferences on the topic to engage in scholarly exchange. Theory-building is a form of sensemaking that is grounded in both individual and social activity (Weick, 1995). As Klag and Langley (2013) explain, being both personally engaged and socially connected when engaging in qualitative research enables the researcher to draw on "more 
resources for generating and developing ideas [and] more conduits for expanding and communicating them" (p. 160).

\subsubsection{Categorisation of data}

The systematic process of engaging with the data and moving towards theorisation began during the data collection with insights gained being used to hone following interviews (i.e., as refinements of, or extensions to, questions and/or new prompts). The research used the software program NVivo as a tool for storing and retrieving the data, as well as for coding and examining the links between codes. Codes or categories are the tags or labels usually assigned to chunks of text of varying size (in this case, paragraphs and sentences) to depict meaning (Miles \& Huberman, 1994). The first set of coding developed 26 categories. Examples included capabilities and expertise, role identity, conceptions of sustainability, responsibilities under the CRI Act, key challenges, key rewards, and group dynamics. As the data gathering progressed, the codes identified electronically were juxtaposed against the literature to identify, revise, and refine categories. The analytic steps taken in refining the initial coding to a set of 21 categories pertinent to paradox are detailed in what follows.

Through theming, I dovetailed particular findings with theorisation on paradox. This analytical process comprised close reading of coded printouts, scanning of field notes and secondary data gathered, reflection on relevant literature, highlighting of pertinent points, making notes of ideas, and developing ideas through writing. To keep track of decisions made during the categorisation process and create an audit trail (Creswell \& Miller, 2000), I developed and progressively updated a tabular summary of main categories based on the documentational table developed by Constas (1992). Table 3.2 (Summary of main categories) presents the analytical actions involved in creating the main 
categories, along with the point in time at which they were developed. The main categories applied are grouped in a key beneath the table. The alphanumeric number assigned to each category is presented alongside the relevant subheading in the left-hand column of Table 3.2. Specifically, it notes: its origination - where the authority for its creation resides (investigative or literature); verification - the basis on which it is justified (participants, rational, referential or empirical); and nomination - the source of the terminology used (participants, investigative or literature).

The point at which each category was specified (i.e., a priori, iterative or a posteriori) is also shown in the relevant column under the heading temporal designation. As noted, the analytic process retained only one category developed a priori (A5 role identity). Table 3.2 attributes most of the authority for categorisation to the literature. It presents the basis on which the majority of categories are justified as referential and participants (see verification) since their development is based on the use of terminology taken from the literature (though not necessarily the literature on paradox), and feedback from participants on a report of preliminary findings. Similarly, Table 3.2 shows that the naming of categories (nomination) reflects concepts theorised in the literature.

Early on during the data gathering, it became evident that participants perceived significant challenges in navigating both public good and commercial research goals. For instance, they often mentioned the complexity inherent in applying their research in commercial settings in ways that were simultaneously holistic in a public good sense, personally satisfying, and acceptable to clients. They presented the management of sustainability in commercial research as a particular challenge, identifying differences in mindset, priorities, time horizons, and expectations to be navigated alongside often ambiguous problems. This insight prompted me to focus on 'salient tensions' (those 
Table 3.2

Summary of main categories based on Constas (1992)*

\section{Component of Categorisation}

\begin{tabular}{|c|c|c|c|}
\hline \multirow[b]{2}{*}{$\begin{array}{l}\text { Origination } \\
\text { (authority for category creation) }\end{array}$} & \\
\hline & $\begin{array}{l}\text { A priori } \\
\text { (before) }\end{array}$ & $\begin{array}{l}\text { Iterative } \\
\text { (during) }\end{array}$ & $\begin{array}{l}\text { A posteriori } \\
\quad(\text { after })\end{array}$ \\
\hline Investigative/researcher & & $\mathrm{C} 3$ & $\begin{array}{l}\text { A4, B2, B3 } \\
\text { C5, D3, D4 }\end{array}$ \\
\hline Literature & A5 & $\begin{array}{l}\mathrm{A} 1, \mathrm{~A} 2, \mathrm{~A} 3 \\
\mathrm{~A} 6, \mathrm{~B} 1, \mathrm{~B} 4 \\
\mathrm{C} 1, \mathrm{C} 2, \mathrm{D} 1\end{array}$ & $\begin{array}{l}\text { C4, D2 } \\
\text { D5, D6 }\end{array}$ \\
\hline \multicolumn{4}{|l|}{$\begin{array}{l}\text { Verification } \\
\text { (basis of category justification) }\end{array}$} \\
\hline Participants & & & $\begin{array}{l}\mathrm{A} 1, \mathrm{~A} 3, \mathrm{~A} 5, \mathrm{~A} 6, \mathrm{~B} 1 \\
\mathrm{~B} 3, \mathrm{C} 3, \mathrm{D} 3, \mathrm{D} 4, \mathrm{C} 5\end{array}$ \\
\hline Referential/prior research & & $\begin{array}{l}\mathrm{A} 1, \mathrm{~A} 2, \mathrm{~A} 3 \\
\mathrm{~A} 5, \mathrm{~A} 6, \mathrm{~B} 1 \\
\mathrm{C} 1, \mathrm{C} 2, \mathrm{D} 1\end{array}$ & $\begin{array}{c}\text { B4, C4 } \\
\text { D2, D3 } \\
\text { D4, D5, D6 }\end{array}$ \\
\hline Empirical & & $\mathrm{C} 3$ & $\mathrm{~A} 4, \mathrm{~B} 2, \mathrm{~B} 3, \mathrm{C} 5$ \\
\hline \multicolumn{4}{|l|}{$\begin{array}{l}\text { Nomination } \\
\text { (source of terminology used) }\end{array}$} \\
\hline Participants & & A6 & \\
\hline Investigative/researcher & & & $\mathrm{A} 4, \mathrm{~B} 2, \mathrm{~B} 3$ \\
\hline Literature & A5 & $\begin{array}{c}\mathrm{A} 1, \mathrm{~A} 2, \mathrm{~A} 3, \\
\mathrm{C} 1, \mathrm{C} 2, \mathrm{C} 3, \mathrm{D} 1\end{array}$ & $\begin{array}{c}\text { B1, B4, C4, C5, } \\
\text { D2, D3, D4, D5, D6 }\end{array}$ \\
\hline
\end{tabular}

Temporal Designation

(Point at which categories specified)

\section{Key: Main Categories:}

Paradoxes (A)

Managing paradox (C \& D)

$\mathrm{A} 1=$ performing

$\mathrm{C} 1=$ differentiating (overarching category)

$\mathrm{A} 2$ = belonging

$\mathrm{C} 2$ = internally diversifying scope of services

$\mathrm{A} 3$ = organising

$\mathrm{C} 3=$ incrementally influencing

A $4=$ service ethos

$\mathrm{C} 4=$ internally differentiating

$\mathrm{A} 5=$ role identity

C5 $=$ developing connections with external groups

A6 $=$ professional integrity

Defensive responses (B)

D1 = integrating (overarching category)

$\mathrm{B} 1=$ opposing

$\mathrm{B} 2$ = isolating

B3 = over-committing

B4 = suppressing

D2 = identifying financial synergies

D3 $=($ re $)$ framing

D4 = (re)positioning, shapeshifting

D5 $=$ harnessing economies of scope

D6 $=$ career mentoring

*Adapted from Constas (1992) table for the development of categories 
recognised by participants), and the ways by which they engaged with these (Bartunek $\&$ Rynes, 2014; Smith \& Lewis, 2011). Participants occasionally characterised these as 'paradoxical' when describing their experiences. Paradoxes were also identified by virtue of their characteristics, including their persistence over time and apparently unresolvable nature. Pertinent here, were scientists' depictions of their work as 'a real balancing act', and their accounts of how avoiding a certain activities tended to prompt 'vicious circles'. Accordingly, I drew on the paradox literature in abductively identifying three main types of paradox, defensive responses to paradox, and productive responses to paradox. What follows discusses the categorisation in more depth.

\section{Types of paradoxes}

Prior studies delineating the types of paradoxes confronting organisations had generated overarching paradoxes of performing, belonging and organising (Luscher \& Lewis, 2008; Luscher et al., 2006). As a broad framework, these enabled me to identify three main paradoxes experienced by research scientists in the context of commercial research and sustainability: paradoxes of performing, belonging, and organising (assigned the alphanumeric numbers A1-A3 in Table 3.2). Moving back and forth between pertinent data in the transcripts, the literature, and an evolving summary of scribbled theoretical insights, I further categorised these as paradoxes of service ethos, role identity, and professional integrity (A4-A6 respectively in Table 3.2) on the basis of the overall nature of the tensions they each encompassed. Table 3.2 does not categorise the tensions each paradox holds. Instead, this research presents these as a series of competing demands or double-binds embedded within providing both a 'public service' and a 'customer service' in Table 8.1 , chapter 8 . 


\section{Defensive responses}

The term 'defensive' is used in the paradox literature to denote the use of avoidance tactics when confronted with paradox (Jarzabkowski et al., 2013; Smith \& Lewis, 2011). The term is used in relation to practices that potentially have a constraining effect on one's engagement with paradox, rather than in the judgemental sense of the term in everyday language. Prior research had identified defensive responses to paradox that can foster unintended and, potentially, harmful consequences (Gotsi et al., 2010; Jarzabkowski et al., 2013). Juxtaposing these with participants' accounts of actions they saw as enabling or constraining their engagement with sustainability in commercial research exposed several types of defensive response. Two of these were consistent with responses already reported in the literature: opposing and suppressing (B1 and B4 in Table 3.2 (Jarzabkowski et al., 2013). The former reflected the defensive stance taken by scientists when they perceived an increasing emphasis on commercial enterprise in their CRI. The latter comprised practices perceived to constitute the neglect of one set of performance-related demands (e.g., exploratory research activities) and the favouring of another (e.g., client-related activities).

Two others were identified through this study and are new to the literature: overcommitting and isolating (B2 and B3 in Table 3.2). The category 'over-committing' encompasses two related defensive tactics: over-promising (when bidding for public funding) and over-delivering (when fulfilling commercial contracts). This research uses the term 'isolating' to categorise a response to paradox that entails creating conditions that isolate oneself from others (i.e., peers and/or clients) and, thereby, from productive engagement in activities. The specific actions each defensive response entails are not recorded in Table 3.2, but are summarised in Table 8.2 (Chapter 8). 


\section{Productive responses}

The term 'productive' is used in the paradox literature to indicate ways in which people constructively cope with paradox, rather than engage in actions leading to greater ‘productivity’ (Jarzabkowski et al., 2013; Smith \& Lewis, 2011). The literature on paradox had identified productive responses to paradox that entail coping or even harnessing the energising potential of tensions (Andriopoulos \& Lewis, 2010; Smith, Besharov, Wessels, \& Chertok, 2012). In particular, some authors usefully describe the management of paradox by distinguishing between differentiating and integrating practices (Andriopoulos \& Lewis, 2009; Bednarek et al., 2012; Smith \& Tushman, 2005). These overarching strategies were identifiable in this study, though the specific approaches and practices tended to differ from those presented in the literature. Their positioning in Table 3.2, shows that this study's application of the overarching categories of differentiating and integrating (C1 and D1) was based on terminology used in the literature (Andriopoulos \& Lewis, 2009; Lawrence \& Lorsch, 1967). Further analysis provided a picture of the range of differentiating and integrating practices scientists saw as enabling their engagement with sustainability in commercial research under these broad categories. Among these, were tactics relevant to participants' immediate interactions with clients, as well as actions scientists saw as indirectly affecting their interactions with industry groups and businesses.

This study identifies five specific differentiating/integrating practices premised on scientists' perceptions of tactics used when dealing with clients to influence them towards sustainability. These include those presented in Table 3.2 as incrementally influencing (C3), identifying financial synergies (D2), (re)framing (D3), (re)positioning (D4), and harnessing economies of scope (D5). The differentiation tactic of incrementally influencing clients (C3) was identified iteratively in participants' depictions of their 
approach to engaging with sustainability, and had not been presented in the paradox literature as a productive response to paradox. However, incrementalising has long been recognised in the strategy literature (Low \& Johnston, 2012; Quinn, 1982), and so following the documentational procedures introduced by Constas (1992), authority for the origins or creation of this category was attributed to this study (investigative), and the source of the name used (nomination) attributed to the literature (Table 3.2).

The productive response of identifying financial synergies (D2) is a novel tactic, particularly as depicted by research scientists (i.e. financial synergies between public good and commercial projects). This study attributes its use of the category 'identifying financial synergies' to the wider literature both in terms of its origination and nomination in Table 3.2. The study identifies the tactic of (re)framing (D3) in participants' accounts of presenting sustainability interventions to clients in ways that highlight their commercial (versus public good) value. The value of internal reframing has been theorised as a way of generating understanding that better reflects organisational intracacies (Denison, Hooijberg, \& Quinn, 1995), and in relation to organisational transformation (Bartunek, 1988). Accordingly, Table 3.2 attributes authority for the creation of this category to the study (investigative), and identifies the literature as the source of the name used.

Finally, the categories '(re)positioning and shapeshifting' (D4) and 'harnessing economies of scope' (D5) represent further new additions to the literature on paradox management. The former category was identified in scientists' accounts of adapting to situations when interacting with clients; the latter, in their claims of generating both a commercial and a public good output by co-authoring with clients. The notions of (re)positioning and shape-shifting have been used in the broader literature as well as harnessing economies of scope. Accordingly, Table 3.2 attributes authority for category 
creation to the study (investigative), and identifies the literature as the source of the names used (nomination).

This study identifies four specific differentiation/integration practices premised on scientists' perceptions of tactics they perceive as indirectly influencing business towards sustainability. These categories include those presented in Table 3.2 as internally diversifying scope of services (C2), internally differentiating (C4), developing connections with external groups (C5), and career mentoring (D6). First, the differentiation tactics of internally diversifying scope of services (C2) and internally differentiating (C4) had previously been used in theorising on the management of paradox (Andriopoulos \& Lewis, 2010). Accordingly, Table 3.2 ascribes authority for the creation and nomination of these categories to the literature.

Second, the category 'developing connections with external groups' (C5) was identified through the study as a novel response to paradox. The term had been used in the wider literature so its origins were attributed to this source. Last, the study's use of the category 'career mentoring' (D6) is based on terminology used in prior theorising on paradox (Gotsi et al., 2010; Tosey, 2005). Its origination (literature), verification (referential), and nomination (literature), is depicted in Table 3.2.

Though the analysis provides novel insights that answer the research questions, it is not exhaustive of all the themes on paradox that could be gleaned from research organisations. Instead, consistent with the aim of this research, the focus was on developing analytical generalisations (Tsoukas, 1989) about the dynamics of paradox in the context of scientists' engagement with commercial research directly or indirectly relevant to sustainability (as perceived by research scientists). 


\subsection{Organisation of findings}

Having categorised the data as discussed in the previous section, I began to consider how best to present the findings. Based on the categories identified in Table 3.2, one scenario was to present the findings in a linear fashion starting with the tensions across the paradoxes of performing, belonging, and organising, followed by the defensive responses to these paradoxes and, lastly, the various approaches to managing these paradoxes. As I started to write, my intention was to make the findings more accessible to the reader. Accordingly, to offer an holistic representation of each of the three paradoxes, I decided to organise the findings chapters around each of the three paradoxes and their respective responses, both constraining and enabling. Hence, there are three findings chapters: Chapter 4, Performing and the paradox of service ethos; Chapter 5, Belonging and the paradox of role identity; and Chapter 6, Organising and the paradox of professional integrity.

\subsection{Concluding summary}

This chapter discussed a research approach designed to generate the understanding needed to address the research questions, and capture perceptions of organisational practices. The use of an interpretive approach is congruent with tenets a constructivist ontology and the use of sensemaking. The chapter also offered an overview of the CRI context, and discussed the use of in-depth interviews as the means of data collection. The study's abductive approach to data analysis was presented as navigating a series of dialectical tensions: deliberation and serendipity, engagement and detachment, knowing and not knowing, and social connection and self-expression. Last, close engagement with the data was made transparent by documenting the procedures used to generate categories during the process of qualitative analysis. 


\section{Chapter 4 \\ Performing and the paradox of service ethos}

I think there is a very strong consensus that science is there to improve living conditions, improve our ability to live on our increasingly small planet, and have good and satisfying lives. But ... it always comes back to, "Well it needs to be this number to be economic". If we can't get it done at that cost, then we can't do it even if there are many benefits. That's the fundamental tension, but it is also the reality (Research Scientist, Innovate). ... marrying what is usually a business model of making money with also concern for the environment is not always an easy relationship (Senior Research Scientist, Create).

Paradoxes of performing consider the tensions generated when performance expectations confront a person with apparently contradictory demands and the potentially conflicted sense of purpose these inspire (Bednarek et al., 2012; Luscher \& Lewis, 2008). Such tensions are prevalent where organisations have a dual mission, and seek to maintain relationships with a diverse range of social groups (Jay, 2013; Margolis \& Walsh, 2003; Smith et al., 2012).

Research scientists discussed how they faced simultaneous imperatives through a paradox of service ethos: on the one hand, performing to public service expectations (based on a public good orientation) whereby their research engages with sustainability in a way that advances society at large; and on the other hand, performing to customer service expectations (based on commercial orientation) and generating financial returns for the CRI through commercial enterprise. The chapter begins by introducing the four strands of the paradox of service ethos. As depicted in Table 4.1, each strand may be viewed as a tension between opposite poles of performance. The chapter then examines the ways in which research scientists respond to perceived competing demands. Here, the analysis considers the defensive practices in which they engage, along with their 
consequences. It also considers a range of strategic practices embedded within differentiation and integration approaches that research scientists draw on in managing paradox.

Table 4.1

Performing and the paradox of service ethos

On the one hand...

On the other hand...

Public service

Customer service

Based on public good orientation

Based on commercial orientation

Serving the wider interests of the country and its citizens by attending to the 'bigger picture'

Serving clients and thereby adding value to the economy

Focusing on the public good and sustainability by addressing research problems holistically

Focusing on the commercial applications of research towards financial viability

Retaining critical expertise through socially and environmentally significant programmes

Allowing client requirements to determine research focus and respective expertise

Engaging in dialogue with citizens on matters of public interest, and speaking out for change in Complying with in-house rules that restrict public policy

\subsection{Underlying tensions}

First, research scientists considered the effects of both the socio-political environment and the institutional context in defining their central constituency and hence the purpose and focus of their service. On the one hand, there was the imperative to serve the wider interests of New Zealand by focusing on "the bigger picture ... how you can sustain planet Earth" (Senior Research Scientist, Create). Specifically, the legislative attempt to institutionalise corporate social responsibility through the CRI Act 1992 
resonated well with all participants in terms of their performance expectations (regardless of whether or not they knew the specific terms of the Act). Some even used it to differentiate themselves from university researchers:

I'm acutely aware of our responsibility. It's also something I think that we're much better at than the universities. They're blue sky research and have a somewhat narrow focus on just doing the research. They don't see the bigger picture (Research Scientist, Innovate).

At the same time, they sought to distinguish their services from those offered by the numerous consultancy firms that had entered the environmental services market. Some emphasised the relevance and ground-breaking nature of their research in doing so:

There's been a bit of a rush towards green growth or the sustainable business model, and a surge in the number of people offering consultancy services. But, as researchers, we're not here to do repeat consultancy. We're here to understand what the pressing issues are, to look for new ways of doing things, to reflect on what's out there that's working or not, and to then move on to keep the game going (Team Leader, Inspire).

There was a perception that key institutional responsibilities included doing research that had a constructive impact on the "citizens of the area because it's their tax money at work" (Research Scientist, Discover). Scientists viewed this as entailing getting key people in business to appreciate the importance of sustainability, and to address its initiatives with other business goals so that they became part of "business as usual" (Team Leader, Inspire). They saw it as also entailing a need to undertake research that benefits humanity at large. However, there was the view that these performance imperatives confronted them with a tension:

I feel very strongly that open-minded, investigative research is the way to greater outcomes, but there is a funny tension between how that works, and then the funding system which tends to be extremely focused towards [economic] outcomes (Research Scientist, Innovate). 
So on the other hand, scientists saw their public good orientation as potentially conflicting with the 'reality': the need to undertake work that generates commercial returns for the respective CRI and its client organisations. Although CRIs had a clear mandate to take account of "things like the environment and risks", they saw the institutional focus as having shifted over the previous ten years from science that benefits New Zealand and its citizens to science that demonstrates an ability to add value to the New Zealand economy (Research Scientist, Innovate). The dominant perception was that this change in focus had been sanctioned by the current government whose focus was on economic imperatives:

I think it's seen as least important by the government that we contribute to other areas [than business] such as the environment and social areas (Research Scientist, Innovate).

Sustainability is sort of on the back burner now. The drivers are economic (Science Group Manager, Inspire).

Second, there was the view that the paradoxical service ethos had implications for the focus of their research and its outcomes. On the one hand, they saw the focus on the public good and broad sustainability goals as implying a need to address research problems and questions holistically. This was entwined with expectations held towards their professional responsibility, especially those of meeting the ideals of sustainability:

You think because somebody else cares, you need to care. It's a sort of "we're all in this together, and we want to row the boat together for a better outcome". So if you think this may have a small contribution toward that outcome [sustainability], you do it (Senior Research Scientist, Discover).

Here, professional expectations intersect with motivation, a point to which the study later returns (in analysing scientists' conflicted sense of belonging in Chapter 5). However, 
scientists saw the economic direction in which the New Zealand science system was heading as confronting them with a tension:

New Zealand [science] is very commercially-driven. I wish it was a little bit less so and that there was more of a government role for science for the common good. We really want to change behaviour. You don't get that with ordinary [commercial] work. You get some money, you do a little project, and they acknowledge your final report: "Thank you very much. Good luck" (Senior Research Scientist, Create).

So on the other hand, there was the view that scientists faced the demands that confront any business (generating income to meet key performance indicators and remaining financially viable) by focusing on the commercial applications of research: We would be in danger if the commercial work dried up. Definitely. It effectively keeps our lab going (Research Scientist, Discover).

You need to generate revenue, full stop. If you only depend on government long-term research, you probably won’t survive (Science Group Manager, Innovate).

Focusing on commercial applications meant interacting with others whose vision and values did not always align with the expectations scientists held towards meeting the ideals of sustainability:

Those industries are not in the least bit interested in [a waste treatment initiative] because, for them, it's too expensive and, more importantly, no-one has yet legislated that they should do this. So until they are pushed into a corner with a gun at their heads saying "We are legislating, you've got to do it", the behaviour's not going to change (Science Group Manager, Innovate).

Yet, scientists often claimed to take pride in their ability to accommodate this requirement, and saw themselves as managing it well: 
I think Inspire is a great example of taking something that was based in science and research and pushing it out to commercial solutions - which is what we're meant to do as CRIs (Team Leader, Inspire).

They also saw their support of business via the exploitation of their science in commercial settings to align with what was generally expected of their CRI:

I see commercial as the life blood. I see blue skies not as a cop out, and it is the bread and butter and backbone. It is what props us up all the time, but the commercial stuff is the stuff the people want now, and there's a real interest for, and I see that as the role of this organisation - supporting New Zealand industry (Senior Research Scientist, Innovate).

The third tension in maintaining focus on public good as well as commercial imperatives was considered in relation to organisational capabilities. On the one hand, CRIs were faced with the threat of losing capability in certain areas. Some expertise had already been lost through the history of institutional change and subsequent loss of career stability for research scientists (many of whom reported having put on hold or abandoned altogether areas of research they saw as pivotal to sustainability in New Zealand). There was the view that decisions made by public funding agencies on which research programmes should be supported were also contributing to the under-utilisation of capability (e.g. on climate change) in CRIs. Several participants saw this situation as prompting various research groups to absorb socially and environmentally significant programmes (with a fundamental science ethos) within the overall workload so as to retain critical research abilities with long-term relevance to organisational viability:

If we don't have fundamental science, we will not have business in ten years' time (Senior Research Scientist, Create).

Accordingly, some saw the need to protect "really clever people who can do fundamental science" (Research Scientist, Innovate) and were relevant to the organisation long term. 
The challenge, however, was that commercial clients did not always appear to recognise the value of the expertise on which their research was mounted:

It's quite a tough sales job to convince clients that they are paying for a level of expertise that is actually unique. It's bringing the best knowledge possible in New Zealand and, in some cases, the world to bear on [their] problem (Senior Research Scientist, Create).

So, on the other hand, scientists spoke of generating productive connections with business by allowing client requirements to drive the focus of their research. Such focus mandated a different service ethos and set of targets:

If it won't lead to cost reduction or efficiency in the primary path target laid out [by the client], then it is of no interest whatsoever (Science Group Manager, Innovate).

There was the suggestion that, in practice, meeting client expectations entailed focusing on short-term goals and the realisation of immediate gains:

If it's driven by business ... you know that it'll be very focused on a particular result and will have an immediate impact. The research will be used straight away because they want to know [the answer to] a very defined question (Research Scientist, Inspire).

Scientists saw the gains to be realised by business as sometimes very significant:

Once [the technology we develop] is up and running, they're just printing money effectively. We've made a number of hapu and various iwi incredibly wealthy (Senior Research Scientist, Discover).

Some held that the financial gains to be made by business were a useful starting point when seeking to forge productive relations with clients:

This is the result and this is how much money we'll save you ... that's worth so many thousand dollars per hectare, and it's all in your pocket at the end of the day (Science Group Manager, Create).

There was also the view that such functional focus for research was acceptable given the ethos of a client relationship: 
It's [an industry group's] money we are taking, and so we have to deliver stuff that's useful to them (Team Leader, Create).

Scientists saw that focus on immediate gains for relatively modest investment offered the potential to secure future investment in their services:

They need to have a quick win because that provides a huge amount of motivation. In cleaner production, you call it 'picking the low-hanging fruit' . . they don't want to wait a couple of years to see benefit from something (Research Scientist, Inspire).

The fourth tension concerned scientists' responsibilities in relation to maintaining dialogue with various external constituents while also complying with managementimposed limits to speaking out. On the one hand, scientists saw a need to represent the public interest by engaging in dialogue with citizens on matters of public interest. Pertinent activities included participating in various industry fora, and showcasing their research through community outreach activities:

We look to see how we can give back to society, and how we can improve or increase our visibility in the public arena (Research Scientist, Discover).

Some saw their focus when engaging in such activities to be on promoting a shift in thinking by increasing understanding of the value of new sustainability interventions:

I talk to kids in schools about issues around sustainability ... I give them information about technologies such as sustainability and biofuels. I give them another approach $-\mathrm{a}$ set of facts on what the technologies are and what they mean (Research Scientist, Inspire).

Several scientists expressed the desire to represent their CRI and showcase their science, and spoke of doing this in their personal time. They saw their public service aspirations reflected in their willingness to engage in such activities:

Many of the different sections now have outreach. We've got quite a high-level, noble aspiration and that is simply this: If we can enhance the public understanding of the 
relevance of science to our society and our economy, then we're doing well (Senior Research Scientist, Discover).

There was the view that when engaging with external constituents on controversial issues of sustainability, they needed to maintain a separation between science and the state by adopting a position of neutrality. They generally saw this as guiding the public "towards a good outcome" by helping to evaluate available options, rather than "advocating a particular outcome" (Senior Research Scientist, Discover). However, the complexity of the science was sometimes such that views became polarised:

I genuinely believe in [hydrogen technologies] because I think they are the only way to effect a step-change. If you talk to anyone about them, they will have one of two views. They will say, "that sounds a good idea" or they say, "oh, don't be ridiculous". There are no shades of grey - it's very black or white (Science Group Manager, Innovate).

Several scientists also spoke of challenges experienced when working with external groups whose cultural norms meant committing to sustainability solutions only after reaching consensus on issues:

In New Zealand, every decision is made very difficult to make because local government has to be consulted and many iwi groups. Each iwi group has a slightly different view. It's a very difficult process to get everybody to agree to do something (Research Scientist, Inspire).

These scientists perceived a need to speak out for change in public policy; however, they saw that the delays in reaching consensus on the needed interventions constrained their engagement with important issues of sustainability.

On the other hand, there were barriers to speaking out. First, some held that the changes made by government in political structures and in the role and structure of CRIs had eroded the public profile they once had: 
Since we've been dissolved into CRIs ... we're not considered policy advisors. I think that New Zealand is poorer for that (Research Scientist, Discover).

Second, they viewed the internally-imposed regulations on communicating with external constituents as restricting their freedom to speak out. Unlike researchers in universities who enjoy some statutory protection when they engage with a role as critic and conscience of society, CRI scientists are known to put their jobs at risk when they speak directly to the media:

I think it's instant dismissal if somebody from the media asks your opinion on [a sustainability issue] if you dare say anything. The first thing you're supposed to do is say "I need to go to the toilet". You hang up the phone, you call the media handler, and get them on to it, and you back off (Senior Research Scientist, Discover).

Scientists working on politically-sensitive issues or in specialised areas were seen as needing to be particularly cautious in order to safeguard their positions:

If you are extremely specialised, you can be extremely glad to just have a job which also limits your ability to speak out ethically or about sustainability issues (Science Group Leader, Discover).

The dominant perception was that the right to speak out was tightly-held, and granted only to those in positions of seniority:

It's mainly the job of senior managers as they can talk with a number of government agencies. They are in constant dialogue with government (Research Scientist, Inspire).

Relevant here is the requirement that CRIs give their shareholding ministers advance warning of any events, issues, or transactions that could be considered to be contentious or that might attract wide public interest (Ministry of Business Innovation \& Employment, 2014). Some saw the hierarchical nature of the structure within the CRIs as reinforcing this message: 
I'm certain they [management] would consider it [speaking out] to be ruffling the waters, and worrying their minister. We function as a government department in many ways, and these sorts of things tend to go up and down the chains a bit (Senior Research Scientist, Innovate).

Research scientists often attributed the competing performance demands they experienced (presented here as a paradox of service ethos) to the transitions taking place in CRIs as they responded to the political manoeuvrings of successive governments focussed on economic transformation and, to varying degrees, sustainable development in New Zealand. The predominant view was that ongoing demands for greater permeability between the publicly-funded science structure and private sector investment through, for example, mutual understanding of the two systems and the exchange of ideas would continue to generate tension and prompt ongoing change. When discussing their responses to tensions, research scientists sometimes spoke of taking actions that provided some initial relief but which had ultimately exacerbated the underlying tension. At other times they spoke of engaging with competing demands in ways that led to productive outcomes. These responses are explicated in turn.

\subsection{Defensive responses to the paradox of service ethos}

People confronted with paradox may respond with tactics of avoidance and resistance in an attempt to eliminate tension (Lewis, 2000). In doing so, they make sense of complex, ambiguous situations by simplifying reality into polarised either/or distinctions (Lewis, 2000). However, performing is inherently paradoxical, and tensions may return with a vengeance when conditions change and organisational routines that ignore complex interrelationships no longer suffice in dealing with challenges faced (Clegg et al., 2002; Gotsi et al., 2010). 
In this section, the study presents examples of the defensive ways in which research scientists engage when confronted with the paradox of service ethos. Each of these responses namely, opposing, isolating, over-committing, and suppressing, are defined and illustrated with an example in Table 4.2. They are also briefly introduced with reference to the literature in the paragraph below. In the analysis that follows, I discuss these responses and consider their consequences for individuals, teams, and CRIs.

Table 4.2

Defensive responses to the paradox of service ethos

\begin{tabular}{lll}
\hline Construct & Response entails & Illustration \\
\hline Opposing & $\begin{array}{l}\text { A response to tension that entails } \\
\text { actively resisting change by } \\
\text { asserting a set of needs that } \\
\text { conflicts with the needs of the other } \\
\text { party }\end{array}$ & $\begin{array}{l}\text { Openly criticising a perceived } \\
\text { emphasis on commercial enterprise, } \\
\text { and vigorously defending traditional } \\
\text { science values and practices }\end{array}$ \\
$\begin{array}{l}\text { Isolating } \\
\text { A response that entails creating } \\
\text { conditions that isolate oneself from } \\
\text { the activities pertinent to one or } \\
\text { another strand of performance }\end{array}$ & $\begin{array}{l}\text { Detaching oneself from the team's } \\
\text { effort by working in silos (pockets of } \\
\text { specialisation) }\end{array}$ \\
$\begin{array}{l}\text { A response to tension that involves } \\
\text { committing oneself beyond what } \\
\text { available resources justify }\end{array}$ & $\begin{array}{l}\text { Over-promising when bidding for } \\
\text { public funding } \\
\text { Over-delivering when fulfilling } \\
\text { commercial contracts }\end{array}$ \\
& $\begin{array}{l}\text { A response to paradox that entails } \\
\text { continuously prioritising one strand } \\
\text { of performance and neglecting the } \\
\text { other }\end{array}$ & $\begin{array}{l}\text { Focusing exclusively on commercial } \\
\text { research responsibilities, and } \\
\text { deferring work objectives pertinent } \\
\text { to publicly-funded research (or vice } \\
\text { versa) }\end{array}$ \\
\hline
\end{tabular}

First, prior research identifies 'opposing' as a response to paradox that entails actively asserting a set of needs that conflicts with the needs of another party 
(Jarzabkowski et al., 2013). Second, this study introduces the term 'isolating' (in the context of performing) as the practice of detaching oneself from the team's effort. Third, it presents another novel response to paradox through the practice of 'over-committing'. This practice comprised two related practices, 'over-promising' and 'over-delivering', and entailed stretching oneself beyond what would normally be expected in a given set of circumstances. Fourth, prior research identifies 'suppressing' as a response to paradox that entails prioritising one strand of performance to the extent that it dominates or overrules the other (Jarzabkowski et al., 2013).

\subsubsection{Opposing}

Scientists across all four CRIs expressed the view that there had been considerable opposition to the changes in science funding and structure that had taken place over the years, and of the related shift in service ethos. It was the perception that some scientists had sought to express their discontent with the movement away from public service to customer service by vigorously defending traditional science values and practices:

There are people who feel frustrated and impotent, and rail against the situation. I've heard people say "I shouldn't be doing commercial work. This is not what I signed-up for. I should be a scientist" (Senior Research Scientist, Discover).

They often attributed their opposition to the changing focus to a lack of alignment with their personal goals and beliefs. For instance, several scientists spoke of "occupying this space of wanting to focus on pure science" (Research Scientist, Innovate), and of their view that the public interest was best served by addressing sustainability problems holistically through “open-minded, investigative research" (Senior Research Scientist, Discover). By contrast, scientists spoke of seeing their managers emphasising the funding 
constraints faced by CRIs, and urging scientists to adapt to the situation by focusing on the generation of income through commercial applications of their research:

We're only getting so much through science funding ... it's going to be commercial.

Learn to live with it (Senior Research Scientist, Discover).

A common perception was that the focus of many in management had been on enforcing change, rather than supporting scientists, and that there was limited understanding of the adjustment needed in order to successfully transition from one research paradigm to another:

When commercial imperatives first came in there was a lot of, "Well, you're on your own now. Make enough money to cover yourself and your technicians or it's curtains for you". I still see a lot of people in our institute almost paralysed by that sort of worry (Science Group Manager, Create).

Scientists often spoke of their concern at the focus in CRIs on achieving full funding, seeing this business imperative as constraining them from responding to important environmental research opportunities that arose from time to time:

If you've got all your staff fully-funded, you don't have any capability to give out (Team Leader, Inspire).

They often linked their discontent to perceived high levels of attrition across CRIs, and to the stress they experienced when views became polarised:

A lot of scientists found it difficult to get down to the business model foisted onto the science community . . . some were dragged kicking and screaming into it. Others just walked away from it (Science Group Manager, Discover).

In turn, they saw the departure of staff as destabilising the work force and contributing to a loss of organisational capability in areas of research important to society: 
I can think of dozens of people who've gone either to a council or into private consulting. Over the years, there's been a sort of bleeding away of all that experience because of those pressures (Team Leader, Create).

Some scientists attributed the conflicting demands they faced to the political manoeuvrings of external constituents, and reflected on the difficulty inherent in determining national science funding priorities:

That question of who should do what science is quite a hard one, isn't it? I doubt that science is doing the best it can (Research Scientist, Inspire).

Others spoke of their opposition to the composition of science funding panels, seeing some panellists as lacking familiarity with the science needs of New Zealand as a nation. There was the suggestion that this was affecting the quality of decisions made and, in turn, eroding opportunities to engage with important areas of sustainability research:

In recent years, those folks with more of an outward focus have done very poorly because the panels of people reviewing them have consisted of a couple of NZ experts or end-users like a regional council and an NGO, and a bunch of CSIRO or university researchers from other countries who have no frikken clue about what's needed in NZ. All they can do is look at the academic excellence of something (Team Leader, Inspire).

In rare instances, an alternative view of the direction of science was held: "only so many of us are sufficiently altruistic to worry about these things" (Research Scientist, Discover). This view was premised on the perception that CRIs had limited freedom to determine their goals and plans and that it was inevitable that client requirements, rather than sustainability issues, would drive their research:

CRIs are not at liberty, by and large, to do what they want to do. So they needn't necessarily be highly principled in terms of sustainability. The bottom-line applies to them, just as it applies to commercial businesses (Senior Research Scientist, Discover). 
However, the predominant view was that many scientists had experienced a significant loss of job satisfaction in transitioning to a research portfolio with a strong focus on commercial research:

To get funding to do research I'm interested in is almost impossible under the commercial system. It's just getting vicious (Research Scientist, Innovate).

Over the years, we have been pushed out of working in [public good] research areas into more industrial-type areas. It has value as industry wants some of this research but, as a researcher, it's not very fulfilling (Senior Research Scientist, Innovate).

Scientists often saw it as difficult to find the necessary thinking time for ideas to gestate when working on ambiguous sustainability problems, and to then generate research outputs from these discoveries that could be widely disseminated:

It's hard to think when you're under a lot of pressure, especially about science concepts. There's so much pressure to get the data, analyse the data, write the results and churn it out. You don't have that thinking space to actually think, "What does this mean? What are we trying to draw out? What is the nugget of information we need to communicate?" (Senior Research Scientist, Inspire).

Several scientists suggested that the legislative requirement that they spend 80 per cent of their time generating revenue for their CRI was unreasonable. They saw the related requirement that they consistently account for their time as exacerbating the challenges they were experiencing:

Doing science, it's not always obvious how time is used. You're not making a widget. You can't say, "I made 10 widgets today". How do you measure productivity? Being made to account for your time all the time is really quite stressful (Senior Research Scientist, Inspire). 


\subsubsection{Isolating}

There was the perception across CRIs that some scientists were isolating themselves from peers by detaching themselves from the team's effort and focusing almost exclusively on their own specialisation or commercial research commitments. Since a multi-disciplinary approach was often taken to addressing sustainability in both publiclyfunded and commercial research, scientists saw their peers' detachment from the wider science group or the research team as impacting on their work. Two reasons were given for the practice.

First, several scientists claimed that the external pressures they faced sometimes made it necessary to isolate themselves from others and to engage only with their most pressing priorities. Some spoke of the tight deadlines set by business, and of the pressure clients applied once the research was underway:

They [clients] are hassling you all the way to meet time commitments, and you work your butt off to get it done on time (Science Group Leader, Innovate).

Second, there was the perception that scientists were naturally inclined to gravitate towards their own specialisation:

Within CRIs, you've got quite a few divisions saying: "we want to do it this way, we want to do it that way". Quite a lot of silos, and "I'm working in my silo, and not talking to them". Scientists are very much like that. It's that defensive barrier around "this is my thinking time; this is my specialism" (Senior Research Scientist, Inspire).

Irrespective of the seniority of their position, scientists saw that the longer reporting timeframes allowed for publicly-funded research (i.e., Foundation work) allowed them the leeway to detach themselves from related activities when under pressure to address commercial research goals: 
If I've got commercial work, I'll definitely do it because you know that somebody out there wants it, and you've said you'll have it done in a particular time. The time horizon for Foundation work can be ... as long as it's done by next June (Research Scientist, Innovate).

I've got a massive amount of Foundation work, I've got a massive amount of commercial work, and it's always the Foundation work that slips behind (Science Group Manager, Create).

However, some team leaders claimed that scientists were not always contributing towards the wider science group's goals in a timely manner, and that this prioritisation could make teams difficult to manage. Several spoke of the frustration they had experienced when a lack of input meant that milestones were not met:

We knew we all had to meet the milestones. We couldn't move until they moved ... so anytime they got behind, we were in the crap because it was going to be us bumping up first against the milestones (Create).

Some perceived that the geographically-diverse make-up of science teams was exacerbating the situation by making it easier for individuals to isolate themselves from the team's effort:

One project we've got at the moment is a collaboration with another CRI and a university. I'm finding it hard work to get responses from people. When you ask for information or ask for feedback on something, you just get silence. So whether that means they're too busy or they're not interested I don't know (Research Scientist, Inspire).

However, others suggested that there was always the expectation that members would deliver on time despite the "huge increase in work pressures" that had occurred in recent years:

As a team leader, I'm aware of what's going on ... we might only talk to each other a few times a year, but when it comes to reporting time, project development time, I trust them to do their job (Team Leader, Create). 
Some scientists saw the potential for the organisation as a whole to suffer the consequences when the performance of teams was undermined by the apparent inability of one or more individuals to contribute towards team goals. A few referred to instances when external parties dissatisfied with "research team dynamics" had severed their ties with the relevant CRIs (Senior Research Scientist, Create).

\subsubsection{Over-committing}

Research scientists described how they engaged in activities leading to work intensification in the face of competing performance demands. The study identifies these practices as a tendency to 'over-commit' by over-promising and over-delivering. These responses are explained in what follows.

First, there was a tendency to 'over-promise' when bidding for public funding. This entailed promising more than was manageable given the level of funding available, as a Senior Research Scientist explained:

You're supposed to quantify almost in dollar terms what the benefit to New Zealand will be of your research, but until you've done the research, you won't know that. You get into this spiral of promising more and more because you think if you promise more, there's a better chance you'll get funding. It becomes unrealistic (Inspire).

Scientists attributed their tendency to over-promise to the intensity of competition in New Zealand for the limited funding available, seeing a need to maintain expertise in areas of science relevant to sustainability:

Unless you talk up your research programme in a way that exaggerates the outcomes and what you are going to achieve, someone else will get the funding (Science Group Manager, Create).

There was the view that this practice was common across science teams, other than those in the relatively secure position of having ongoing and extensive industry links due to 
strong industry-backing for research with a sustainability element (e.g., industries seeking to develop more sustainable methods of production in order to access new overseas markets). Some acknowledged the practice with regret:

You over-promise because a lot of the things are competitive, and you think, "Why the hell did I say that" (Science Group Manager, Create).

However, more often scientists saw themselves as caught in a vicious cycle perpetuated by the public funding system in place, and sought to justify their actions:

You have a programme in mind, and then you bid for a certain amount of dollars. You don't get them all, but you don't necessarily cut the project ... you cannot reduce the consumables because you need them, and so you cut into the time of people [in order to] send deliverables. You understand it's going to be stretched (Create).

The small size of the New Zealand market within which scientists competed for funding was often seen as compounding the problem:

New Zealand is a very small country. The government spends a fixed amount of money on science. We probably have a higher percentage of the population doing research than anywhere else in the world. Theoretically, that's a good thing. In reality, scientists spend a lot of time competing, rather than doing the work (Senior Research Scientist, Inspire).

Second, scientists spoke of a tendency to 'over-deliver' in the fulfilment of commercial contracts, particularly when sustainability issues were at stake. This was said to entail going over and above what was actually paid for by clients, as a Science Group Manager explained:

When they [clients] see the prices that are charged by organisations like ours, they wince quite terribly. So what we have to do is essentially cut the price, and solve the problem at a price we know they will pay, and sometimes you have to put in a few extra hours to make sure it happens (Create). 
Scientists spoke of the practice occurring across commercial contacts, both when the client was a public sector organisation and when it was a business in the private sector. In terms of the former, they perceived the dearth of funding available to be constraining publicsector investment in $\mathrm{R} \& \mathrm{D}$ (rather than any lack of appreciation of the value of the services offered by CRIs on the part of ministries and government organisations):

If it becomes too expensive for them to pay for, they won't go for the whistles and bells sort of solution if that's what you're suggesting ... we don't have to convince them of the value of our information, but of the cost (Team Leader, Discover).

In terms of the latter (i.e., private sector businesses), research scientists often attributed an apparent reluctance on the part of clients to fully compensate them for their services to a well-entrenched 'culture of expectation' in the New Zealand commercial sector:

It is common for clients to come back and say, 'Could you tell us about this, and do this a bit more?'. You end up having hours of conversations with them to develop whatever it is they're trying to do. Then, if you try to say, "we're going to have to charge you for this", they say, "Oh no, this is an extension of the original programme" (Science Group Manager, Innovate).

Comments made by clients had prompted the view that businesses saw CRIs as taxpayerfunded institutions: "You are government funded and I pay taxes towards your knowledge" (Science Group Manager, Create). Scientists saw this view of CRIs as underpinning the unrealistic expectations of their clients. At the same time, they claimed to empathise with clients struggling to maintain viability in saturated markets, for example:

Deregulation has certainly not been beneficial [for clients], because they're still always at the receiving end: "Who to send their [product] to? Who is going to get the best deal for them?" . . there used to be a single [body representing the industry]. Now, there are multiple exporters and when times are hard, supermarkets play them off against each other (Team Leader, Create). 
Research scientists offered a range of reasons for their tendency to over-commit themselves (often at personal expense). For instance, some attributed it to their early career experiences, including their development of a public service ethos that continued to underpin their work. That is, there were those who saw themselves and their colleagues as beginning their careers with a "public good, public service, public servant tag", and as continuing to see what they did as "in the public good - that means social as much as environmental” (Science Group Manager, Discover). As a Research Scientist who had "fallen prey" to the tendency to "over-deliver" when working with business clients explained: "I like to know if it's been useful" (Create). Ensuring that it had been useful entailed overseeing the integration of sustainability interventions following the completion of a project, and not simply leaving clients "with a tool and a piece of information" (Team Leader, Inspire).

Others rationalised their tendency to over-commit by speaking of synergies between their commercial research efforts and work with a public good focus:

Our research money comes from the public purse as well ... Most of the commercial work we do is actually taking the science understanding we've got and making it valuable to people in the management of the environment on a day-to-day basis (Team Leader, Discover).

By contrast, there were those who saw themselves as compensating for their CRI's conservative approach to business through their tendency to over-commit: Commercial science is far more risky [than pure science] in terms of funding. You've got that boom and bust, and CRIs are not good risk takers (Senior Research Scientist, Discover). 
Specifically, these individuals saw themselves as meeting the needs of businesses in such a way that they secured the longer-term relationships pivotal to the commercial viability of their CRI:

Once you've got a foot in the commercial world, other things crop-up, and it opens the door to other real applications (Research Scientist, Inspire).

Another reason given for over-committing was the difficulty inherent in resolving ambiguous sustainability problems within the time frame available:

Usually we're doing things that no one has ever done. Sometimes that's easy to do, and sometimes it's not. Usually, sitting behind all this is some corporate body that wants to spend some money or make a decision about something and they need some answers. But, technically, it can be very difficult to solve that problem within the time scale that is being offered (Science Group Manager, Innovate).

At other times, science managers attributed the tendency to over-commit to a lack of capability on the part of scientists who, as a group, were sometimes perceived to be "chronically pathetic at budgeting", inclined to "stab too low" and as agreeing to "addons" when what needed to be said was: "that'll cost you another $\$ 5,000$ or $\$ 10,000$ " (Science Group Manager, Create).

Some scientists had warned others to be wary of the unrealistic demands of business: "Look, that industry group is taking advantage" (Research Scientist, Create). However, they claimed that decisions made were generally left to the discretion of science teams. These teams were perceived to be made up of individuals who were "personally very motivated to help an industry [and] unlikely to say 'You got what you paid for you're on your own now"” (Science Group Manager, Create). Scientists acknowledged that the extra responsibilities they assumed meant that they were often working to maximum capacity for extended periods: 
I must say that this year, I feel more stretched than I've ever been. If it's really urgent, you do things. I take work home in the evenings, and don't take a lunch break. I'm happy with that, but no more, please (Team Leader, Create).

I typically turn my computer on again at about 9 o'clock at night and I'll work to whenever, pulling an all-nighter to get stuff done [if I have to] (Team Leader, Inspire).

Though they saw themselves as working under considerable pressure, there was the view that scientists were often reluctant to take leave (Senior Research Scientist, Inspire). The way in which they tended to depict their circumstances suggested that scientists were resigned to the situation:

My work cannot be fitted into a normal working week. You can't complain too much because you're a scientist: you don't want to be out of work, but you don't want to have so much that it's difficult to maintain quality (Senior Research Scientist, Inspire).

Some scientists reflected on the wider implications of the promises made when navigating the public funding system, and of the practice of 'talking-up' projects in order to attract public funding:

You may get three or five years of funding to do it ... and maybe along the way there will be spinoffs which are benefits. However, the stated outcome has probably been a waste of everybody's time and money because it was never really achievable (Science Group Manager, Create).

There was the perception that the latter practice was not confined to scientists in CRIs but extended across scientists employed by universities and other research organisations.

\subsubsection{Suppressing}

The majority of research scientists saw a need to maintain a diverse portfolio that included a mix of both publicly-funded and commercial research programmes. However, in each CRI there were those whose work had attracted ongoing funding, allowing them to focus exclusively and indefinitely on only one strand of performance - most often 
publicly-funded research. Recent policy changes aimed at easing the administrative burden in accessing public funding were seen as enabling such a focus:

You had to put in a new programme proposal every year just about, and you got short-term funding. It was absolutely ridiculous. There was no security. Now you get funding for six, eight, ten years if you're successful. That's helped a lot (Team Leader, Discover).

Yet, the shifting nature of science funding priorities meant that there was always uncertainty around funding:

We're still very directed by what we sense is going to be popular, what's going to be sexy, what has all the right catchphrases in it (Team Leader, Discover).

Reasons given for focusing exclusively on publicly-funded work included the costs associated with often protracted contract negotiations:

It's not so bad with bigger contracts with more money involved, but if you're dealing with contracts that are only worth $\$ 10-\$ 15,000$ dollars, and you have to spend days on acquiring the contract - going back and forth with the client, the government agency, putting forward what you want to do, and they want to change it back and forth - it becomes hardly worth the effort (Team Leader, Discover).

Scientists often saw it as easier to focus on one strand of performance to the extent that it dominated or overruled the other than to attempt to straddle two different research paradigms. However, some had found that in ignoring the need to maintain currency with both strands of performance, they had exposed themselves to considerable risk. One acknowledged the sudden loss of support for publicly-funded programmes with a sustainability focus:

We did some work in the . . arena a few years ago, but now there's no funding for [research in this area]. That's just dried up (Senior Research Scientist, Innovate). 
They saw businesses' investment in sustainability interventions as equally uncertain:

Costs dictate the extent to which businesses will engage [with sustainability]. If it's done for marketing reasons only, then the next whizz-bang thing that comes along will be the one that gets the money (Science Group Manager, Inspire).

Some scientists had experienced a loss of career stability when "multi-million dollar programmes over five or six years" ended, and their specialist skills that had taken years to develop were no longer needed:

You create your expertise, and now the whole CRI model is changing. Suddenly, I feel exposed because they don't have that flexibility to put me in the right place (Senior Research Scientist, Create).

A team leader confirmed that multiple positions were sometimes disestablished when changes in funding priorities meant that the work of a science group was no longer supported:

There was a change in funding priorities. As a result, we lost almost all our social science researchers (Science Team Leader, Inspire).

A science group leader pointed out that CRIs sometimes suffered a significant loss of capability and status when they were unable to continue to support the specialised work of scientists who then departed for other organisations:

We had two major international partners, and had huge international status. The Foundation pulled the plug on it after five years, and I had the lovely job of phoning these people and saying, "Sorry, but the plug's been pulled on the money. In six months' time, we have to fade this out". Within 24 hours, those two organisations made job offers to my senior researcher and he took one of them. You can't blame them. People want careers (Science Group Leader, Innovate).

There was the view that while scientists exposed themselves to risk by suppressing the need to maintain a diverse research portfolio, CRIs needed to recognise that areas of 
research that missed out on funding during a particular bidding round often became "fashionable" again when public awareness of sustainability increased, and environmental groups lobbied for action (Senior Research Scientist, Create).

Altogether, this research finds that some scientists responded defensively when confronted with the paradox of service ethos. Specifically, there were scientists who initially opposed the introduction of change, others who isolated themselves from peers by detaching themselves from the team's effort, individuals who over-committed themselves when under pressure, and scientists who suppressed the need to engage with one or another set of performance demands. Though scientists sometimes regarded these responses as a means of obtaining temporary relief from tension, there was the view that they often led to negative consequences for individuals, science teams, and CRIs. First, some associated scientists' initial opposition to the introduction of change with considerable discontent and high levels of attrition in CRIs. Second, they saw the tendency for some to over-commit themselves as leading to work intensification. Third, team leaders viewed the practice of isolating oneself from the wider team as making teams difficult to manage. Last, some associated the suppression of the performance objectives pertinent to one or another strand of performance with a loss of career stability.

Science managers and other scientists spoke of the ways in which they had sought to initiate a shift towards more productive practices in their CRI. The next section examines these as managing the paradox of service ethos.

\subsection{Managing the paradox of service ethos}

You've got different cultures, and different specialisms with particular views on an issue, and you're trying to manage that. One group of scientists might approach it one way, and another might do it a different way. When you're trying to manage competing demands, it's quite difficult (Team Leader, Inspire). 
Productive responses to paradox involve recognising the importance and interdependence of competing demands (Jarzabkowski et al., 2013), and actively engaging with related tension (Luscher \& Lewis, 2008). The goal is to journey beyond negative reinforcing cycles by rethinking past perceptions and practices, and to arrive at an understanding of the productive potential of paradox (Andriopoulos \& Lewis, 2010; Lewis, 2000).

Scholars have emphasised the salience of strategies based on the confluence of differentiation and integration in managing paradox (Andriopoulos \& Lewis, 2010; Poole \& Van de Ven, 1989). Differentiation entails recognising the unique contributions of competing goals, and purposefully and simultaneously attending to the related demands of each (Weick, Sutcliffe, \& Obstfeld, 1999). The focus is on addressing the seeming contradictory demands in ways that realise the distinct benefits of each. Specific tactics may include the separation of different activities into distinct organisational units, for example. Integration denotes the use of mechanisms that accentuate the importance and interdependence of opposing poles (Andriopoulos \& Lewis, 2009). The understanding this fosters generates a willingness to engage with competing demands simultaneously (Weick et al., 1999) through the integration of procedures that better accommodate both/and responses to paradox (Jarzabkowski et al., 2013; Lewis, 2000).

This section presents examples of the strategic practices embedded within the differentiation and integration approaches deployed by research scientists in managing the paradox of service ethos. Perceived approaches to differentiation included offering a diverse range of research services, and drawing on the varied capabilities and expertise of research scientists (Table 4.3). In many instances, scientists saw themselves drawing on their personal and professional connections with external groups in meeting the conflicting demands they faced. Perceived integration practices included finding synergies between 
public good and commercial projects, and reframing problems and solutions for clients. This study addressed the implications of these practices for individuals, teams, and the organisation from the perspective of research scientists.

Table 4.3

Managing the paradox of service ethos

\begin{tabular}{lll}
\hline Construct & Response entails & Illustration \\
\hline Differentiating & $\begin{array}{l}\text { A productive response to paradox } \\
\text { that encompasses efforts at } \\
\text { addressing each of the seeming } \\
\text { contradictory elements }\end{array}$ & $\begin{array}{l}\text { Internally diversifying scope of } \\
\text { services } \\
\text { Developing personal and } \\
\text { professional connections with } \\
\text { external groups }\end{array}$ \\
Integrating & $\begin{array}{l}\text { A response to paradox that involves } \\
\text { stressing the interdependencies } \\
\text { between apparent opposites }\end{array}$ & $\begin{array}{l}\text { Identifying financial synergies } \\
\text { between public good and } \\
\text { commercial projects } \\
\text { (Re)framing problems and solutions } \\
\text { for clients (2-in-1) }\end{array}$ \\
& &
\end{tabular}

\subsubsection{Differentiating}

Perceived differentiation tactics included developing a diverse research portfolio that enabled focus on both blue-sky research programmes and commercial science work. This was initiated at an organisational level:

Inspire divides its income streams into Foundation [science] and commercial, and commercial can be business or just contracts with government departments (Research Scientist, Inspire).

Scientists saw such diversification as involving close attention to work 'balance' across the organisation: 
We have grant-writing and commercial, and we have blue-sky aspirational and then, on the other side, we have trials and manufacturing, and it's a real balancing act (Senior Research Scientist, Innovate).

They also saw internal diversification in scope of services as having implications for assigning researchers to various roles based on their capabilities. In particular, some scientists were seen to be more suited than others to commercial work and there were managers who sought to accommodate this dynamic:

There will be some who are not of the right temperament to do short-term work. Those are the ones you concentrate on your core science and long-term technology development. There are those who can straddle half and half, and you just let them do it. And there are those who actually prefer consultancy work for one reason or another (Science Group Manager, Innovate).

There was also the view that the assignment of roles and utilisation of individuals' varied capabilities and expertise was best facilitated through the use of multidisciplinary research teams. This was seen as enabling the input of a range of stakeholders in a way that accommodated and encouraged the interests of the wider community (as required under the legislation governing CRIs):

We generally have a project manager and specialist researchers. One might be working with particular tools; one might have particular expertise on a particular issue, and we have internal and external peer review as well. That's on the research side. Then you have the business representatives - which may be a sector, company representatives, and then other interested stakeholders. They all have their input into a lot of the research we do (Senior Research Scientist, Inspire).

Commercial service was also managed through dedicated business development units or commercial managers in the organisations, a measure introduced by CRIs to support scientists' transition to a research portfolio with a strong commercial focus. Some spoke of the productive value of strong working relationships with commercial managers: 
It's really important, and I still have a really good relationship with the commercial manager ... we've travelled the world together (Team Leader, Discover).

Though the research also finds (chapter 5) that some regarded it as problematic when scientists relied extensively on commercial managers, there was the view that commercial managers had an important role to play in initiating and maintaining productive business relationships. Some emphasised the relevance of the connections these managers built with industry, and of the professional skills and attributes which set them apart from scientists:

They have very good contacts. They're dealing with business all the time . . I I think scientists, for the most part, aren't great business people; great at that hard-ball negotiation type thing. I think we're better off left out of it (Research Scientist, Inspire).

However, they also saw a need for the organisation's commercial services to be dovetailed with the organisation's research facets effectively to generate value. For example, a team leader emphasised the need for mutual understanding of the significance of the part each played during contract negotiations as well as the need to maintain a cooperative front when seeking to address the management of sustainability alongside commercial goals:

You've got to have an empathy between the scientist and the commercial manager because he [sic] can be hard-nosed about driving the bargain, and you're the one there to convince them that that bargain's worth driving (Team Leader, Discover).

Another spoke of the relevance of simultaneous internal differentiation when engaging with clients. Relevant here were professional distinctions, and the need for a strategically coordinated approach to utilising the competencies of both the commercial manager and the scientist when navigating different relationships with the client organisation:

Some years ago, I got a really good commercial manager, and it was a dual act. He could talk to business because I wasn't in business, but I could talk to the science and technology to convince the engineers. You're not so much talking to corporate guys, you're talking to 
engineers who'll make the capital case with their commercial guys about purchasing the service. So you've got to pitch it at the right levels (Team Leader, Discover).

Accordingly, there was the perception that when internal differentiation was supplemented with holistic unity, it generated value at the systemic level of the organisation. The perceived importance of simultaneous internal differentiation and a cooperative front when engaging with clients was also addressed through the differences in mindset could affect the outcome of contract negotiations:

In science, we tend to be very negative because we always point out all the flaws. The marketing people say, "It does 80 per cent of what we want - it's perfect", whereas, we say, "It only does 80 per cent of what I tried to achieve - it's seriously flawed" (Senior Research Scientist, Innovate).

The predominant view was that the different capabilities of commercial managers and scientists were crucial to presenting a credible case when dealing with complex issues of sustainability. In some cases, there were clear demarcation lines surrounding the responsibilities of each. Here, scientists saw it as their role to convey technical knowledge in a way that was clear and convincing and so win the confidence of clients contemplating investment in new technologies:

We, as scientists, are actually leading that business awareness/business development. If you get some person with an MBA trying to talk sustainability to an industry, it'll come out as mumbo-jumbo. But, if I start talking water or soils or carbon to someone in an industry, they'll know I've got the 'gummies' (Science Group Manager, Create).

By contrast, they expected that commercial managers would assume responsibility for managing marketing, legal issues, and other contractual matters, seeing their own expertise as limited in these areas:

It's a three-way thing - us, the client, and the business/legal people. It's quite complex and challenging, especially some of the intellectual property things. I think scientists who 
think they don't need those people are living in the past really (Science Group Manager, Create).

A further differentiation tactic spoken of by some scientists was that of navigating in-house rules restricting speaking out and external communication by developing personal and professional connections with various groups that enabled them to engage in dialogue with citizens on matters of public interest. Specifically, they spoke of seeking to represent the public interest by forging personal and professional connections with external parties that had the capacity to lobby for change in public policy:

There are various networks you can plug into, if you want to, like Greenpeace, and community events . . . it can be quite influential. There's the Royal Society that does environmental-related lectures once in a while, and other professional groups and networks. I sit on the steering committee of [a professional group] (Senior Research Scientist, Inspire).

Though membership of such organisations was "very much a personal choice", some scientists perceived that they had established some "tremendously valuable working relationships" with external groups through which they had initiated change in policy on sustainability:

We saw an opportunity to make quite a paradigm shift in terms of the way we manage energy ... We got the minister at the time to change his view, and New Zealand became a member of [an international sustainability partnership] (Science Group Manager, Innovate).

This approach appears to generate value by simultaneously creating opportunities to speak out, and advance the public good through change in public policy around sustainability. The popularity of a recent conference organised by the New Zealand Association of Scientists dedicated to exploring the issues scientists face in stepping up and speaking out on science-related issues, illustrates the salience of this tactic. 


\subsubsection{Integrating}

Scientists across CRIs spoke of two approaches to integration. First, there was the practice of identifying and utilising financial synergies between projects so as to simultaneously achieve both a public good and a commercial orientation. Second, there was the integrative tactic of reframing approaches to sustainability in ways that were relevant to clients. These are addressed, in turn, below.

First, research scientists sought to identify and exploit financial interdependencies between publicly- and privately-funded projects in various ways. One way they saw of achieving outcomes with a public good aspect was to extend a commercial programme to incorporate a sustainability element:

The idea is to make it more meaningful for New Zealand rather than just relevant to the client. [So we say], "If we do it this way, it's relevant to you, but if we do it this way and add a little bit, it's relevant to New Zealand and we can apply it to multiple regions" (Research Scientist, Inspire).

Perceived approaches to realising financial synergies included drawing on external public grants, and on 'top-up' funding available from government sources: "For small sectors that don't have a lot of funds, we leverage with other funding streams" (Science Group Manager, Create). For example, some scientists saw the Sustainable Farming Fund as providing them with the flexibility they needed to incorporate sustainability elements when negotiating commercial contracts with clients. Some scientists also perceived opportunities to build on commercial research by, with research office support, getting "those ideas sorted and put into proposal form" ready to apply for public funding (Research Scientist, Discover).

Another way in which to realise financial synergies was to draw on internal resources to supplement commercial projects that could yield public research. Scientists 
spoke of their use of "non-specific" job codes or "non-chargeable accounts" to cover the additional time spent accommodating competing research demands, and of the rationale underlying their deployment of this tactic:

If you have a commercial project running alongside a long-term research project, you might just think, "Oh well, it's just going to cost us another two weeks' worth of work and we can do it under the requirements of the long-term project" (Science Group Manager, Innovate).

Some scientists spoke of the availability of specific funds to supplement commercial projects relevant to long-term organisational capability in sustainability research, and of utilising this resource to sell their science:

We responded to that [interest in sustainability] by putting something to them. As part of that proposal, we said, "Wow, you'll get 20 per cent for free because we'll co-invest through our Capability Fund Project" (Science Group Manager, Create).

The second integrative practice they discussed relied on reframing problems and new sustainable interventions in ways that highlighted their commercial value for clients:

We have to be really thoughtful in terms of approaching companies and help them to see [a new technology] as a real business opportunity in its own right. It cannot be sold as an environmental clean-up or sustainability intervention (Senior Research Scientist, Innovate).

There was the view that the organisations they dealt with invested strategically, and that the owners and boards they dealt with had little power to make values-based decisions on behalf of shareholders:

Unless you can root sustainability right back into their key business model, it's hard for owners or boards to justify the additional investment. That's why we have to sell things back in terms of the business (Team Leader, Inspire). 
So scientists perceived a need to initiate change towards sustainability by generating an awareness of the commercial advantage to be gained though the uptake of new technologies:

The biggest challenge by far is getting practices to change: getting the industry to do something different from what they have previously been doing; [getting] some piece of innovation that we've managed to show is an improvement actually taken up (Science Group Manager, Create).

This '2-in-1' integrative approach to sustainability recast the focus in client communication on the potential for improved efficiency and greater profitability:

We don't tend to talk about sustainability. We tend to talk about business benefits and business growth, and tackling environmental issues and lower costs (Senior Research Scientist, Inspire).

There was the view that reframing was particularly relevant to industries that relied on product differentiation:

The industries we work with secure an eco-premium. So we say, "Your profitability is enhanced through demonstration of a metric of your sustainability ... We're trying to help you on issues that might arrive around environmental aspects of [chemical] use" (Science Group Manager, Create).

Scientists saw themselves as better able to accommodate both the shorter-term vision and goals of business and their own longer-term public service aspirations when they reframed sustainability in ways that were relevant to clients:

If you can help New Zealand-based companies to see export or other countries as a good business opportunity, and if the business proposition focuses one aspect around sustainability, this will obviously have an effect on how things are done in New Zealand as well (Senior Research Scientist, Create).

Through this tactic, they saw the potential to generate returns that helped to secure the financial viability of their CRI, as well as to meet the legislative requirement that their 
research benefits New Zealand by addressing critical economic, environmental, and social issues:

Some of the questions [clients] are trying to deal with are major issues, and they are putting a lot of money into it. So if we can help them address some of these issues, it will have wide-ranging benefits for the country including a huge shift in GDP (Team Leader, Innovate).

Altogether, by engaging paradox to manage sustainability in commercial research (using a blend of practices premised on differentiation and integration strategies), research scientists saw themselves as productively engaging with competing performance demands. Specifically, they saw their engagement as generating value at the systemic level of the organisation by creating new commercial opportunities that helped to secure the financial viability of their CRI, while also addressing critical economic, environmental, and social issues faced by New Zealand through their research. There was also the perception that by constructively engaging with paradox, they were less likely to find themselves in the position of having limited opportunities to engage in either publicly- or privately-funded research activities. 


\section{Chapter 5 \\ Belonging and the paradox of role identity}

A perfect scientist, if there is one, should be very good at basic research. He [sic] should also be very good at developing ideas into technology, and at getting that technology applied by the end user. Ideally, he should be able to do anything (Senior Research Scientist, Inspire).

Paradoxes of belonging stem from opposing yet coexisting roles, and reflect tensions between the self and others (Luscher \& Lewis, 2008). They are instigated by shifting social relations whereby actors continuously re-identify themselves in relation to different groups, along with their competing values and goals (Gotsi et al., 2010; Luscher \& Lewis, 2008). People may also define themselves through multiple, potentially conflicting identities (Stryker \& Burke, 2000) when they attach different sets of responsibilities to their professional position (Cornelissen, 2012).

This study finds that scientists see themselves as having a dual role that blends both traditional and contemporary science values and goals. On the one hand, they saw themselves as advocates of change on issues of sustainability (as expert leaders who engage in, and are motivated by, innovative approaches to sustainability); and on the other hand, they saw themselves as allies of business who were conversant with, and supportive of, a private research agenda (as followers who pursue, and are motivated by, practical outcomes relevant to clients). This research presents this paradox of belonging in the context of science work and sustainability as one of 'role identity', a notion discussed by Jain et al., (2009) in the literature on academic entrepreneurship. A role identity is the view of self in relation to a particular role (Ashforth \& Kreiner, 1999) that arises from an 
ongoing commitment to certain beliefs, goals, norms, values, time horizons, and interaction styles (Ashforth, 2001).

The chapter begins by discussing the three facets of role identity confronting research scientists. Table 5.1 presents each of these themes as a tension between seeming opposites in terms of the way in which research scientists view their positioning and standing, what they see themselves doing, and what drives them. The chapter then examines the ways in which research scientists respond to the opposing pulls they experience in navigating their dual roles. The analysis considers several defensive responses, the actions scientists sometimes associate with negative consequences. The chapter then examines the ways in which scientists productively engage with the paradox of role identity, distinguishing between their responses according to their representation of either differentiation or integration.

Table 5.1

Belonging and the paradox of role identity

On the one hand...

On the other hand...

\section{Public service}

Advocates of change
Customer service

Allies of business
Leading the way in innovative approaches to sustainability

Engaging in efforts to change views and practices towards sustainability

Motivated by a passion for science, the environment, and dealing with 'big' sustainability issues
Following client-driven goals and accepting the primacy of profit

Pursuing the requirements of business and supporting clients

Motivated by making a difference for clients by taking their practical realities into account in solving more immediate problems 


\subsection{Underlying tensions}

First, research scientists considered their role identity in relation to their positioning and standing. On the one hand, they viewed their role as leading the way in sustainability and its practices - as summed-up by a Science Group Manager (Innovate), "leading New Zealand down the right paths" in terms of sustainability innovation. This view applied to the organisational and personal levels. In describing the former, scientists stated:

We've got a lot to contribute not only in a socially responsible way, from society's perspective, but from a scientific perspective (Senior Research Scientist, Discover).

There's a lot of creative science around in New Zealand, especially around primary production. We could easily be leading globally in this area (Senior Research Scientist, Create).

A view of themselves as leading the way in a sustainability sense was also relevant to scientists' personal standing across both pure and applied research. The value they attached to the outcomes associated with each varied between scientists:

There are people who derive immense satisfaction from knowing they have helped growers and they have got a bit of a personal reputation from being the 'go to man' for that group. It's sort of like social standing, I guess. Whereas others may think my CV looks quite good as a scientist and quietly feel that that gives them status (Science Group Manager, Create).

On the other hand, many scientists saw themselves as accepting and, thereby following, the primacy of the financial imperative and the respective aim of profit generation. Underpinning their alignment with business values was a view that any attempt to promote a shift in thinking would be futile:

Industry behaviours are driven by financial imperatives or profitability and, in rare cases only, will that align with a sustainability attitude. No matter what we might do to change 
that, if it doesn't make a buck, it's not going to happen (Science Group Manager,

Innovate).

There was the perception that pursuing client-driven goals had organisational as well as personal implications. As individuals, scientists saw a need to follow the market and adapt to its ways. Such an approach to science did not always align with their career expectations or the values to which they ascribed as research scientists:

The thing that is most difficult to cope with is the whole expectation around the role of scientists these days. You're trying to do science, and that's what you did in university. You come out of there and find that you've got to be a business person: you've got to be able to market what you're trying to do, market yourself, market your area of science (Senior Research Scientist, Innovate).

Several scientists stated that, in effect, the ability to attract commercial funds (or not) was entwined with value judgments of a scientist's contribution:

The funding signals probably direct the kind of researcher you are. That's probably the strongest signal because you're only a good researcher if you've got cash. If you ain't got cash, you're out (Science Group Manager, Inspire).

Second, role identity was tied in with the focus of their research engagement, what they saw themselves 'doing' - the purpose of their scientific pursuits. On the one hand, they viewed themselves as advocates of change:

As a scientist, you've got a professional and social responsibility. It's just the way you conduct your life or your career. It's especially in dealing with a sustainability issue that impacts on society (Team Leader, Discover).

We've got the ability to generate scientific evidence for sustainable practices that can be used by ... corporate New Zealand (Science Group Manager, Create).

A scientist explained that instigating change entailed being comfortable with the ambiguity inherent in dealing with sustainability, and in addressing its challenges: 
If I do solve this problem, am I actually creating another one? Or, should I be tackling it differently because I'm not actually solving the most environmentally undesirable component? (Science Group Manager, Discover).

Another claimed that instigating change towards sustainability was also entwined with motivation (to which I return shortly):

I get to change people's lives. That's a reward for me ... it's almost like a religious conversion really - this idea of working together to do something (Senior Research Scientist, Create).

I personally invest a lot of myself in my work, and I think most people do if you like what you do and you're passionate about the things you do (Senior Research Scientist, Inspire).

Several scientists spoke of seeking to change fundamental ways of thinking. They viewed their efforts in this regard as an ongoing process of manoeuvring towards a 'middleground':

The sustainability agenda is addressed at shifting basic assumptions made $\ldots$ because there are realities of business, there are realities of the environment . . . it's an ongoing process of pulling and pushing and moving into a necessary middle-ground depending on the urgency of the issues (Team Leader, Inspire).

There was also the perception that scientists had made a difference towards the public good through their efforts to influence clients:

There's been a change in attitude. At first, the farmers didn't want a bar of anything other than farming, but there's been a shift in public perception and understanding, and a change in land use in a number of areas ... it's always good when you can look back and think that you helped make a difference in something like that (Team Leader, Discover).

On the other hand, as allies of business, scientists saw themselves as increasingly focusing on pursuing and delivering what the client, their key constituent, wanted. At times, maintaining such focus involved reconceptualising the client as a stakeholder, and finding ways to support them: 
We do a lot of work with stakeholders and saying, "Well, what does our stakeholder want?" We're beginning to get much closer to understanding what they want from us, and that's the key factor. You can't go wrong if you do that (Senior Research Scientist, Inspire).

There was the suggestion that pursuing and delivering what the client wanted sometimes meant reigning in their sustainability ideals, and focusing only on what was required:

If you're targeting making a new way of making something cleaner, then that's what you do. You may look at it and go, "Well, actually if you turned this inside out, you could use that new piece of science to do something else". But you wouldn't have the leeway to do that if there was no value to that company. You can't really blame the business for that as it's not really their focus (Research Scientist, Innovate).

Scientists also perceived that in aligning themselves with the expectations of clients, there was a need to recognise and appreciate the practical realities faced by business when investing in sustainability:

These things give off so much $\mathrm{CO}_{2}$, you would gulp at it ... Our technology, which we think is brilliant, has a tiny footprint ... [but] I can understand why they don't want to do it - it's expensive and, in some cases, they don't have the land adjacent to the plant to even contemplate it (Science Group Manager, Innovate).

So there was the view that, as allies of business, scientists needed to engage in finding ways to navigate the challenges faced by their clients:

For a scientist, it's about how you juggle those things ... they might have 20 challenges stopping them from doing something, and it's getting over those by rearranging or changing them (Research Scientist, Inspire).

Several scientists alluded to the fact that they took pride in their ability to address critical sustainability issues under the tight timeframes offered by business:

There's always limited funding, but this is a double-edged sword. I like the fact that you have to justify your position. I do a lot of self-funded projects, and that means they're 
quite tight and sharp, and to the point. You're generally tackling a really acute problem (Senior Research Scientist, Inspire).

The commercial aspect makes it rather nice. It puts a framework around it where people have a deadline. They have to deliver whatever they can in the timeframe (Research Scientist, Innovate).

Though scientists spoke of their affinity with clients, often emphasising their ability to identify with the challenges businesses faced, several stated that they found it difficult to rationalise the need for compromise in applying their science:

Scientists are driven by wanting the answers ... that's how we are motivated, and then to kind of go, "Oh no, you can only afford half the answer" - it really goes against your training as a scientist (Science Group Manager, Create).

The third facet to role identity addressed what drives and motivates scientists. On the one hand, there was the perception that as advocates of change, scientists were driven by a passion for science and sustainability. Several research scientists stated that they saw themselves as inherently principled people driven by a strong work ethic, and as highly motivated to make a contribution to society through their work:

You have a lot of scientists here who are very focused on public good ... they see their work as their life, and they work extremely long hours; put in a lot of discretionary effort and frequently work on a shoe-string to make things work because they are passionate about it (Team Leader, Inspire).

Specifically, they were also motivated by the ambitious goals of sustainability, seeing their engagement with these as integral to their identity as research scientists:

People are motivated to do the work that has that big sustainability goal. They are the kind of people who turn the lights out anyway. It kind of happens by default (Science Group Manager, Create).

It's the feeling of doing something good, something beneficial to society and the environment ... people are not in my field to make money, it's a passion ... At the end of 
the day, people go to bed thinking, "I'm doing something that's worthwhile" (Research Scientist, Discover).

On the other hand, as allies of business, research scientists stated that they were also motivated by commercial goals, and that the majority welcomed the opportunity to work alongside business:

Why I like commercial work is that you have an idea, you prove it in the lab, you get commercial interest, you come up with an industrial prototype, get it installed and see the results of your science working, and making a difference for the business (Team Leader, Discover).

There were those who saw that the realisation of their vision for society as advocates of change was best facilitated through their everyday interactions with industry groups and businesses:

Many of us actually believe that by interacting with people in the commercial world, our vision and our hopes can be better achieved (Research Scientist, Inspire).

They saw the rewards, in this case, in the immediate application of their research, and in the ways this then makes a difference for the client and society at large:

I'm sort of motivated by the fact that doing nothing's not an option, so we had better do something to help a billion dollar industry adapt [to climate change] (Science Group Manager, Create).

You know that it's made a difference and often it's a very indirect difference because you've hopefully saved the company some money. But it also means that there are resources - whether human or physical - that can be used somewhere else for some other benefit (Research Scientist, Innovate).

Some research scientists suggested that the rewards also lay in occasionally connecting with others who shared the same commitment to engaging with sustainability:

The big reward is working with somebody that you know is thinking similarly to yourself - getting feedback from them, their ideas, new information and, mostly with the businesses 
who are actively pursuing sustainability, their enthusiasm. They're in it because they want to be, not because they've been told to be. It may not necessarily be company-wide (Science Group Manager, Inspire).

It's good, solid work that people go, "Gosh, that was really valuable. Thank you very much". That's enough to keep me happy (Senior Research Scientist, Discover).

As presented in this section, research scientists see themselves as having a dual role (as advocates of change and allies of business) that entails a focus on both traditional and contemporary science values, beliefs, and goals. Underlying these roles are tensions they experience as pulls in opposite directions in terms of how they view their positioning and standing, what they see themselves doing, and what drives them. Though scientists often spoke of their passion for science work and sustainability, taken to excess passion can prompt employees to intensify their efforts in a particular direction leading to a negative reinforcing cycle (Andriopoulos \& Lewis, 2010). Such responses to paradox are explicated in the next section.

\subsection{Defensive responses to the paradox of role identity}

Paradoxes of belonging can spur defensiveness when tensions emerge between the self and others in relationships (Smith \& Berg, 1987a). As previous studies have suggested, individuals in organisations may fear rejection or a loss of the sense of self as they reveal themselves to others outside their group (Gotsi et al., 2010; Luscher \& Lewis, 2008). This prompts feelings of insecurity and strategies of identity regulation that can intensify cynicism and resistance (Kosmala \& Herrbach, 2006). For example, in rolerelationships of unequal power (such as scientists may have with clients), those with less power may over-identify with the values and priorities of the other party in gauging the issues to be addressed and the actions to be taken (Sluss \& Ashforth, 2007). Altogether, 
issues of identity have been found to be more problematic and yet pertinent to managing relations in knowledge-intensive situations (Alvesson \& Willmott, 2002).

When reflecting on the ways in which scientists dealt with competing role demands, participants spoke of practices they saw as defensive and as constraining the development of productive relations between research scientists and their clients. First, there was the practice of 'isolating' which some perceived in others' extensive reliance on commercial managers for ongoing contact with industry. Second, the practice of 'suppressing' was noted in the view that there were those who engaged exclusively with the demands associated with one or another role for extended periods. These responses are presented in Table 5.2 then addressed in turn.

Table 5.2

Defensive responses to the paradox of role identity

\begin{tabular}{lll}
\hline Construct & Response entails & Illustration \\
\hline Isolating & $\begin{array}{l}\text { Creating conditions that isolate } \\
\text { oneself or one's team from } \\
\text { industry }\end{array}$ & $\begin{array}{l}\text { Distancing oneself from clients by relying } \\
\text { primarily on commercial managers for } \\
\text { industry contact }\end{array}$ \\
Suppressing & $\begin{array}{l}\text { Identifying primarily or } \\
\text { exclusively with one or another } \\
\text { role while suppressing the } \\
\text { demands of another }\end{array}$ & $\begin{array}{l}\text { Engaging exclusively with the demands } \\
\text { associated with one role at the expense of } \\
\text { another for extended periods }\end{array}$ \\
\hline
\end{tabular}




\subsubsection{Isolating}

Several scientists claimed that there were times when their work was judged harshly by the business community and that, as a professional group, they tended to be seen as unable to relate to the everyday realities businesses faced:

It can be relatively thankless because even when you do what you feel is a good piece of work, pushing the agenda, there will always be a spectrum of people who criticise it from the absolute green to the neo-liberal (Senior Research Scientist, Discover).

All scientists are seen as 'prima donnas'. Businesses often think that scientists don't actually know what's going on, and see scientists who do a lot of work on environmental issues as producing biased science where [they've] cherry-picked the information (Senior Research Scientist, Create).

There was the perception that it was because of the difficulties some had experienced when interacting with clients, scientists across CRIs had been encouraged to utilise the services of non-scientist commercial managers. However, several suggested that there were scientists who were relying on the support of commercial managers to the extent that it was isolating them from the industry groups and businesses they needed to work with if they were to change views and practices towards sustainability. Among this group, there were those who would not engage productively with industry, as well as others who could not effectively manage this aspect of their role.

First, scientists spoke of individuals who would not engage productively with industry groups and businesses. There was the perception that these scientists saw the pursuit of commercial goals and financial imperatives as conflicting with their traditional science values:

Some of the more pure scientists see us as getting our hands dirty and as [betraying science] for pieces of silver (Team Leader, Inspire). 
Specifically, participants claimed that there were scientists who had struggled to come to terms with the requirement that they pursue client-driven goals since they believed that in "crossing the divide" to support business, they compromised their position as research scientists. This was especially the case when sustainability issues were at stake:

[Some scientists] really struggle with the realities of engagement with business because they see it as their [role] to stand back and criticise business, and show the limits that are being broken . . . and think that if we cross the divide to assisting business, we'll get into that whole consultancy/auditing conundrum. [They think that] you can't actually help someone create the solution [while] telling them what the limits for their behaviour should be (Senior Research Scientist, Inspire).

Second, there were those who saw among their peers individuals who consistently relied on commercial managers as they could not engage productively with industry themselves. Many participants held that scientists, as a professional group, struggled to convey the complexities of their science in ways that enabled clients to see the value of scientific research to their organisation:

If they talked to the board, they'd be perceived as talking complete gobbledegook because they don't know how to filter the information ... the focus has to be on them [the client] for you to be able to distance yourself and see what they need (Research Scientist, Inspire).

Several suggested that some scientists were a liability at the 'application end' as they were unable to communicate effectively with clients:

I see scientists who should never be talking to customers. There's a lot of scientists who think that - I'm trying to be polite here - who really shouldn't be interacting at the application end (Senior Research Scientist, Innovate).

There were also relatively inexperienced scientists who saw themselves as having yet to acquire the necessary social standing to deal directly with clients. These scientists valued 
the support of commercial managers, but perceived that others did not always share the same view:

I personally don't feel that I've got the standing to negotiate directly with clients. I do value that layer of support, but know that my manager is very frustrated with it (Research Scientist, Create).

Indeed, scientists with extensive industry experience were often critical of their peers' reliance on commercial managers, seeing their use as the primary point of contact between scientists and their clients as counterproductive:

They put in these portfolio managers, and industries could only talk to them . . . that didn't work, other than for the really effective portfolio managers (Senior Research Scientist, Create).

Specifically, they saw their peers' excessive reliance on commercial managers as isolating them from the industry groups and businesses they needed to serve. A perceived consequence was the eroding of long-held relationships through which some scientists had envisaged the potential to create opportunities to both make a difference for clients and generate income:

[Things became] really dependent on those peoples' characters and who they talked to within the research organisation. If they didn't get on with some people in the industry, that relationship just fell over. That was quite risky - it isolated the researchers from the industry (Senior Research Scientist, Create).

As a scientist with decades of industry experience claimed, commercial managers tended to have relatively short careers of only one to two years in CRIs, whereas scientists sometimes spent decades forging productive relations with clients. They valued these relationships and saw them as needing to be nurtured:

After years and years of dealing with clients and reading body language ... we've built up goodwill with the client which is very easy to break (Team Leader, Innovate). 
Another claimed that there was a need to be "less in the 'back room' [and to be] visible and seen to be participating in the issues of the day", particularly in relation to changing patterns of behaviour around sustainability (Team Leader, Discover). A scientist spoke of making a conscious decision to attach value to this aspect of her role:

You have to make a decision in your career whether you stay in that little box or you take a step back and say, "No, I can't be good at everything, but I can be good at talking to everyone and trying to bring the pieces together" (Team Leader, Inspire).

The metaphor of the "little box" used in the above quote was drawn on by several scientists who sought to emphasise the precarious position their peers placed themselves in when they relied on others for contact with industry. Specifically, it was claimed that some scientists' reliance on commercial managers was confining them to a difficult space from which to manoeuvre, while also narrowing their focus and range of experiences in a way that was potentially risky:

You mustn't make business development people your gatekeepers which is what I think some [people in] CRIs are trying to do. If you do that, you are going to breed scientists who just sit in a box and wait for people to pose problems to them (Science Group Manager, Innovate).

Altogether, there was the perception that relying unduly on the support of commercial managers in the face of competing demands was counterproductive since it isolated scientists from their clients. Scientists who engaged in this practice were seen as constraining their development in ways that enabled them to productively engage with the competing demands of their dual role.

\subsubsection{Suppressing}

There was the perception that research scientists who had repeatedly been successful in securing public funding often over-identified with their public good role and 
suppressed the need to engage in commercial research. Though there had once been the leeway for scientists to gravitate towards research areas of particular interest and one role or the other, this was no longer considered to be the case:

They had the [leeway] to decide if something was important and needed to be done. There's no longer that flexibility. The government has mandated [against it] (Science Group Manager, Innovate).

There were scientists with long and distinguished careers in areas of sustainability who saw their own or others' identification with a particular role as too entrenched to be able to make a new start:

I am who I am after that length of time, and I can't go back. If I was starting again at 20 or so, it might be a bit different (Team Leader, Discover).

Most held that being unable to adapt to new ways of thinking limited one's career prospects:

People can't adapt and when a big new idea comes along, they go down with the ship. They won't change their ideas (Science Group Manager, Innovate).

There was the view that external factors often underpinned the need for change, and that CRIs and their scientists did not always have the flexibility to respond effectively when circumstances required them to modify roles in some way:

I think we'll lose some staff . . . external factors have meant that they can no longer focus as much on sustainability as they might have liked. There was never a Plan B (Team Leader, Inspire).

Some suggested that this apparent lack of flexibility was because retraining and engaging with a new set of role demands was profoundly challenging for scientists who had come to define themselves through the responsibilities they attached to their position:

It can cause them to completely rethink who they are, what they are doing, and it can be quite traumatic (Team Leader, Innovate). 
Specifically, scientists held that adapting to change sometimes required them to identify with new values, norms, interaction experiences, and time horizons. Change was seen as particularly challenging for those who found themselves needing to engage with clientdriven goals for the first time:

They feel challenged because there's a new value set being raised. They're going to deal with industry partners. They're going to have to take on applied science and technology and an engineering viewpoint to their work, and all of a sudden they might be told or asked what to do, rather than dreaming it up for themselves (Science Group Leader, Innovate).

As a team leader explained, it took time to acquire the skills and understanding needed to be a research scientist, and to be recognised for one's contribution to a field of science:

It's very hard to be a flexible scientist. It takes years to learn the skills to do something new and of value. A colleague was told he'd have to train in another area. It had taken him 20 years of his life to get to the level where he was internationally respected (Team Leader, Innovate).

Consequently, though scientists often regarded their peers as experts in their respective fields, they also saw them as victims of a system that demanded relevance and "some outcome for an end-user" when circumstances changed and their specialised skills were no longer needed (Senior Research Scientist, Discover):

Altogether, scientists saw their peers' engagement with one role at the expense of another for extended periods as risky in the dynamic CRI environment. Specifically, there was the view that scientists who had not sought to maintain a diverse research portfolio risked finding that when circumstances changed, their prior focus and skill-set no longer sufficed in meeting the new challenges.

The next section examines the ways in which scientists saw themselves productively engaging with role identity tensions. 


\subsection{Managing the paradox of role identity}

This study identifies scientists' use of tactics embedded within a blend of differentiation and integration approaches in managing role identity tensions. The main differentiation approach identified is one of incrementalism, an active, negotiative process of incremental manoeuvring used by scientists in order to simultaneously advocate change and ally with business (Table 5.3). This finding represents a novel contribution to the literatures on paradox and research management. Incrementalism refers to the continuous evaluation of knowledge and exploitation of opportunities while remaining mindful of relational dynamics (Low \& Johnston, 2012). In the context of science work, it has been described as the step-by-step advancement "from broad visions toward final specific positioning strategies" through the uncovery of new phenomena, the amplification of discoveries, the reduction of concepts to practice, the building of prototypes, and interaction with potential users (Quinn, 1982, p. 614).

The main integration approach this research identifies is one of fluid positioning (repositioning and shape-shifting). Positioning tactics have not previously been theorised in the literature on paradox management. However, this study finds that scientists view these as enabling them to engage with a variety of situations when interacting with clients (Table 5.3). Positioning tactics are the discursive constructions through which people can shift identifications and hence build relationships with clients "while simultaneously preserving their own status within these relationships by staking out the self against various others" (Ellis \& Ybema, 2010, p. 299). The next section explicates these practices, along with the ways in which scientists saw them as enabling their engagement with sustainability when working with clients. 
Table 5.3

Managing the paradox of role identity

\begin{tabular}{lll}
\hline Construct & Response entails & Illustration \\
\hline Differentiating & $\begin{array}{l}\text { Addressing each of the } \\
\text { apparently contradictory } \\
\text { elements }\end{array}$ & $\begin{array}{l}\text { Incrementally influencing } \\
\text { clients }\end{array}$ \\
\hline Integrating & $\begin{array}{l}\text { Stressing the interdependence } \\
\text { between opposites }\end{array}$ & $\begin{array}{l}\text { (Re)positioning and shape- } \\
\text { shifting (2-in-1) }\end{array}$ \\
\hline
\end{tabular}

\subsubsection{Differentiating}

The main differentiation practice that addressed the simultaneous need for advocating change while allying with business comprised an incremental approach to working with clients. Put simply, scientists cast the focus of their engagement on different issues at different times, gradually introducing measures relevant to sustainability. Some scientists regarded this approach to be consistent with sustainability science, generally:

Sustainability science is incremental and continuous improvement - doing a bit better tomorrow than what we're doing today (Science Group Manager, Create).

Through such an approach, scientists saw themselves as initially following clients so that they could then influence and lead them towards sustainability outcomes by taking incremental steps:

It's a softly-softly incremental approach, rather than large and expensive ideas . . they will take the cheap, low-hanging fruit to start with [but] if you invest that time, you will see that in the following year, they will probably ask, "What can we do now?" (Senior Research Scientist, Inspire). 
I had what I thought was a great technology and very simple for [clients] to use to reduce run-off. A lot of people were like, "It's extra effort", but three years on, we can actually see some traction. It's just a matter of gently, gently catch the monkey (Research Scientist, Create).

There was the perception that incremental steps resulting in immediate cost savings for the business were an effective means of motivating clients to explore the possibility of other more significant interventions:

They've got all these things that they could do, but I pick out one or two to get out of the way in the first month to get them motivated, happy, and enthusiastic. They might not be the ones that have the most environmental improvement, but it's about getting them on board (Research Scientist, Inspire).

Accordingly, scientists saw their role as necessitating subtle influence rather than overt leadership. There was the view that the sharing of information with industry was pivotal to this end:

When we see something coming over the horizon, we send links to papers and stuff like that to our key industry people. You think, "Why did this [industry group] finally come round to a closed tender on water?" Maybe, they bumped into something or they've seen the groundswell of information coming from the popular scientific media that reinforces the little titbits that we send them (Science Group Manager, Create).

Some also saw the maintenance of ongoing relations with industry as integral to their use of incrementalism. There was the suggestion that this often necessitated a willingness to initially focus primarily on client-driven goals, and to also accept the possibility that science goals would be rejected:

In this field of science, you have to have a fairly thick skin. If you think, "Well, I've done this wonderful piece of science, now it should be used", you'd probably have to change your profession because it doesn't necessarily happen that way, especially if your science is saying there's a sustainability issue out there that needs to be dealt with and it's an issue that's actually going to cost people money to fix (Senior Research Scientist, Discover). 
Some spoke of seeking to influence industry groups during face-to-face interactions by drawing attention to and legitimising individuals' conflicting vision and values on aspects of sustainability. They also saw their use of humour as an effective means of alleviating tension and of facilitating a shift in thinking:

The key challenge is getting everybody in the room on the same page, realising the different agendas. [This entails] being blatantly honest; saying, "Well, of course you would say that, you are an exporter". Then, you get a bit of a chuckle in the room. It's about making things light-hearted and obvious (Senior Research Scientist, Create).

At the same time, they recognised that incrementalism also involved staged perseverance when encouraging clients to engage with sustainability:

I think you have to have a bit of change and adaptation in a sort of steady state: you push things, then let it calm down. If you push a little bit, then take the pressure off, people get it. Like a frog in hot water ... (Senior Research Scientist, Discover).

Here, the use of the systems analogy of the frog (that accommodates to its slowly heated water and so does not jump out) underlines the gradual change required for scientists to be able to influence clients, in effect a form of incremental leadership.

\subsubsection{Integrating}

The main integrative approach to addressing the paradox of role identity involved fluid positioning on the part of the scientist, navigating paradoxical demands by engaging in repositioning and shape-shifting. Scientists described how they simultaneously positioned themselves in a variety of ways when engaging with their constituents, in effect "wearing different hats" (Research Scientist, Discover) whereby the same scientist adopted various roles. For example, scientists sometimes positioned themselves as neutral in a sustainability sense, and so occupied the middle ground: 
We need to be more involved in presenting our information out there, but that's as far as we need to go. Otherwise, we could risk being labelled either a 'greenie' or 'in the pocket of business' (Team Leader, Discover).

Relevant to the notion of positioning is that a person often adopts more than one identity. In this case, there was the view that managers and senior researchers sought to nurture paradoxical identities through a '2-in-1' approach that enabled a scientist to undertake different roles:

Sometimes they are research scientists dealing with pure science. At other times, they apply those problem-solving skills to projects that are funded by multi-nationals or large industry groups that have their own private agenda (Senior Research Scientist, Discover).

It was perceived that such multiple identities enabled scientists to reposition themselves, (and their respective contribution) as necessitated by the situation when dealing with clients:

I think there's an art to it . . if they don't invite your opinion, we don't tend to volunteer it. But we invite people to consider what their options are so that they get a rounder view . .. We still have that stand back. I can say what I like. You are paying me, but you're not paying me (Senior Research Scientist, Inspire).

This dynamic wherein a scientist is both 'hired and free' resonates with what Ellis and Ybema (2010) describe as 'tensile positioning'. In a study of inter-firm relationships, they described how people oscillated between different identities when faced with conflicting obligations, articulating and embracing each identity as required to conserve professional status. In this case, scientists discussed how repositioning entailed skilful adaptation to a given situation:

It's made me a better scientist. You can't take things for granted. You have to be determined. You have to be adaptable and flexible... You have to be able to fit the situation you're working in very well. A lot of scientists are good 'chameleons' (Senior Research Scientist, Inspire). 
The use of the chameleon analogy here echoes the 'academic chameleon' described by Barry et al. (2006). In their study on academic identity-positioning in complex internal environments, they discuss a process of 'shape-shifting' that enabled people to manage their relationships. In this case, repositioning was seen as relevant to managing external relationships, particularly when a scientist sought to influence a client, as described here:

I typically have to listen a lot at the beginning of the conversation and understand the words they use, how they talk about things, because you've got to modify how you talk quite quickly to actually reflect stuff that they say. You've got to look at their eyes because as soon as you see their eyes glazing over, you've got to change the way you're talking (Team Leader, Inspire).

Accordingly, repositioning in managing external relationships entailed facilitating interactions by following the cues given by clients. For instance, there were times when scientists saw situations as calling for a business-like approach and an overriding focus on making a sale:

It's a real balancing act in marketing. I think marketing wins more in the renewables game than the actual overall economic, environmental or renewable cost. It's a tricky one (Senior Research Scientist, Innovate).

When adopting a business-like persona, a different 'look' and manner of communicating were often part of the equation:

If I have to discount my scientist being and wear a suit as I have today, because we have an event, that's fine. The other way as well. If you have to talk science language, you have to talk detail, and forget about the business thinking for a while (Research Scientist, Inspire).

This entailed presenting themselves in a way that reflected the values and norms to which their clients subscribed. At other times, there was the perception that a more personal approach was needed. This entailed finding some common ground that worked by 
chatting with clients and, subsequently, gaining insights that led to "seeing things through their eyes" (Science Group Manager, Innovate). In effect, by following clients, scientists saw themselves as better able to respond to the immediate requirements and, thereby, create opportunities to lead them in new directions.

Overall, the blend of differentiation and integration approaches enabled most scientists to address their belonging through a role identity in which they could advocate change and ally with commercial clients. First, scientists attributed small shifts in thinking and practice as they interacted with clients to their use of incrementalism, a tactic that they saw had allowed them to sequentially introduce measures relevant to sustainability over time. Second, scientists saw that their use of fluid re-positioning, aided by the adopting of dual identities, had allowed them to productively engage with clients whose vision and values tended to differ from their own. 


\section{Chapter 6 \\ Organising and the paradox of professional integrity}

On the one hand, they're saying we've got to bring in money and, "You're going to be judged by your impact in the sector", but they want high profile publications at the same time (Science Group Manager, Create).

Paradoxes of organising consider the ways by which various participants confront contradictory practices in the work process (Luscher \& Lewis, 2008; Smith \& Lewis, 2011). In focusing on scientists' engagement with sustainability in commercial research relationships, this paradox stems from the competing yet simultaneous demands for different practices that sustain professional integrity. The notion of 'integrity' as it relates to science implies the need for people to act morally and in accordance with a transparent set of beliefs and values (Kaiser, 2014). Relevant here are the principles of practice research scientists may subscribe to as employees of CRIs or by virtue of their voluntary membership of professional organisations, such as the Royal Society of New Zealand. For instance, inherent in scientists' sensemaking may be their commitment to guiding principles such as those published in formal codes of professional standards and ethics:

A member must not endeavour to compromise the well-being of society or the sustainable use of the natural environment. In instances of conflict, the welfare and the needs of the community must take precedence over responsibilities to clients, colleagues or other interests (Royal Society of New Zealand, 2012).

This chapter examines the contradictory practices research scientists perceive when navigating their own and others' expectations of professional standards in the context of commercial research (Table 6.1). On the one hand, research scientists saw a need to engage in research on sustainability that maintained their scientific credibility based on science values (generating novel research insights, transparent peer review, scholarly 
publication, and accurate reporting). On the other hand, there was the view that scientists needed to focus on delivering a professional commercial service to clients (one that is practical and delimited in scope, retains commercial confidentiality and intellectual property, effectively communicates to industry practitioners, and offers certainty).

This chapter begins by explicating the four strands of this paradox of professional integrity. It then examines the ways in which research scientists see themselves responding to seemingly competing integrity demands.

Table 6.1

Organising and the paradox of professional integrity

On the one hand...

Public service

Retaining scientific credibility and recognition based on science values

Generating world-class knowledge through cutting edge research

Maintaining openness and transparency by subjecting work to peer review

Disseminating new knowledge through scholarly publication

Admitting when wrong, and not 'doctoring' the results
On the other hand...

\section{Customer service Meeting client expectations based on practical value}

Providing practical solutions to business problems

Respecting commercial sensitivities, and honouring confidentiality agreements

Packaging knowledge in ways that clients can understand and therefore use

Maintaining professional standards by getting everything 'right' 


\subsection{Underlying tensions}

First, research scientists considered the focus of their practices, what it is they $d o$. On the one hand, these were centred around the value of generating world-class, cuttingedge research on sustainability:

You need to prove that you have a credible group behind you that has done everything correctly, and that they are at the forefront of whatever they are developing (Science Group Manager, Innovate).

Such research practices were premised on the pursuit of creativity and respective publishing prospects even if at times scientists went above what was required:

Scientists want to do what's novel, new, improves their publishability, is really exciting, a bit cutting-edge, and shows how clever they are. All they had to do was put some paint on the stapler and it would have been a red stapler - which is what the client asked for. Instead, they created one that sparkled at night, stamped itself, and stuff like that (Senior Research Scientist, Innovate).

The predominant view was that the academic publishing practice was a necessary 'scientific integrity check' and a central responsibility of research scientists. Some also held that the generation of world-class knowledge relied on scientists' commitment to maintaining openness and transparency by subjecting their work to peer review:

There's this idea [among clients] that science is easy and anyone can do it. Well, it could be if we let things slip away, but we don't. One of the ways is to have peer review and to try to publish some stuff overseas so that we don't slip into doing just quick, look-see stuff, and never actually gain any decent knowledge (Science Group Manager, Create).

Most scientists saw the international recognition that came with academic publishing as integral to maintaining both their professional credibility, and the reputation of their CRIs:

I want to be part of an international community of scientists, and the only way to do that is to be publishing research that is read by my peers. If you are not publishing, then people don't know who you are (Research Scientist, Innovate). 
I lead a group of about 40 or 50 people and my boss seems to be pleased enough with the view I take that peer reviewed publications are hugely important. Without that, how can we call ourselves a science organisation? (Science Group Manager, Create).

In turn, they saw their reputation for cutting-edge environmental research and advances in technology as securing commercial opportunities for themselves and competitive advantage for their CRIs:

We need that recognition as scientists and also as institutions. If we don't have that check record anymore, companies will just go elsewhere (Science Group Manager, Discover).

[The client] wanted the original team back in because they knew we delivered . . . because it's got street credibility (Team Leader, Discover).

On the other hand, their practices were also often aimed at providing solutions to immediate business problems. So in negotiating commercial contracts, scientists saw a need to focus on the specific problem at hand:

I need to promote a path that goes from $\mathrm{A}$ to $\mathrm{B}$ to $\mathrm{C}$ to $\mathrm{D}$ to $\mathrm{E}$, and here's your product at F. If I start to say, "You could do something there", they don't want to know (Science Group Manager, Innovate).

They don't [necessarily] want something that's been peer-reviewed and referenced. They just want some basic help (Research Scientist, Inspire).

There was the perception that the financial constraints faced by industry groups and businesses were often such that clients were reluctant to meet the costs involved in pursuing research-oriented goals:

I have seen situations where clients will want a piece of work done, we'll cost it, design an experiment to answer the question they want answered, and they will say, "Well, we can't afford that. Why don't you just do two treatments, not four?" (Science Group Manager, Create).

Though focus on 'problem-solving' often left little leeway in suggesting sustainability initiatives, some scientists considered it a necessary supplement to effective practices: 
The benefit of being engaged with industry is that they come to you to solve problems. You don't necessarily get that if you sit in your office and simply put out papers because they don't know who you are. It's a fine balancing act (Research Scientist, Create).

Such practices may not generate publications, but scientists saw them as a productive step towards addressing sustainability:

I might be doing a piece of work which is being presented to industry ... It's not the sort of thing which you are necessarily going to go out and publish. However, in terms of its relationship to sustainability, you've got a different audience and a different opportunity (Science Group Manager, Discover).

Second, there was a tension in the ethics premised on research ownership, specifically whether findings relevant to sustainability ought to be universal or commercial. On the one hand, they held science values that both encouraged practices of reciprocity in contribution to knowledge as well as mandated openness and transparency (by subjecting the results of their research to peer review):

There is an ethical component. Publishing contributes to science as a whole. It's giving back to the education that we've taken from scientists before us ... There's such a thing as having too much confidence. I've got examples of people who have led science astray as a whole because they refused to share certain details of what they had done, and didn't cooperate with the peer review process. Getting things confirmed is the responsible thing to do as far as the science community [is concerned] (Research Scientist, Innovate).

Alluded to in the above quote are the guiding principles to which scientists ascribe as members of a profession, as well as the social responsibilities that apply under the CRI Act 1992 (Appendix I). Many claimed that the principles of openness and transparency to which they subscribed were sometimes challenging to accommodate in the context of commercial research:

The whole mid-ground of what made the thing tick is generally not able to be put into the literature. If it didn't have that patent attachment, you'd be able to describe your whole 
process, technology, the science and all the nitty-gritty bits and pieces, which is what people want. It's what every scientist needs and wants to do. Suddenly, you can't do that - it's like having a hand cut-off (Science Group Leader, Innovate).

There was also the view that the expectations of some clients around research ownership were incongruent with those of scientists. Some scientists claimed that if commercial considerations were allowed to prevail, there was the potential that they would constrain the dissemination of new knowledge of value to society through scholarly publication:

There are companies that try and tie [knowledge] down permanently, and to me that is criminal and should not be allowed. Who are they to play God in that way? They show incredible arrogance. The normal deal is that reports are embargoed for five years which isn't so bad ... But it's still a way by which an industry really does control because they are interrogating the [environment and taking information] in a way that most of us cannot [because of the cost] (Senior Research Scientist, Discover).

On the other hand, while the results of publicly-funded research were publicly available and could be subjected to peer review, this openness and transparency was not necessarily the case with commercial research where confidentiality arrangements often applied:

We are required to work on commercial jobs - some of which are confidential; some of which are commercially sensitive ... (Research Scientist, Inspire).

We work closely with [a particular] industry and there is some fabulous data and knowledge locked-up in confidential reports. Some of us are individually privy to that information, but we can't talk about it legally because we can't identify the sources (Senior Research Scientist, Discover).

There was the view that the latter accrued private value whereby integrity mandated respect for commercial ownership (by clients) and its respective sensitivity:

You can't take work that's been done for a commercial client and directly use it. An organisation like ours would fail if they did that because they would instantly break business confidence. There's a business ethic thing involved ... the client needs to know 
that we're not going to threaten that relationship by disclosure (Science Group Manager, Innovate).

The multifaceted nature of integrity as it applied to commercial research was such that some used it to differentiate themselves from academic scientists who they saw as less attuned to industry and the wider impact of disclosure:

New Zealand is a funny little country, and you've got to make sure that you don't stuff-up the export system by being egotistical and shouting your head off [about controversial discoveries]. We are very closely attuned to industry so we are very aware of the sensitivities. People in universities, for example, might isolate a problem, write a sexy paper on it and bingo, we've got a problem with market access (Science Group Manager, Create).

The third tension related to modes of communicating and disseminating research findings. On the one hand, scientists voiced that science values promoted academic dissemination through scholarly publication, not least through the widely circulated adage, "We have to; we publish or perish" (Science Group Manager, Innovate). Hence, they saw communicating research through publication as underlining their personal credibility:

To have scientific credibility, you do need to publish. You need to publish in high quality journals from time to time at least (Science Group Manager, Create).

The papers that you publish are important because that is your scientific credibility - that you are doing something good and well, and really innovative (Science Group Manager, Inspire).

In turn, scientists perceived their researcher credibility to be entwined with organisational research capability and its attraction of both public funding and commercial contracts:

If you're putting a bid into the Foundation, as it was, then your CV and relevant track record is very important and probably always will be (Senior Research Scientist, Innovate). 
You have to make sure that you have a technology pipeline which kind of matches the global market out there ... From that point of view, the papers you publish are important because that is your scientific credibility that you are doing something good and well ... It gives your work competitive advantage (Science Group Manager, Innovate).

On the other hand, potentially challenging the primacy of publishing was the view that maintaining professional integrity with clients necessitated presenting knowledge in ways that clients and practitioners could understand and utilise:

Publication is just a means of communication ... not the ultimate goal of science (Research Scientist, Inspire).

Several held the view that alternative modes of communication were of specific relevance to sustainability since client and public engagement were central to effecting change.

They saw these as necessitating different skills:

It's very important to put a voice to your research that people can understand. To take it from a technical to a more applicable, "Here's why you should care about my research sustainability affects you", and that kind of thing. When you bring it down to people's levels of understanding, they get quite excited because they sometimes do genuinely care (Research Scientist, Discover).

There was also the view that making a difference through client and public engagement required them to work with those with the power to influence decision-making in organisations. To this end, they saw a need for scientists to find ways to "bridge the gap" between themselves and their clients:

I'm seen as somebody who has quite a bit of commercial focus. I tend to get a short shrift from some of the more pure scientists. There is a need for people to bridge those gaps. A lot of people here want to make a difference ... to do that, you need to also engage with the people on the ground. You have to find ways to change their behaviour or support them to make the right choices (Team Leader, Inspire). 
Some held that bridging the gap required a shift in thinking around how knowledge might effectively be utilised, and an appreciation of the value to be derived by clients when they understood what scientists had to offer:

There are still some scientists who look down their noses at the consultancy side of things. To them, it's not much use. They don't value the fact that if you are able to solve the guy's problem ... you've just saved the guy many millions of dollars. Some people don't see it that way because it's not the purest view of what scientists do (Senior Research Scientist, Innovate).

There were those who took this bridging of the gap to also imply a hermeneutic role for the scientist:

You have to be a translator between your client and the science community. There's a lot of science, there's a lot of detail, there's a lot of complex jargon, there's a lot of different opinions floating around about what's right and what's not, and what you're really, really trying to do is communicate it to someone so that they can understand it and then translate it into their everyday business concepts (Senior Research Scientist, Inspire).

Engaging with clients in a way that effected change towards sustainability also entailed creating a relationship through which the values and traditions shaping the priorities of both scientists and their clients, at times Maori, could be surfaced and debated:

People say this a lot of applied research - that you have to be a translator. In this case, the client was a Maori trust (Science Group Manager, Discover).

Relevant here are the social responsibilities that apply under the CRI Act 1992 (Appendix I) that require CRIs to accommodate and encourage the interests of communities. Scientists saw value in applying this principle:

They had some really good thinking around, "Where do we go?" They came together as a group and some huis [social gatherings] happened [from which] emerged a strategic plan (Senior Research Scientist, Create). 
Fourth, scientists considered the integrity of their service delivery - how they deliver results to external constituents. On the one hand, maintaining professional standards entailed being open and honest about the outcomes of their research and admitting when a 'wrong' approach had been pursued:

You've got to be honest with them from the start and say, "This isn't working, and I think our approach is wrong”, rather than, "Okay, I'll just try it again” (Science Group Manager, Innovate).

At the same time, some scientists saw a need to address clients' unrealistic expectations openly and honestly when clients sought to pursue a 'wrong' approach:

Usually, they've got an idea about what they would like done; they've got expectations around what results they expect which is very dangerous. So it's managing the expectations of the client, and trying to suggest different approaches (Research Scientist, Innovate).

There was also the view that ethical service delivery entailed adhering to the accepted rules of good conduct when demands were made to 'doctor' results:

They wanted us to say that it was all safe by providing them with a statement at the end saying that, technically, it was a safe ... In that particular case, the answer was, 'No, we're working to a scope' (Science Group Manager, Discover).

[The client's] focus was on making sure that the result from our report made the project come out glowing, and not the environmental nightmare that everyone was predicting (Science Group Manager, Inspire).

When reflecting on the broader context, some spoke of a need to be wary of political interference in maintaining their objectivity:

$\mathrm{We}$, as scientists, have to maintain our objectivity and it has to be evidence-based, and we have to stick to our scientific principles. Frankly, science gets badly construed once it's in the political arena (Senior Research Scientist, Discover). 
Implied in the above quote was the potential for scientists to respond to external pressures in ways that undermined their professional integrity. A perceived challenge was that external parties often had a vested interest in the results of the research, and sometimes sought to impose their priorities on scientists:

Scientists will often do research that doesn't give people the answers they like, and that would be true of research that's related to sustainability, particularly if the person hearing the results is a politician and it's going to affect some constituents or stakeholders (Senior Research Scientist, Create).

The view that scientists were sometimes under pressure to produce results that aligned with a particular set of requirements resonates with claims in the sensemaking literature that power struggles can occur when external groups seek to compel individuals in organisations to conform with their expectations (DiMaggio \& Powell, 1983).

Scientists' wariness of the situation suggests that they were aware of these attempts. Theorists warn of the possibility that the meanings others seek to impose may be accepted and normalised within organisations (Weber \& Glynn, 2006).

On the other hand, maintaining professional standards when interacting with clients meant getting things 'right', an expectation compounded by the myth of scientific expertise:

There's a fundamental misunderstanding about what research can deliver, and the role of research. There's a lot of tension in that people expect, if you are living in the real world, you should be able to tell me this or that. You're under a lot of pressure to get absolutely everything right when you work with external organisations (Senior Research Scientist, Inspire).

However, the inexact nature of science, and the often ambiguous nature of sustainability research, meant that certainty was often elusive: 
A lot of people we work with expect a research project to go from A to B. In a research project, you can say this is what we will do, and this is what we hope to achieve ... but you can have a lot of unexpected turns ... there are all the unknowns and it's like asking you to be a fortune teller to tell them how it's going to pan out. You can't. You just hope like hell that you achieve it (Science Group Manager, Innovate).

Participants sometimes spoke of clients who took issue with unexpected twists and turns in the research, seeing these as evidence of the irrelevance of science:

They'll jump on anything that's not exactly perfect, and then use it as, "you're not right; that means the whole thing's rubbish" (Senior Research Scientist, Inspire).

Irrespective of the stance adopted by business when research results disappointed, research scientists saw a need to empathise with the expectation of a tangible return on investment in delivering a professional service to clients:

It costs $\$ 5,000$ for a week of my time. No-one wants to invest that unless they're going to get the answer immediately . . \$20,000 worth of work would probably be the starting point for a couple of people to try and knock something out, and you'd really want something at the end of that, wouldn't you? (Senior Research Scientist, Innovate).

Altogether, scientists spoke of a range of seemingly conflicting principles of practice underlining their professional integrity. On the one hand, there was the perception that they needed to engage with research on sustainability in ways that aligned with traditional science values; on the other hand, they saw a need to abide by the norms of professional service delivery in meeting the needs of clients. The opposing pulls scientists experienced in relation to the paradox of professional integrity pertained primarily to what it is they $d o$, the ethics of research ownership, modes of communication and dissemination, and modes of service delivery.

Scholars suggest that as environments become more complex, diverse, and dynamic, either/or thinking will no longer suffice as an approach to managing competing 
demands in organisational life (Lewis, 2000; Smith \& Lewis, 2011). The next section focuses on the circumstances that can occur when scientists' responses to paradox are premised on such 'either/or' thinking.

\subsection{Defensive responses to the paradox of professional integrity}

The bright young things who are really wanting to prove themselves and write scientific papers and do great academic work - that's a hard path to follow in the CRI structure because there will be pressure to convert science to technologies, and not to papers. That's a big mind-set change ... some take to it like a fish to water, and some shudder and try to go back to the beginning of their loop again (Science Group Manager, Innovate).

As suggested in the above statement, there was the view that the CRI environment was a challenging one in which to exercise one's professional aspirations around publication. Some even held that the increasingly client-centred, competitive, and secretive nature of their work was such that traditional science values and norms were no longer salient. Yet, there was the expectation that they continue to engage with these.

The research identifies several defensive practices in which scientists engage when responding to the paradox of professional integrity: opposing, over-committing, and suppressing (Table 6.2). The former, opposing, entailed challenging management expectations that they engage in both scholarly publishing and commercial research activities. The practice of 'over-committing' involved escalating one's efforts for sustained periods so as to engage in both scholarly and commercial research activities. The latter, suppressing, entailed allowing one's focus on commercial service to dominate or overrule scholarly research activities. These are addressed, along with their perceived implications, in turn. 
Table 6.2

Defensive responses to the paradox of professional integrity

\begin{tabular}{lll}
\hline Construct & Response entails & Illustration \\
\hline Opposing & $\begin{array}{l}\text { Actively resisting change by } \\
\text { asserting a set of needs that } \\
\text { conflicts with the needs of the } \\
\text { other party }\end{array}$ & $\begin{array}{l}\text { Challenging management } \\
\text { expectations that scientists engage in } \\
\text { the scholarly publishing process as } \\
\text { well as commercial research }\end{array}$ \\
Over-committing & $\begin{array}{l}\text { Committing oneself beyond } \\
\text { what available resources justify }\end{array}$ & $\begin{array}{l}\text { Escalating one's efforts for sustained } \\
\text { periods when attempting to engage in } \\
\text { scholarly research activities as well as } \\
\text { commercial research }\end{array}$ \\
Suppressing & $\begin{array}{l}\text { Continuously prioritising one set } \\
\text { of activities, and suppressing the } \\
\text { need to engage with another }\end{array}$ & $\begin{array}{l}\text { Continuously allowing a customer } \\
\text { service orientation to dominate or } \\
\text { overrule scholarly research activities }\end{array}$ \\
\hline
\end{tabular}

\subsubsection{Opposing}

In each CRI, there were individuals who saw the commercially-sensitive or applied nature of their research as a barrier to publication:

There's no question that we are constrained in keeping-up with international peers by the short-term nature of our work. We are required to work on commercial jobs - some of which are confidential, some of which are commercially sensitive. You can't publish (Science Group Manager, Create).

Things that we get involved in can be very practical though quite extensive, like auditing entire operations and environmental management type things, right through to systems planning - talking about what the environmental issues are in the whole supply chain (Senior Research Scientist, Inspire).

Among this group there were those who perceived that some managers had little understanding of the commitment that was needed to deliver a professional customer service, and who saw the requirement that they publish as unrealistic: 
They demand that we write high-profile papers in high profile journals, yet we don't have the resources to do that as we are so busy writing client reports. I find the attitude of management frustrating (Science Group Manager, Create).

I know writing is important, but there's not much I can do about it, unfortunately (Research Scientist, Inspire).

Some rationalised their disengagement from the publishing process by suggesting that their peers were in a better position to make the conceptual leaps needed to generate publishable ideas in complex areas of sustainability:

I think a lot of papers now, particularly [to do] with climate change, have got to have someone who can sit back and think, "Well, maybe this links to this other aspect", then provide some type of overview. I don't feel like it's worth me wasting my time trying to do that. Someone else could do that far better (Research Scientist, Innovate).

Collectively, there's this idea that it's good to publish ... but lots of people have writer's block and things like that (Science Group Manager, Create).

Others justified their decision not to focus on the goal of publishing by suggesting that they attached limited value to the system:

We've got a mix of scientists who publish and a mix who don't. I'm the sort who doesn't ... I've never rated the publishing system as something to aspire to (Senior Research Scientist, Inspire).

Publication record is one of the weaknesses so my boss keeps telling me. I tend to focus on other things (Science Group Manager, Discover).

A common view among scientists who did not publish academically was that their efforts were better directed at making a difference in a sustainability sense by packaging knowledge in ways that industry groups and businesses could understand and immediately utilise:

Historically the emphasis has been on science publications. I'm not convinced they lead to impact because they are for another scientist to read and do a good job. I focus my efforts 
on client reports and a lot of industry publications because I feel that if we are charged with the responsibility to make an impact, then without that engagement, we aren't going to get it (Research Scientist, Create).

They are helping industry with very useful and essential information. The basic research is all very interesting, but it doesn't mean anything to the industry. They want to know what actually works. Often, that's not publishable (Team Leader, Create).

There was also some criticism of the emphasis placed on scholarly outputs, with one suggesting that the authority often attached to academic publications merely perpetuated the "chasm" that existed between sustainability and the business sector:

This organisation is no different to anyone else's in the spin that's put on everything. You know, everything gets written-up and hyped-up as if it's going to solve all the world's problems, but in reality I think we over-emphasise some of the results (Research Scientist, Inspire).

However, there remained the view that scientists who organised their work in this way placed themselves in a precarious position:

I now have a publication gap and I do worry about that (Research Scientist, Inspire).

As discussed earlier (6.1 Underlying Tensions), a gap in publication exposed scientists to the risk of losing scientific credibility. Illustrating the interwoven nature of paradox in management and organisation, it also had the potential to affect their positioning (role identity), and their ability to perform as research scientists (service ethos).

\subsubsection{Over-committing}

It was widely perceived that there were scientists in each CRI who sought to manage the competing demands they faced by escalating their efforts for sustained periods of time, and by also increasing the hours they spent working:

It's quite common for scientists to find extra time in their weekends or holidays for writing papers (Senior Research Scientist, Inspire). 
I do my writing at home at weekends and in the evenings which isn't ideal. My line manager is the same (Research Scientist, Create).

Scientists often sought to rationalise their tendency to intensify the work process by presenting it as a necessary means to an end - specifically, as a way of enhancing their chances of survival within the CRI environment. There was the view that a track record of cutting-edge research and scholarly publication was crucial to their survival:

Giving up publishing is not sustainable for our future. CRIs are now moving toward a focus on outputs and outcomes, rather than inputs. I think there's going to be pressure on scientists to publish (Science Group Manager, Create).

However, cutting-edge research leading to scholarly publication required public funding and a longer timeframe for completion. Accessing public funding relied on a credible track record of research, there being the likelihood that a gap would prompt the funding agency to ask: "Was none of their science of peer reviewable, world-class quality?" (Team Leader, Create). Evidence of industry support for the proposed research was also needed: You have to have some industry funding. If you don't have industry funding, it doesn't matter what your CV says (Senior Research Scientist, Innovate).

Accordingly, many scientists saw the route to achieving a credible track record as a challenging one to navigate:

To get funding to do research I'm interested in is almost impossible under the commercial system. It's just getting vicious (Team Leader, Innovate).

Some scientists responded to the situation by finding alternative ways to facilitate their engagement in cutting-edge research. Specifically, there were scientists who saw themselves or their peers as stimulating opportunities to engage in cutting-edge research by over-delivering for clients. This response was sometimes encouraged: 
We were in this business drive of, "Don't over-deliver for the client". Now, we're saying, “over-deliver for your own career's sake and for outputs . . . unless you want to be stuck in your current job with your current employer, and that could be tenuous anyhow" (Science Group Manager, Create).

Professional customer service delivery entailed working to tight deadlines. This way of working, scientists saw as requiring a major shift in approach for scientists transitioning from a university background:

Converting science into a technology [entails looking] at issues of scale, issues of commercialisation, and issues of business partnership ... young scientists haven't done that before. Graduates have been used to working on a time frame measured in years, while here's an industry partner that wants the whole job done in three months (Science Group Manager, Innovate).

There was the perception that workload pressures had led to high levels of stress among scientists:

I don't know any scientists who aren't a bit stressed about the amount of stuff they have to do (Team Leader, Inspire).

Yet, it was thought that few were willing to challenge the situation, seeing the potential for such a stance to diminish their chances of securing career stability:

You can't complain too much because you're a scientist. You don't want to be out of work, but you don't want to have so much [to do] that it's difficult to maintain quality in what needs to be done (Senior Research Scientist, Inspire).

Accordingly, there was the view that scientists would continue to put themselves in the position of escalating their efforts for sustained periods in order to engage in scholarly research activities. 


\subsubsection{Suppressing}

Across CRIs, there were scientists who stated that they had allowed the objectives pertaining to one pole (most often, customer service delivery activities) to dominate or overrule their engagement in another (scholarly research activities):

We should be doing heaps of [peer reviewed writing]. I spend my life writing reports and proposals (Research Scientist, Create),

I've got five papers that I was supposed to have written two years ago, but I didn't. Other priorities come into play and they just sit there unwritten (Senior Research Scientist, Create).

Some linked the difficulty they had experienced in organising their work in such a way that it was possible to produce both peer reviewed outputs and commercial products to a management directive that they spend 80 per cent of their time on income-generating activities, and no more than 20 per cent of their time on other activities (e.g., general administration, meetings, and writing papers). Among this group, there were those who asserted that their stance was both supported by some managers and reflected an approach that aligned with the "economic reality" confronting CRIs:

You've not published for a few years, but you've delivered a product and a solution, and you can point to it - it's in production, it's being manufactured. They [management] really don't care that you haven't published because that counts more than publications. It's not an academic question - it's an economic reality (Senior Research Scientist, Innovate).

Altogether, scientists saw the value attributed and attention given to income-generating activities during formal evaluation processes as more significant than that given to academic publications:

Every four or five years, there's this little fuss about your research involvement. We've got to justify our existence. On the one hand, you get a pat on the head for having 
publications, but when it comes to your performance and how the organisation is evaluated, it's all strictly commercial: "How are you doing commercially? How are you contributing? Are you above budget?" When you get evaluated as an individual, those are the questions that are asked (Team Leader, Discover).

These scientists tended to view the goals of producing a commercial product and achieving a peer-reviewed output as largely incompatible. Some drew on their industry experience to justify their ideas:

If I want to publish data, I have to get the written approval from the commercial partner. Sometimes, I choose not to publish at all because the process is complicated . . . So if your research can be used by somebody in the real world - that will be enough (Research Scientist, Inspire).

You have to liaise with people who are not interested in the nuts and bolts. They just want to hear the outcome and to see bullet points. They don't want to read a paper of 20 or 30 pages (Senior Research Scientist, Inspire).

There were also those who drew on their industry experience to suggest that applied work was more relevant to society and, thus, a more worthy pursuit than scholarly publication:

I'd say the less realistic your work, the more publications you do. The more applied it becomes, the more IP is tied up in it, and the less you should be publishing. The closer you are to implementation, the less you should be publishing because that's how you create competition for NZ (Science Group Manager, Innovate).

Pertinent here, was the suggestion that the tacit knowledge acquired through applied research was more relevant than the learning that could be achieved through scholarly reading and writing:

We know more than those guys [academics] do because we're close to it. Our gut reaction is going to be better than what they can do with all their reading because they haven't felt it, they haven't lived it (Team Leader, Inspire). 
As indicated in this section, scientists sometimes saw themselves or their peers as responding defensively to the competing demands encompassed within the paradox of professional integrity. Scientists tended to rationalise their responses on the basis of the constraints they faced or an assumed need to prioritise customer service delivery. At the same time, there was the perception that such responses were risky since they compromised scientists' ability to retain their scientific credibility and professional integrity.

The next section examines the ways in which research scientists seek to simultaneously engage with both scholarly research endeavours and professional service delivery.

\subsection{Managing the paradox of professional integrity}

Managing the tensions relevant to scientists' professional integrity also involved strategies embedded within a blend of differentiation and integration approaches (Table 6.3). The former entailed internal differentiation of responsibilities through use of multidisciplinary work organisation. The latter involved nurturing an ability to engage with paradox by underlining ways of managing both facets during the career mentoring, and performance planning and review processes. Others describe the process as entailing the fostering of a paradoxical mindset: an understanding of the importance of, and interdependencies between, conflicting role demands (Andriopoulos \& Lewis, 2010). The premise is that a vision of organisational life as paradoxical can build commitment to competing demands. Integration also involved identifying opportunities to overlap the organisation and production of both a peer-reviewed output and a commercial product. 
Table 6.3

Managing the paradox of professional integrity

\begin{tabular}{lll}
\hline Construct & Response entails & Illustration \\
\hline Differentiating & $\begin{array}{l}\text { Addressing each of the seeming } \\
\text { contradictory elements }\end{array}$ & $\begin{array}{l}\text { Internally differentiating } \\
\text { responsibilities, including by co- } \\
\text { authoring with colleagues }\end{array}$ \\
Integrating & $\begin{array}{l}\text { Stressing the interdependencies } \\
\text { between apparent opposites }\end{array}$ & $\begin{array}{l}\text { Harnessing economies of scope by } \\
\text { co-authoring with clients (2-in-1) }\end{array}$ \\
\hline
\end{tabular}

\subsubsection{Differentiating}

Addressing the paradox of professional integrity involved internal structural and temporal differentiation through the use of multi-disciplinary work organisation. They saw that work organisation around different skills and roles as providing them with the diversity of opinion needed for robustness:

We tend to put together teams of collaborators with different skill sets where we have robust discussions. Rather than everyone agreeing that everything's hunky dory, we actually look for challenge - trying to find discord, but not for the sake of discord (Senior Research Scientist, Innovate).

Putting your ideas up and having them shot down. That's what makes good scientists - the challenge to what we think (Science Group Manager, Create).

There was also the view that this work arrangement provided the opportunity to work through individual priorities and values and then arrive at a mutually satisfactory position. A scientist pointed out that this enabled their identification of any differences of opinion prior to engaging with clients since when the time came, in the interests of maintaining their credibility, it was necessary to present a united front: 
There are always different ideas. It can be difficult, but you try to resolve them because if you don't sometimes someone can be giving some advice, and someone else can be giving contrary advice. If the client gets two different sets of advice, it becomes very confusing or difficult for them (Senior Research Scientist, Discover).

More specifically, they viewed this structural and temporal approach to differentiation as enabling them to effectively engage with both commercial value and academic values through joint authorship with colleagues:

There are two ways you can manage it (peer reviewed writing)... You could share all the work around more and resource everyone better with time and help so that they could have that time to write stuff up. Or, you could say, "You guys are doing the commercial stuff and you guys are doing the prestigious papers" (Science Group Manager, Create).

Some held that the success of this approach relied on a willingness to cooperate with others in finding novel ways by which to combine their efforts towards the end goal of publication:

A lot of it [peer reviewed publication] depends on 'holding hands'. Most of this work is in close collaboration with colleagues so while I'm dashing around doing stuff, they might be doing the lion's share of the writing (Senior Research Scientist, Discover).

Accordingly, scientists saw themselves as securing professional integrity across both science values and commercial service delivery when they directed their efforts as a group at addressing each of the apparently contradictory demands.

\subsubsection{Integrating}

The integrative approach to paradox relied on developing capabilities that enabled scientists to generate scientific credibility as well as meet client expectations. Relevant here, was the predominant view of a significant gap between the understanding and skills acquired through formal training, and the relational and technical skills required to operate 
effectively as a CRI scientist: "They have no clue what they're getting into until they get here" (Team Leader, Create).

Accordingly, scientists reflected on three main practices utilised. First, they saw formal and informal mentoring processes as underlining ways of intertwining both professional facets. For example, a manager described the integrative approach to mentoring individual scientists as follows:

Scientists have layers to their careers. You are getting money to do a piece of work. You get all this piecemeal funding which allows you to keep your job and get paid. There is a layer above that - kind of your career purpose. And, it's the personal thing. You've got a passion and I think what people do is they use those little bits of stuff that come out of those contracts, as long as they have permission to use them, and they use those to piece together a jigsaw puzzle of a bigger story which then you publish. It's really challenging (Science Group Manager, Create).

Importantly, some managers considered that meeting science values while also generating practical value to be an ability that could be acquired and developed through a relational approach to mentoring in their organisation:

They are learned, progressive skills that require a lot of mentoring and nurturing from people who have been there and done it before. Those guys need to work with others as part of a team, or, under the wing of others to see how it's done. It doesn't come naturally, and it's hard work ... (Science Group Manager, Innovate).

They saw this relational approach to mentoring and the abilities some had acquired as lowering attrition rates and so having implications for organisational capability:

Some of them I think we would have lost years ago except that we were very honest and said, "Look, you can't do this particularly well at all. So this year, we're going to work on this". It's amazing, you give them a little bit of water and they blossom (Team Leader, Inspire). 
Similarly, scientists with experience of the mentoring process saw it as a strong engagement process through which they had acquired an understanding of what was required in order to effectively function as a research scientist:

My supervisor really took me under his wing and gave me opportunities to grow. Being around that sort of atmosphere is really what shaped me to where I am now (Research Scientist, Create).

Some acknowledged that it was through mentoring that they had been alerted to the dangers in identifying too strongly with one or another role, and of the need to actively engage with both:

I have grown within the role with various mentors that have basically said, "This is how things operate. If you want to progress your career, there are the things you need to work on" (Senior Research Scientist, Create).

The whole concept of how they're all interlinked is the biggest lesson I've learned; that you can't live in isolation as a scientist making things (Senior Research Scientist, Innovate).

Scientists also saw that their organisation's use of printed materials and the YouTube channel had helped to promote an understanding of the various facets of the scientists' role (both internally and externally):

I think [we] do a good job at that with videos on the YouTube channel, and all sorts of things like that ... we get to the public with issues that they very much care about (Senior Research Scientist, Discover).

These communications (which featured the work of research teams or individual research scientists), often emphasised the synergies achieved between pure and applied research. Several participants also acknowledged the merits of the formal performance planning and review processes in place in CRIs, seeing them as mechanisms through which an holistic approach to goal setting was being emphasised: 
We have this milestone system and people become very aware of that. Mostly, they are very obliging . . . it does encourage more realistic planning or, at least, realistic articulation of the planning (Science Group Manager, Create).

They viewed the same processes as useful mechanisms through which to identify the need for professional development. There was the perception that investment in leadership development was integral to capability development in CRIs:

We've invested a huge amount of resources into leadership training, and that's paid massive dividends around understanding people, and what drives people (Science Group Manager, Create).

The second integrative approach involved identifying opportunities to overlap the organisation and production of both a peer-reviewed output as well as a commercial product:

You are still measured by your peers through publications. Yet, our funding is tied to more applied or impact driven science. So the challenge for us as scientists is how do we overlap the two? That's really what we are trying to do - sort of go "Okay, within our commercial work, what can we add in to create a bit more science?" Sort of work back in so that we get both outcomes - we get a paper and something industry wants. It's not easy, but that's our challenge (Research Scientist, Create).

Alluded to in the above quote is the perception of synergies to be achieved between academic and applied research outputs through forward planning. There were those who saw merit in seeking to supplement relatively straightforward commercial programmes by injecting more science. Others emphasised their focus on achieving synergies through the use of both/and thinking in their approach to organising their writing. Once again, this entailed planning so as to generate client reports of high academic merit that could then be used as the basis for scholarly publication:

When we write reports, we write them primarily with the needs of the client in mind, but for your own career and the value of the work, we write it of high academic merit so that 
you can get a publication or think about publication as you're putting all the graphs together (Science Group Manager, Create).

The achievement of synergies also involved collaboration. Specifically, some scientists saw that producing both peer-reviewed outputs and commercial products relied on the relationships they had formed with peers and a shared willingness to combine their efforts:

We just tidied-up the [client] report to tailor it for academic publication. We've always done that - sort of on the internal black market; not double dipping but complementary [activities]. So when we wrote that paper, we acknowledged the original work and that there was internal resourcing that enabled us to do that (Science Group Manager, Create).

It's about sharing the knowledge and sharing ideas ... I think the secret is building up a network and sharing with others (Senior Research Scientist, Create).

A recognised approach to the challenge of overlapping different outputs was to involve the client as co-author. This '2-in-1' approach rested on economies of scope (whereby some of the same resources were used to generate different products):

We've written a number of joint papers with commercial partners. It's the usual collaborative paper. We do joint measurements, we share info and results, and we publish (Senior Research Scientist, Innovate).

Through such 'symbiosis', each side gets something different out of the shared product. Though scientists considered the scientific merit of publication to be less relevant for clients, they perceived it as conferring the authority the client sought - whether from the public or private sector. For example, a manager described co-authorship from each as follows:

The last author [is from] a District Council. He was happy for that because he's used ratepayers' money to fund us to do that work. So now, if a [business owner] comes in grumpy and says, "Who's this bloody [Create], and what would they know?" he can say, "Well actually it's peer reviewed and published as a book chapter - meet you in court" (Science Group Manager, Create). 
We did a commercial job on a sustainability issue for an industry group. We wrote the report that met the needs of the client, and the client was very happy to have the imprimatur of peer review of our report so that they could then go away and use it. There's a paper that's just been accepted into publication, and look at the affiliation of the last author. He wants that because if [a prospective buyer] asks him, he goes, "Here's a peer reviewed paper" (Science Group Manager, Create).

Altogether, scientists viewed the blend of practices premised on differentiation and integration approaches as enabling them to maintain professional integrity based on science values as well as practical value. The former included both structural and temporal differentiation (through use of multi-disciplinary work organisation) to separate tensions and assign different internal responsibilities. Here, scientists saw their joint authorship with colleagues as enabling them to effectively communicate with both practitioners and academia through joint authorship with colleagues. Integration included fostering both/and thinking (by underlining ways of intertwining both professional facets) through use of mentoring, performance review and planning processes, and promotional materials. Integration also included the identification of opportunities to achieve synergies through a '2-in-1' approach that entailed involving the client in the achievement of a mutuallybeneficial outcome (i.e., a scholarly research output). 


\section{Chapter 7}

\section{Discussion}

I'm liaising with two groups of people and the first is a research group interaction with my staff and with research scientists in all corners of the globe. Then there's another major set of interaction partners with New Zealand industry. That's the most useful area to look at in this discussion because that's the big picture: the issues that we face as a nation, and that industrial partners face in terms of managing a business, and managing resources, and whether they care about sustainability or is it too hard or too expensive? (Science Group Manager, Innovate).

The purpose of this research is to examine the paradoxes research scientists perceive when working with industry groups and businesses on issues of sustainability in commercial research. Though the constructs of sustainability, commercial research, and organisational paradox have each been examined from a variety of perspectives, their nexus has received little attention. Accordingly, this research represents a novel approach to the study of research management. The premise is that paradoxical inquiry can offer new and more enabling understandings of the contradictory demands and ubiquitous tensions inherent in everyday organising (Luscher \& Lewis, 2008).

Drawing on research scientists' accounts of the tensions they experience when addressing sustainability in commercial research, this study offers two sets of findings. First, it identifies paradoxes of service ethos, role identity, and professional integrity, and elucidates their dynamics. These paradoxes were enmeshed in the confluence of scientists' understandings about their key constituents and aspects of the social, political, and organisational environment. Specifically, scientists often reflected on their interactions with clients, funding constraints, organisational controls, legislative requirements, as well as their own research priorities and negotiation of opportunities to engage with these. 
Second, the study explicates the productive and counterproductive ways in which research scientists respond to competing demands, introducing several responses new to the literature on paradox in management and organisation. This chapter discusses relevant themes across all three paradoxes, and examines the dynamics of their management.

\subsection{The interrelated nature of paradox}

Recognising the interrelationships between competing demands inherent in organising is a first step in holistically managing organisational paradox (Andriopoulos \& Lewis, 2009; Jarzabkowski et al., 2013). The premise is that there is a need to be aware that problems and solutions that occur at one level of organisation can manifest themselves in contradictory ways at other levels (Lewis \& Smith, 2014; Poole \& Van de Ven, 1989). Prior research locates paradoxes at the individual level of everyday interactions and selfunderstanding, at the group level as individuals face identity conflicts, and as also embedded in organisational level controls (Clegg et al., 2002; Jarzabkowski et al., 2013; Luscher \& Lewis, 2008).

Based on the practices scientists associate with their defensive and productive responses to competing demands, this research identifies several interconnections between the paradoxes of performing, belonging, and organising. First, the desire to make a difference cuts across identity and professional integrity. The dynamics underlying this claim became apparent in scientists' assumption that their productive engagement with competing performance demands had the potential to make a difference in both a public good and a commercial sense. They were also apparent in the explicit links scientists made between their desire to make a difference as 'advocates for change' and 'allies of business', and the vision and values they held towards sustainability as research scientists. In turn, there was their association of making a difference with an approach to organising 
that maintained high standards of integrity and transparency. Last, but not least, it can be seen that such an approach to organising aligns with the principles of operation set down in the legislation governing CRIs (Appendix I).

Second, motivation is relevant to role identity and also ties in with ethos. There was the view that scientists' passion for science work and capacity to engage with the ideals of sustainability emanated partly from their identification with a particular research field, and the recognition they received for their contributions to science. Underpinning the development of each, and integral to their advancement as research scientists, were publications in international science journals, and the sharing of practical knowledge with end-users including industry groups and businesses. The achievement of these outcomes called for an approach to organising that took into account the need for both exploratory and exploitative research activities (identified earlier - 6.1 'underlying tensions' - as the creation of a "technology pipeline which matches the global market" to ensure that the "well does not run dry"). Hence, there was an awareness of the interconnections between positioning oneself within a particular field, gaining recognition for contributions made, and engagement in both publicly-funded, exploratory research activities and shorter-term, commercial applications of science.

There was the perception that opportunities to engage in commercial research activities relevant to both one's field of sustainability (and more widely) emanated from scientists' ability to sell themselves and their science. They saw that this ability necessitated their development and maintenance of close relations with industry, and also dovetailing the organisation's research facets with its commercial services. Presenting a credible case to industry called for simultaneous internal differentiation of responsibility whereby the different capabilities of research scientists and commercial managers were drawn upon strategically, while also presenting a united front to clients. 
Third, the question of publishing spans across ethos and professional integrity. By contributing to knowledge on aspects of sustainability in ways that were credible (e.g., through publication in world-class academic journals), scientists saw themselves as leading the way in cutting-edge research and, thereby, enhancing their own as well as their organisation's reputation. They also linked their scholarly writing endeavours and their enhanced reputation to increased opportunities to exploit their research in the marketplace. In a broader sense, they saw their publications as contributing to the public good by potentially leading to the uptake of more sustainable technologies and practices on a global scale. Further confirming the interrelated nature of the three paradoxes was the view that when scientists experienced a publication gap, they exposed themselves to considerable risk. Specifically, they associated a loss of profile and limited recognition of their work with an inability to attract public funding or commercial work, a situation they saw as potentially jeopardising both their engagement with a particular field of sustainability research, and the stability of their careers in science.

In summary, there are several interconnections between the three paradoxes through scientists' association of their productive engagement with one set of demands with an enhanced capability to cope with other, seemingly unrelated, demands.

\subsection{Developing the capability to engage with paradox}

Paradox studies stress the need to encourage a shift from either/or thinking to both/and thinking (Bartunek, 1988) by promoting more complex or visionary thinking (Clegg et al., 2002), a strategy sometimes referred to as cultivating a 'paradoxical vision' (Andriopoulos \& Lewis, 2009, 2010; Lewis, Andriopoulos, \& Smith, 2014). A paradox perspective is one that recognises the dangers in over-simplification, and that sees in maintaining a tension between opposites the potential to realise synergies through the 
exploitation of their bi-directional relationship (Clegg et al., 2002; Smith \& Lewis, 2012). Though prior literature suggests the potential for synergies to be found by engaging with paradox, few have attempted to provide specific examples (see Jay, 2013 for a rare example).

Due to the interrelatedness of organisational paradoxes, researchers have stressed the importance of accepting, even embracing, competing demands (Luscher \& Lewis, 2008; Luscher et al., 2006). Accepting paradox entails recognising competing demands as inherent to organising, and learning to live with them (Lewis, 2000; Poole \& Van de Ven, 1989). Accepting paradox provokes greater complexity (Luscher et al., 2006) and the active pursuit of 'both-and' possibilities (Luscher \& Lewis, 2008; Luscher et al., 2006; Poole \& Van de Ven, 1989), as it leads to an engagement with patterns and possibilities that might otherwise be overlooked in organising (Weick, 1979).

Acceptance in this case underpinned the three paradoxes identified, whereby the science managers in this study saw a need to encourage colleagues to embrace them, "We've got to accept that those tensions exist" (Science Group Manager, Create). They sought acceptance by nurturing paradoxical identities: a way of seeing themselves that enabled scientists to undertake different roles (e.g., as research scientists dealing with pure science and/or research professionals working with industries or multi-nationals with a private agenda). The realisation of this vision of themselves required the commitment of resources to mechanisms designed to develop more complex thinking at both an organisational and individual level.

This research finds that science managers sought to promote a 'paradoxical vision' (Andriopoulos \& Lewis, 2009) at the organisational and individual levels.

Organisationally, they facilitated the dual focus on commercial research and the public good by emphasising the relevance of each through goal setting, milestones, as well as 
clearly articulated performance planning and public reporting (including online and printed promotional materials profiling the sustainability research conducted by teams, and the benefits derived from commercial applications). At the individual level, they alerted scientists to the relevance of simultaneously achieving competing goals:

There are individuals who prefer one side to the other, but we encourage [focus on] both even though it's a real juggling act (Science Group Manager, Innovate).

The demands inherent in maintaining both a social and a commercial mission require more sophisticated interpersonal and decision-making skills than those normally acquired through higher-education (Clegg et al., 2002; Smith et al., 2012). Such skills are largely acquired through the internalisation of "shared mental models or technical know how" (i.e., the development of tacit knowledge) (Nonaka, Toyama, \& Konno, 2000, p. 10). In this case, mechanisms through which scientists were supported in acquiring the skills needed to engage with competing demands included leadership training, mentoring, and the use of multi-disciplinary research teams. Scientists saw these mechanisms as having enabled a shift from the "dark days when things were pretty desperate" to a time when it was common to find scientists who were routinely and creatively engaging with competing demands (Science Group Manager, Create) They saw mentoring, in particular, as integral to developing the tacit knowledge and relational skills needed to productively engage with business, both initially, and through to the successful integration of sustainability initiatives.

This research identifies several specific skills scientists see as needing to be applied with high levels of sophistication when influencing clients towards 'a big mindset change' and engagement with sustainability. These included skills in self-marketing (there being a need to 'sell' yourself and your science) and communication. The latter was particularly 
relevant given the perception that scientists often struggled to engage effectively with industry because they got 'so down to the nitty-gritty' when discussing their science.

\subsection{Defensive responses to paradox}

Studies of paradox often find that individuals may struggle to simultaneously engage with competing demands, and instead focus on identifying trade-offs between opposing routines and logics, with the effect of over-simplifying situations (Andriopoulos \& Lewis, 2009, 2010; Lewis \& Smith, 2014; Smith \& Tushman, 2005). Research on corporate sustainability similarly finds that firms often attempt to bypass tensions by seeking to reconcile social and environmental goals with economic goals or by making choices between them (Van der Byl \& Slawinski, 2015). Escalating one's efforts toward a preferred pole and opposing or suppressing the need to engage in activities associated with the other is a typical reaction when faced with dual and conflicting demands (Lewis, 2000; Pache \& Santos, 2010). Such one-sided responses to paradox can temporarily alleviate tension (Andriopoulos \& Lewis, 2009; Jarzabkowski et al., 2013). However, tensions pushed underground tend to persist and can trigger unintended negative consequences that destabilise organisation under conditions of plurality, change, and scarcity (Andriopoulos \& Lewis, 2010; Argyris, 1988; Smith \& Berg, 1987a).

This study offers a more nuanced account of the defensive responses to paradox of opposing and suppressing (e.g., Jarzabkowski et al., 2013; Poole \& Van de Ven, 1989) than is provided elsewhere, with scientists' adoption of these responses spanning all three paradoxes. Drawing on research scientists' sensemaking of their own and peers' approaches to dealing with competing demands, this research introduces two novel defensive responses to paradox scientists draw on. These entailed over-committing by over-promising and over-delivering, as well as isolating oneself from peers or clients. 
Though scientists' engagement in these practices was premised on the alleviation of tension, there was the view that such responses were often associated with unintended, negative consequences and so were counterproductive. For instance, they saw the practice of over-committing as exposing scientists and their CRIs to considerable risk by triggering a 'spiral of promising more and more'. Perceived consequences of such vicious cycles included work intensification leading to burnout, higher levels of stress, cynicism, and reduced morale. These and other harmful effects of high performance work practices are well-documented (see, for example, Mariappanadar, 2014 for a review), but do not appear to have been acknowledged in the literatures on research management, sustainability and science work, or paradox in management.

Similarly, scientists perceived that the practice of isolating oneself from others whether by detaching oneself from peers (through disengagement with the team's effort) or distancing oneself from clients (by relying primarily on commercial managers for industry contact) - exposed them to risk. Specifically, they saw that it constrained their ability to engage with their work in ways that allowed them to maintain the public and professional profile they needed to achieve required outcomes. For instance, they associated scientists' isolation from peers with delays in meeting publicly-funded research project milestones, and subsequent difficulties in attracting the funding needed to ensure that 'the well' did not run dry (i.e., to engage in the exploratory research needed to be able to provide solutions to business problems). They saw that some scientists' isolation from industry had limited their exposure to experiences from which they might acquire the necessary relational skills and tacit understanding to productively engage with clients and, thereby, maintain established relationships. 


\subsection{Managing paradox}

Prior research on paradox presents the complementary strategies of differentiation and integration as a productive means of engaging with paradox (Andriopoulos \& Lewis, 2009; Gotsi et al., 2010; Smith \& Tushman, 2005). The former involves recognising the unique contributions of competing goals, and attending to their related demands (Weick et al., 1999), whereas the latter denotes the use of mechanisms that accentuate the linkages between opposing poles (Andriopoulos \& Lewis, 2009). This research similarly draws on differentiation and integration to explicate the ways in which scientists productively engage with paradox. In doing so, it identifies several novel tactics scientists see themselves applying when seeking to influence clients towards sustainability. These are discussed below.

\subsubsection{An incremental approach towards addressing sustainability}

The literature on strategy process has long signalled the relevance of incrementalism (Quinn, 1980), suggesting that it represents a "purposeful management technique for integrating analytical, behavioural, and political and timing aspects of strategy formulation" (Quinn, 1982, p. 614). This research finds that scientists see themselves adopting an incremental approach to influencing clients, with specific relevance to sustainability. Specifically, there were scientists who spoke of leading incrementally - by initially following and then influencing. This incremental approach to engaging with paradox represents a subtle form of leadership - guiding from within rather than outside the relationship by focusing on identifying with the needs of clients, and relying on signals given by them as a reference point for action. This research posits that when used in external organisational relationships, incrementalism is a differentiation tactic that draws acutely on scientists' interpersonal and decision-making skills, there 
being a need to engage with clients on both a personal and professional level. Specifically, there was the view that when seeking to effect long-term change towards sustainability incrementally, there was a need to get to know clients, to develop a deep appreciation of the constraints they faced, and to be able to find ways of working through these. This research also finds that scientists see themselves as applying fluidity in positioning when seeking to incrementally influence clients.

Relevant to the notion of positioning is that people enact personas consistent with the qualities prescribed by their professional roles, leading them to adopt more than one identity. In the case of a professional group, the identity construction process entails observing, experimenting, and evaluating their provisional selves through social interaction, building "a store of tacit knowledge, attitudes, routines, and impression management techniques" to be drawn on in future interactions (Ibarra, 1999, p. 774). This research finds that scientists sometimes see themselves enacting different personas, drawing on qualities they associate with their identities as agents for change and allies of business, as a way of managing external relationships. The enactment of different personas entails (re)positioning and even engaging in shape-shifting at times (Barry et al., 2006), as indicated in the claim made earlier that scientists tended to be good 'chameleons' (Senior Research Scientist, Inspire).

In sensemaking terms, Weick might describe the skilful adaptation process involved as one of drawing on a confluence of understandings while chopping "moments out of continuous flows and extract[ing] cues from those moments" (1995, p. 43). The signals some scientists saw themselves drawing on when determining which self to adopt were the words clients used, how they talked, and their eyes. Seeing a client's eyes 'glazing over' signalled the need for an immediate shift in approach via the adoption of a more business-like persona, for example. There was the perception that a business-like 
persona was one clients would more readily identify with, and that this entailed a more aggressive approach to marketing, as well as a different 'look' and manner of communicating than came naturally to scientists. When interacting with clients, scientists saw a need to maintain their professional integrity by sustaining their independence as researchers. They did so by engaging in a process of tensile positioning (Ellis \& Ybema, 2010), oscillating between different identities when faced with conflicting obligations; in effect, they were enacting their environments in ways that allowed them to remain true to their core values. Altogether, scientists' incremental manoeuvring amounts to an approach to paradox whereby leading (on the path to sustainable processes and practices) is done by following (clients' immediate needs and interests).

\subsubsection{The relevance of requisite variety}

Theoretical insight can be gleaned by considering the notion of requisite variety (Ashby, 1960). Requisite variety is related to notions of differentiation and integration and posits that the internal mechanisms of a system need to be as diverse as the environment in which it operates for that system to be able to respond to its challenges. Since this inherent ability to meet the demands of external variety is important to all living systems, organisational theory has long recognised its significance, generally (Morgan, 1997), and specifically, as it pertains to an organisation's strategic responsiveness to its environment (Miller, 1993). Studies into systems have also underlined the potential value of requisite variety in responding to paradox (Pearlson \& Saunders, 2001; Prenkert, 2006). This research explicates the relevance of requisite variety to all three paradoxes, what has been termed the 2-in-1 approach.

At the individual level, this included the perceived ability to re-position and adapt one's pattern of engagement when dealing with a client or, put differently, to draw on a 
repertoire of patterns of engagement that was at least as great as the variety of exchanges likely to be encountered. Indeed, the 'chameleon' metaphor used by a participant earlier is a salient example of requisite variety in biology whereby a living system offers an adaptive response to its environment. At the organisational level, this research theorises that two main integration strategies facilitated responsiveness and demonstrate the relevance of requisite variety. First, the literature on paradox notes the relevance of reframing in the way organisational members interact with, and view, their environment (Quinn \& Cameron, 1988). Emphasis has been on internal management of paradox by reframing dualities (Putnam et al., 2013) as well as reflexively questioning and altering entrenched organisational frames (Luscher \& Lewis, 2008) to set expectations, shift business strategies and enhance performance (Jay, 2013; Smith \& Tushman, 2005). However, this research conceptualises that reframing is used externally by the organisations as they engage with clients. Specifically, scientists saw themselves as reframing measures relevant to sustainability in terms more palatable to clients, such as eco-marketing, efficiency and performance. The effect here, like the chameleon, is in the eyes of the beholder. It rests on the ability to represent interventions to external parties, here clients, in a way that generates an affirming response.

Second, this study conceptualises the relevance of requisite variety in scientists' perceived ability to engage clients in economies of scope whereby the same resources and components of research could be used to generate different products (co-authored publications and applied technologies or processes). Here again, it is the ability to present the value of publication to a client so they willingly participate that matters. Co-authorship subsequently binds researcher and client in a symbiotic relationship whereby each side gets something different out of publication: research recognition on the part of the scientist and legitimacy for the scientific intervention on the part of the client. On the 
other hand, Weick also contends that when simple processes are applied to complex situations, only a small portion of the dynamic occurring will be registered, dealt with, and made unequivocal, leaving people struggling to comprehend and manage the environments with which they are faced (1979). This research finds that not all scientists were able to tolerate the equivocal processing needed to apply this 2-in-1 approach when engaging with clients, tending instead to keep publishing and commercial goals separate; in effect, they are simplifying their interactions with clients.

Altogether, this research finds that requisite variety is a relevant consideration in paradox. Correspondingly, it posits that individual and organisational ability to respond to multiple, apparently contradictory, demands in the environment is pertinent to effective management of paradox.

\subsection{Concluding comments}

This chapter has drawn together the findings of this study in light of prior research to elaborate on what is known and to generate new insights. By focusing on scientists' sensemaking, it sheds light on the interconnections between the paradoxes of performing, belonging, and organising when issues of sustainability are at stake. Pertinent here, was the bi-directional relationship perceived between making a difference in a social, environmental, and economic sense and engaging in activities that reinforce role identity and professional integrity. The discussion of the interconnections between paradoxes also underlined the importance for research scientists of opportunities to engage in both exploratory research activities and commercial applications of science, and to engage in recognition-gaining activities that enhance their positioning within a field and simultaneously help to sustain areas of science crucial to sustainability. Some scientists seek to encourage others to accept paradox, and to support them in doing so. Consistent 
with prior research on paradox, this work discusses the value of such support mechanisms as leadership training, mentoring, and multi-disciplinary research teams, and the apparent need for more sophisticated interpersonal and decision-making skills than those normally acquired through higher-education when the focus is on addressing both social and/or environmental and commercial goals. Going a step further here, the discussion links the relational skills and tacit knowledge acquired through experience to the capability to productively engage with paradox.

In discussing the ways in which scientists respond to paradox, this chapter elaborates on practices identified in earlier studies across theories of paradoxes. It also surfaces new ways in which scientists respond, both defensively and productively, to paradox. The former, defensive responses, include the practices of isolating (in two forms) and over-committing, a practice this research posits is associated with work intensification. The latter, productive responses, are reflected in the differentiated practices of seeking to incrementally influence clients, and the division of labour so as to allow co-authorship with colleagues, for example. They are also apparent in the integrative practices of (re)framing problems and solutions for clients, (re)positioning and shape-shifting, and the realisation of economies of scope by co-authoring with clients. Across the three, the study finds a '2-in-1' approach and so the relevance of requisite variety is posed.

Altogether, the discussion in this chapter has addressed the ways in which research scientists see themselves engaging with paradox as they interact with industrial partners who face challenges in terms of managing a business and managing resources, and who may or may not care about also managing for sustainability. 


\section{Chapter 8 \\ Conclusion}

We are all planted into this sphere where we have to use economic jargon and talk about dollars. On the one hand, I can understand why the economic benefit is the focus, but there's this odd tension that sort of means that nobody dare use real language. It's a bigger debate than just a New Zealand debate ... how we are being paid or funded to do specific things with specific outcomes. At some point, you feel like you have a responsibility to your education and society and it's not entirely trivial. It's something that we don't discuss very much - how you deal with that tension (Research Scientist, Innovate).

This study draws on sensemaking to examine the paradoxes research scientists perceive when managing for sustainability in commercial research. The overarching premise is that sensemaking guides practice (Weick et al., 2005), and that paradox is pertinent to management and organisation more broadly (Clegg et al., 2002; Luscher \& Lewis, 2008). Though prior work posits that paradox has pervasive effects on science work (Hackett, 2005) and managing for sustainability (Benessia et al., 2012; Ramirez, 2012), it remains underexplored in these contexts. Hence, this study introduces a new theoretical perspective on research management by answering the following questions:

What paradoxes do public research scientists perceive when engaging with sustainability in commercial research?

What responses (to paradox) do public research scientists see as constraining or enabling their engagement with sustainability in commercial research?

This chapter addresses the research findings, and draws together the study's contributions to the literature. It then acknowledges several limitations and avenues for future research, before concluding with an overview of the ways in which the study bears relevance to practice. 


\subsection{Summary of research findings}

First, by focusing on research scientists' sensemaking of managing for sustainability in commercial research, three main paradoxes are identified across the themes of service ethos, role identity and professional integrity (Table 8.1). Scientists experienced apparently conflicting performance imperatives whereby, on the one hand, they saw a need to address research questions holistically and offer public service based on a public good orientation; while on the other, they perceived a duty to provide customer service based on short-term goals and a commercial orientation. Turning to role identity, scientists saw a tension in being both advocates for change towards sustainability and allies of business accepting the primacy of profit. Last, but not least, they faced conflictions in professional integrity, seeing a need to simultaneously retain their scientific credibility based on science values while also meeting client expectations.

The paradoxes scientists perceive are interrelated, and reflect perceptions of practices at the individual, group, and organisational levels. For example, the desire to make a difference cuts across identity and professional integrity: a dynamic apparent in some scientists' view of themselves as personally motivated to deliver on both a public good and a commercial front, and as also committed to an approach to organising for sustainability that maintained their credibility and professional integrity. The study also finds participants' perceived motivation as relevant to role identity and tied in with ethos: a dynamic found in scientists' depiction of their passion for science work as entwined with the satisfaction they gained from providing both a public service and a customer service, as well as from the recognition they gained for their work. The question of publishing spans from ethos to professional integrity as evident from a view of scholarly publication as 


\section{Performing:}

\section{Service Ethos}

\section{Public service Based on public good orientation}

Serving the wider interests of the country and its citizens by attending to the 'bigger picture'

Focusing on the public good and sustainability by addressing research problems holistically

Retaining critical expertise through socially and environmentally significant programmes

Engaging in dialogue with citizens on matters of public interest, and speaking out for change in public policy

\section{Customer service Based on commercial orientation}

Serving clients and thereby adding value to the economy

Focusing on the commercial applications of research towards financial viability

Allowing client requirements to determine research focus and respective expertise

Complying with in-house rules that restrict speaking out and external communication

\section{Belonging: \\ Role Identity}

\section{Advocates of change}

Leading the way in innovative approaches to sustainability

Engaging in efforts to change views and practices towards sustainability

Motivated by a passion for science, the environment, and dealing with 'big' sustainability issues

\section{Allies of business}

Following client-driven goals and accepting the primacy of profit

Pursuing the requirements of business and supporting clients

Motivated by making a difference for clients by taking their practical realities into account in solving more immediate problems

\section{Organising: \\ Professional Integrity}

\section{Retaining scientific credibility and recognition based on science values}

Generating world-class knowledge through cutting edge research

Maintaining openness and transparency by subjecting work to peer review

Disseminating new knowledge through scholarly publication

Admitting when wrong, and not 'doctoring' the results

\section{Meeting client expectations based on practical value}

Providing practical solutions to business problems

Respecting commercial sensitivities, and honouring confidentiality agreements

Packaging knowledge in ways that clients can understand and therefore use

Maintaining professional standards by getting everything 'right' 
central to scientific credibility, and underpinning scientists' ability to address research questions holistically and thereby manage for sustainability in commercial research.

Second, the analysis details the ways in which research scientists see themselves responding to paradox, explicating the perceived constraining and enabling effects of practices on their engagement with sustainability in commercial research. Prior research on paradox finds that individuals often view competing demands as dilemmas and, accordingly, attempt to defend existing practices by choosing between alternatives (e.g., Jarzabkowski et al., 2013; Lewis, 2000). This study identifies responses that scientists see as unproductive, viewing them as undermining their efforts to advocate change towards sustainability and address it by improving industrial practices (Table 8.2). These include the practices of 'opposing' (i.e., openly criticising commercial performance imperatives) and 'suppressing' (continuously focusing on the demands associated with one role at the expense of another).

Based on scientists' perceptions of the longer-term consequences of certain practices, several new defensive responses to paradox are posed. These include the practices of over-committing and isolating which manifest themselves in several ways. While some science managers saw certain of these practices as necessary (assuming that they enhanced one's career prospects, for example), the predominant view was that they were associated with negative consequences. These included higher stress levels, employee burnout, difficulties in managing teams, and the erosion of relationships with clients. Altogether, they saw these practices as constraining scientists' development in ways that enabled them to productively engage with competing demands. 
Table 8.2

Perceived defensive responses to paradox

\begin{tabular}{|c|c|c|}
\hline Paradox & Construct & Illustration \\
\hline \multirow[t]{5}{*}{$\begin{array}{l}\text { Performing: } \\
\text { Service Ethos }\end{array}$} & Opposing & $\begin{array}{l}\text { Openly criticising a perceived emphasis on } \\
\text { commercial enterprise, and vigorously } \\
\text { defending traditional science values and } \\
\text { practices }\end{array}$ \\
\hline & Isolating & $\begin{array}{l}\text { Detaching oneself from the team's effort by } \\
\text { working in silos (pockets of specialisation) }\end{array}$ \\
\hline & Over-committing & $\begin{array}{l}\text { Over-promising when bidding for public } \\
\text { funding }\end{array}$ \\
\hline & & $\begin{array}{l}\text { Over-delivering when fulfilling commercial } \\
\text { contracts }\end{array}$ \\
\hline & Suppressing & $\begin{array}{l}\text { Focusing exclusively on commercial research } \\
\text { responsibilities, and deferring work objectives } \\
\text { pertinent to publicly-funded research (or vice } \\
\text { versa) }\end{array}$ \\
\hline \multirow[t]{2}{*}{$\begin{array}{l}\text { Belonging: } \\
\text { Role Identity }\end{array}$} & Isolating & $\begin{array}{l}\text { Distancing oneself from clients by relying } \\
\text { primarily on commercial managers for } \\
\text { industry contact }\end{array}$ \\
\hline & Suppressing & $\begin{array}{l}\text { Engaging exclusively with the demands } \\
\text { associated with one role at the expense of } \\
\text { another for extended periods }\end{array}$ \\
\hline \multirow[t]{3}{*}{$\begin{array}{l}\text { Organising: } \\
\text { Professional Integrity }\end{array}$} & Opposing & $\begin{array}{l}\text { Challenging management expectations that } \\
\text { scientists engage in the scholarly publishing } \\
\text { process as well as commercial research }\end{array}$ \\
\hline & Over-committing & $\begin{array}{l}\text { Escalating one's efforts for sustained periods } \\
\text { when attempting to engage in scholarly } \\
\text { research activities as well as commercial } \\
\text { research }\end{array}$ \\
\hline & Suppressing & $\begin{array}{l}\text { Continuously allowing a customer service } \\
\text { orientation to dominate or overrule scholarly } \\
\text { research activities }\end{array}$ \\
\hline
\end{tabular}


The study also identifies several productive ways in which research scientists see themselves responding to and managing paradox (Table 8.3). Drawing on prior research and theorisation on paradox (Clegg et al., 2002; Gotsi et al., 2010), it finds that scientists' perceptions of their productive efforts reflect their engagement with a blend of differentiation and integration approaches. Differentiation tactics include internal diversification in scope of services (e.g., the development of research portfolios that include a mix of publicly-funded and commercially-funded research activities), and variation in work organisation and responsibilities (both in dealing with clients and with colleagues internally). New to the literature on paradox are the differentiation tactics this study identifies of developing personal and professional connections with external groups (to enable speaking out on issues of sustainability), the division of labour (to enable coauthorship with colleagues) and incrementalism (when influencing clients towards sustainability).

Turning to integration, tactics used with external parties when addressing sustainability included identifying financial synergies between public and commercial projects, reframing sustainable practices in ways that aligned with client interests, repositioning across roles and identities, as well as harnessing economies of scope in generating both commercial and publication outputs. Scientists' deployment of these tactics was underpinned by the notion of 'acceptance', and overarched by a paradoxical vision on the part of some managers that guided performance monitoring and reporting. 
Table 8.3

Managing paradox through differentiation and integration

\begin{tabular}{|c|c|c|}
\hline Paradox & Construct & Illustration \\
\hline Performing: & Differentiating & Internally diversifying scope of services \\
\hline \multirow[t]{3}{*}{ Service Ethos } & & $\begin{array}{l}\text { Developing personal and professional } \\
\text { connections with external groups }\end{array}$ \\
\hline & Integrating & $\begin{array}{l}\text { Identifying financial synergies between } \\
\text { public good and commercial projects }\end{array}$ \\
\hline & & $\begin{array}{l}\text { (Re)framing problems and solutions for } \\
\text { clients (2-in-1) }\end{array}$ \\
\hline Belonging: & Differentiating & Incrementally influencing clients \\
\hline Role Identity & Integrating & $\begin{array}{l}\text { (Re)positioning and shape-shifting } \\
\text { (2-in-1) }\end{array}$ \\
\hline \multirow{2}{*}{$\begin{array}{l}\text { Organising: } \\
\text { Professional integrity }\end{array}$} & Differentiating & $\begin{array}{l}\text { Internally differentiating responsibilities, } \\
\text { including by co-authoring with colleagues }\end{array}$ \\
\hline & Integrating & $\begin{array}{l}\text { Harnessing economies of scope by co- } \\
\text { authoring with clients }(2-\text { in- } 1)\end{array}$ \\
\hline
\end{tabular}

The study finds that scientists perceive the integration tactics of mentoring and multidisciplinary research teams to be particularly effective means of conveying the message that there was a need to accept the inevitability of tensions in science work. There was also the perception that these mechanisms facilitated scientists' acquisition of the vision and capabilities needed to productively engage with tension when seeking to influence clients towards sustainability. At the same time, scientists viewed their capability to productively engage with sustainability in commercial research as primarily arising from the relational skills they acquired through exposure to the 'realities' of the 
commercial research environment. Other capabilities seen as integral to influencing clients towards sustainability included sophisticated skills in budgeting, marketing, and in communicating. The former allowed scientists to better organise their work and find ways by which to engage with sustainability. The latter enabled scientists to 'sell' themselves and their science to clients.

The study posits that requisite variety is relevant to complex environments. The relevance of this fundamental tenet of systems theory spans strategies of integration at both an individual- and organisational-level. Strategies are described here as '2-in-1' approaches to organising (e.g., re-positioning and adapting one's pattern of engagement when dealing with a client, reframing measures relevant to sustainability in terms more palatable to clients, as well as engaging clients in economies of scope whereby the same resources and components of research are used to generate different outputs).

\subsection{Contribution of the research}

The research contributes to three discussions in the literature on research management: science work and commercial research, conflictions in science work, and issues of role identity. It offers a secondary contribution to the literature on sustainability and science work, and to the literature on paradox in management.

\subsubsection{A paradox perspective on research management}

First, the research adds a novel dimension to the literature on research management by casting the emphasis on engagement with sustainability and perceived paradoxes. Further, whereas previous studies on commercial research had largely focused on university scientists (Jain et al., 2009; Lam, 2011), this study sheds some light on the experiences of public research scientists, a science group faced with simultaneously 
generating economic, social and environmental wealth through extensive engagement with public and private sector clients.

The analysis complements previous research on the tensions faced in science work, and specifically contributes to a nuanced understanding of role identity (e.g., Jain et al., 2009) by explicating the paradoxes of belonging. It outlines the contradictory tensions scientists perceive, and how these are addressed. Specific tensions identified include whether to lead or follow clients in the pursuit of sustainability, the focus of research scientists' practices, and the drivers of their motivation. Interestingly, scientists' capability to reposition their engagement with clients and to incrementally influence them towards sustainability points to the paradoxical approach of leading by following.

\subsubsection{Managing for sustainability in the context of science work}

The concepts posed in this research provide new insight into the ways by which research scientists engage with sustainability; though they play an important role in that movement, the tensions they face have rarely been the subject of analysis. Specifically, this research posits that scientists' engagement cuts across ethos through their desire to address research problems holistically towards long-term results. It also proposes that scientists' engagement with sustainability shapes their views on knowledge generation and sharing, both by underpinning the relevance of dissemination and communication, as well as broadening the scope of research impact from publishing to the practical effects it has on businesses and their respective communities.

Emerging work that examines the conflictions in science work that addresses sustainability (and in engaging with sustainability more generally) has tended to focus on ways by which tensions can be avoided or resolved, rather than accepted and explored through trade-offs, for example (Van der Byl \& Slawinski, 2015). Though scholars have 
begun to conceptualise and promote the management of corporate sustainability using paradoxical frames (Hahn et al., 2014), few have explicitly linked empirical observations to the paradox perspective. Accordingly, this study of the tensions scientists perceive when engaging with sustainability offers a novel contribution to this literature by emphasising the polarising effect of tensions, and the inherent value in finding ways by which to engage with these.

\subsubsection{The paradox perspective in organisational analysis}

By drawing on paradox, this research advances the paradox perspective in organisational analysis by contextualising general paradoxes and their management into the environment for science work and sustainability. Specifically, the findings contribute to understanding in both fields by affirming the defensive responses to paradox of opposing and suppressing (Jarzabkowski et al., 2013), and by identifying new responses that constrain the finding of pathways through which to engage with sustainability in commercial research (i.e., the practices of isolating and over-committing). Also significant is the finding that some scientists associate these responses to paradox with potentially harmful work practices (work intensification). It is plausible that others working in similarly pressured, highly politicised, dynamic environments may do the same.

The findings contribute to understanding research management and paradox by affirming the utility of the management strategies of differentiation and integration, and related tactics of internal diversification in scope of services and career mentoring (e.g., Andriopoulos \& Lewis, 2009; Gotsi et al., 2010). The study makes a new contribution to these literatures by explicating such tactics as the identification of financial synergies and incremental manoeuvring. It introduces three novel approaches to integration (external reframing, repositioning and economies of scope), and posits that through their 
sensemaking, scientists learn to anticipate future events. This allows them to engage in preventative identity work as a way of circumventing problems. Finally, this research advances the paradox perspective in organisational analysis by underlining that requisite variety is pertinent to complex environments, and can inject novelty into theorising on paradox.

\subsubsection{The sensemaking perspective}

The focus on scientists' perceptions of their everyday, often taken-for-granted, experiences of interacting with colleagues and clients has usefully produced a range of views on issues. As Weick explains:

The greater the variety of beliefs in a repertoire, the more fully should any situation be seen, the more solutions that should be identified, and the more likely it should be that someone knows a great deal about what is happening (1995, p. 87).

The variety achieved enhances the contribution this study makes across all three literatures by bringing to the fore the subtleties of practice that scientists see as characteristic of their engagement with the complexities of paradox, as well as the explanations that underly their responses. Though sensemaking is not absent from the literatures on research management (see, for example, Cohen et al., 1999; McAuley, Duberley, \& Cohen, 2000) and paradox (Calton \& Payne, 2003; Jay, 2013; Luscher \& Lewis, 2008), its use is relatively rare.

The focus of this study on individuals' views and experience also represents a departure from the norm of a group- or organisational-level focus and the pursuit of objectivity in the literature on research management (Hackett, 2005; Leitch \& Davenport, 2005; Zabusky \& Barley, 1997), sustainability and science work (Brandt et al., 2013; Epstein, 2008; Garud \& Gehman, 2012; Gibbs, 2009) as well as paradox in management 
(Quinn \& Cameron, 1988; Smith \& Tushman, 2005; Vince \& Broussine, 1996).

Understanding the ways in which individuals see themselves and their environment is important to organisations since the meanings they make shape their expectations and the ways by which they engage with problems (Weick, 1995). Accordingly, the value of this research lies in the contextualised understanding it generates via the production of a rich account of scientists' experience of paradox.

\subsection{Limitations of the research and avenues for future research}

There are limitations to this study. First, it is based on the perceptions of 44 research scientists and as such the insights can be enhanced through further research that encompasses a larger sample, possibly through quantitative design. Future studies could also assess how the central tensions raised in this study, and the notion of paradox more broadly, are relevant in other national contexts with similar/different science structures. The focus could also be extended to include other research contexts, such as universities and private research organisations.

Second, the study focused on the opinions of research scientists, some of whom were also science managers and leaders. While this is a strength in that access to research scientists can be difficult to gain and, in terms of the present study, has produced illuminative data, future research that further extends the range of views could determine the degree to which these paradoxes engage others in science production, such as commercial managers, clients and stakeholders. In particular, those less intimately involved with research may have different arguments and experiences to contribute. A useful approach might be to adopt a project-based perspective, comparing several commercial research projects with a sustainability focus simultaneously. 
Research scientists saw a need for better utilisation of the capability held by CRIs, and spoke of their desire to play a more extensive role in addressing sustainability through their interactions with business. However, there was the view that businesses were often sceptical of the science involved, and had entrenched views that were difficult to shift. Future research might examine business wariness of sustainability science as a paradox of organisational learning. Specifically, it would be useful to explore how efforts to instigate change towards sustainability in organisations foster tensions between the old and new (i.e., the need to draw upon and replace past understandings with new, and more complex ways of seeing). This might be approached as a project-based study that focuses on the arguments constructed by scientists when advocating for change towards sustainability, and on the messages received and transitions made towards both/and thinking by one or more of the industry groups or businesses with which they interact.

Last but not least, there was the perception that scientists required specialised skills (e.g., relational, communication, and marketing) in order to instigate change towards sustainability when dealing with clients. Consistent with claims made in the paradox literature, scientists saw these skills as more sophisticated than those normally acquired through formal education and training. Future research might examine scientists' specialised skills as dynamic capabilities: focusing both on their identification and on the experiential learning that leads to their accumulation. There is the potential for such a study to contribute to several literatures by bringing a process perspective to dynamic capabilities development in the context of scientists' interactions with industry.

\subsection{Implications for practice}

The challenges raised by paradox are not merely insights to mull over in academia, but define everyday processes for science practitioners involved in commercial research 
and sustainability; hence, this study also bears relevance to practice. Paradox enables one to explore dynamics beyond traditional dualities and to develop a more nuanced view of the contradictions that science work encompasses. For those managing research organisations, an appreciation of the key tensions research scientists perceive would offer better insight into the issues they (as managers) need to address, and the range of outcomes that might be realised. For instance, there is the significant learning scientists see as taking place when given ample opportunities to interact with clients, and the view that this is central to developing the capability to effectively engage with clients on both commercial goals and sustainability. Understanding scientists' variegated engagements with sustainability and its role in shaping their opinions of commercial outputs may enable science managers to work through the various decisions with a heightened level of responsiveness.

Further, those in CRIs contemplating and managing for sustainability alongside financial imperatives need to be aware that both processes touch on service ethos and professional integrity so as to develop credible evaluations of their productive potential. There is also the need to recognise that the interrelated nature of tensions is such that responses to the demands associated with one set of imperatives (e.g. financial) can constrain scientists' ability to engage with the demands associated with other imperatives (e.g., the maintenance of professional integrity). Also important at a managerial-level is an understanding of the place of tempered incrementalism when engaging with both commercial goals and sustainability.

Finally, practitioners need to be aware that paradoxical tensions need not be resolved through a singular focus on commercial success or public value; rather, incorporating a simultaneous appreciation of the need for both may be a salient strategy. 


\subsection{In closing}

This research examines the tensions in science work with particular reference to the paradoxes confronting public research scientists in commercial research that addresses sustainability. It details three main paradoxes research scientists perceive, and poses concepts that provide new insight into the ways by which they respond defensively and engage productively with paradox to manage sustainability. The insights gleaned from the study point to the value inherent in drawing on a paradox perspective when grappling with questions pertinent to managing sustainability in complex environments.

Many of the social, economic, and environmental issues nations face have partly arisen as a result of the successful application of scientific knowledge to past industrial problems. The findings of this research suggest that research scientists are productively engaging with paradoxes in their work contexts while also trying to manage the problems they and others have created through, for example, light-handed regulation, and a lack of understanding of the longer-term effects of past business and industrial practices. Accordingly, they inspire the vision of a future based on the exploitation of science and use of resources in ways that better reflect the needs of a sustainable society. As a researcher and a citizen of New Zealand, it was a privilege to have had the opportunity to engage with the ways by which research scientists seek to make a difference for us all. 


\section{References}

Abolafia, M. (2010). Narrative construction as sensemaking. Organization Studies, 31(3), 349-367.

Allen, W. J. (1997). Towards improving the role of evaluation within natural resource management R\&D programmes: The case for 'learning by doing'. Canadian Journal of Development Studies, XVIII(Special Issue), 625-638.

Allen, W. J., Bosch, O., Kilvington, M., Oliver, J., \& Gilbert, M. (2001). Benefits of collaborative learning for environmental management: Applying the Integrated Systems for Knowledge Management approach to support animal pest control. Journal of Environmental Management, 27(2), 215-223.

Allum, N., Sturgis, P., Tabourazi, D., \& Brunton-Smith, I. (2008). Science knowledge and attitudes across cultures: A meta-analysis. Public Understanding of Science, 17, $35-54$.

Alvesson, M. (2003). Beyond neopositivists, romantics, and localists: A reflexive approach to interviews in organizational research. Academy of Management Review, 28(1), 13-33.

Alvesson, M., \& Karreman, D. (2007). Constructing mystery: Empirical matters in theory development. Academy of Management Review, 32(4), 1265-1281.

Alvesson, M., \& Willmott, H. (2002). Identity regulation as organizational control: Producing the appropriate individual. Journal of Management Studies, 39, 620-644.

Andre, R. (2011). Organizational responsiveness to the sustainability paradigm: A comparison of government departments, government sponsored enterprises, and private firms. International Journal of Business Insights \& Transformation, 3(S3), $8-15$.

Andriopoulos, C., \& Lewis, M. W. (2009). Exploitation-exploration tensions and organizational ambidexterity: Managing paradoxes of innovation. Organization Science, 20(4), 696-717.

Andriopoulos, C., \& Lewis, M. W. (2010). Managing innovation paradoxes: Ambidexterity lessons from leading product design companies. Long Range Planning, 43, 104-122.

Angus-Leppan, T., Benn, S., \& Young, L. (2010). A sensemaking approach to trade-offs and synergies between human and ecological elements of corporate sustainability. Business Strategy and the Environment, 19, 230-244.

Argyris, C. (1988). Crafting a theory of practice: The case of organizational paradoxes. In R. E. Quinn \& K. S. Cameron (Eds.), Paradox and transformation: Toward a 
theory of change in organization and management (pp. 255-278). Cambridge, MA: Ballinger.

Ashby, W. R. (1960). Design for a brain: The origin of adaptive behaviour (2nd ed.). London: Chapman and Hall.

Ashforth, B. E. (2001). Role transitions in organizational life: An identity-based perspective. Mahway, NJ: Lawrence Erlbaum Associates.

Ashforth, B. E., Harrison, S. H., \& Corley, K. G. (2008). Identification in organizations: An examination of four fundamental questions. Journal of Management, 34(3), 325-374.

Ashforth, B. E., \& Kreiner, G. E. (1999). "How can you do it?": Dirty work and the challenge of constructing a positive identity. Academy of Management Review, 24, 413-434.

Bammer, G. (2008). Enhancing research collaborations: Three key management challenges Research Policy, 37, 875-887.

Bansal, P., Bertels, S., Ewart, T., MacConnachie, P., \& O'Brien, J. (2012). Bridging the research-practice gap. Academy of Management Perspectives, 26, 73-92.

Bansal, P., \& Hoffman, A. (2010). Oxford handbook of business and the natural environment. Oxford: Oxford University Press.

Barry, D., \& Meisiek, S. (2010). Seeing more and seeing differently: Sensemaking, mindfulness, and the workarts. Organization Studies, 31(11), 1505-1530.

Barry, J., Berg, E., \& Chandler, J. (2006). Academic shape shifting: Gender, management and identities in Sweden and England. Organization, 13(2), 275-298.

Bartunek, J. M. (Ed.). (1988). The dynamics of personal and organizational reframing. Cambridge, MA: Ballinger.

Bartunek, J. M., \& Rynes, S. L. (2014). Academics and practitioners are alike and unlike: The paradoxes of academic-practitioner relationships. Journal of Management, 40(5), 1181-1201.

Bartunek, J. M., Rynes, S. L., \& Ireland, D. R. (2006). What makes management research interesting, and why does it matter? Academy of Management Journal, 49, 9-15.

Basu, K., \& Palazzo, G. (2008). Corporate social responsibility: A process model of sensemaking. Academy of Management Review, 33(1), 122-136.

Battilana, J., Sengul, M., Pache, A., \& Model, J. Harnessing productive tensions in hybrid organizations: The case of work integration social enterprises. Academy of Management Journal, Published online before print November 11, 2014. doi: 10.5465/amj.2013.0903 
Bednarek, R., Blumenfeld, S., \& Riad, S. (2012). Union-division: On the paradoxes of purpose and membership scope in union mergers. Industrial Relations Journal, 43(6), 548-571.

Bellamy, J. A., Walker, D. H., McDonald, G. T., \& Syme, G. J. (2001). A systems approach to the evaluation of natural resource management initiatives. Journal of Environmental Management, 63(4), 407-423.

Benessia, A., Funtowicz, S., Bradshaw, G., Ferri, F., Raez-Luna, E. F., \& Medina, C. P. (2012). Hybridizing sustainability: Towards a new praxis for the present human predicament. Sustainability Science, 7(Supplement 1), 75-89.

Bercovitz, J., \& Feldman, M. (2008). Academic entrepreneurs: Organizational change at the individual level. Organization Science, 19, 69-89.

Bevir, M., \& Kedar, A. (2008). Concept formation in political science: An anti-naturalist critique of qualitative methodology. Perspectives on politics, 6(3), 503-517.

Bhattacharya, C. B., Korschun, D., \& Sen, S. (2008). Strengthening stakeholder-company relationships through mutually beneficial corporate social initiatives. Journal of Business Ethics, 85(2), 257-272.

Biscotti, D., Lacy, W. B., Glenna, L. L., \& Welsh, R. (2012). Constructing "disinterested" academic science: Relational work in univesity-industry research collaborations. Politics \& Society, 40(2), 273-308. doi: 10.1177/0032329212441601

Blaikie, N. (2007). Approaches to social enquiry: Advancing knowledge (2nd ed.). Cambridge, MA: Polity.

Bloodgood, J. M., \& Bongsug, C. (2010). Organizational paradoxes: Dynamic shifting and integrative management. Management Decision, 48(1), 85-104.

Blumer, H. (1969). Symbolic interactionism: Perspective and method. Englewood Cliffs, NJ: Prentice-Hall.

Bolander, P., \& Sandberg, J. (2013). How employee selection decisions are made in practice. Organization Studies, 34, 285-311.

Box, S., \& Cotgrove, S. (1996). Scientific identity, occupational selection, and role strain. The British Journal of Sociology, 17(1), 20-28.

Brandt, P., Ernst, A., Gralla, F., Luederitz, C., Lang, D. J., Newig, J., . . . von Wehrden, H. (2013). A review of transdsciplinary research in sustainability science Ecological Economics, 92, 1-15.

Brown, A. D., Colville, I., \& Pye, A. (2015). Making sense of sensemaking in Organization Studies. Organization Studies, 36(2), 265-277. 
Brown, A. D., Stacey, P., \& Nandhakumar, J. (2008). Making sense of sensemaking narratives. Human Relations, 61(8), 1035-1062.

Brundtland, G. H. (1987). Our common future: Report of the World Commission on Environment and Development. Retrieved August 10, 2012, from http://www.undocuments.net/wced-ocf.htm

Calton, J. M., \& Payne, S. L. (2003). Coping with paradox: Multistakeholder learning dialogue as a pluralist sensemaking process for addressing messy problems. Business \& Society, 42(1), 7-42.

Cameron, K. S., \& Quinn, R. E. (Eds.). (1988). Organizational paradox and transformation. Cambridge, MA: Ballinger.

Capozucca, P., Hutter, L., Kalish, I., Kahlon, S. R., Nayyar, S., Krantz, R., \& Mastioni, M. (2009). Sustainability for tomorrow's consumer: The business case for sustainability. Retrieved September 10, 2013, from http://www3.weforum.org/docs/WEF_CI_SustainabilityForTomorrowsConsumer Report_2009.pdf

Carroll, A. B. (1979). A three-dimensional conceptual model of corporate social performance. Academy of Management Review, 4, 497-506.

Cartner, M., \& Bollinger, T. (1997). Science policy reforms: The New Zealand experience. Social studies of science, 27(5), 775-803.

Cassell, C. (2005). Creating the interviewer: Identity work in the management research process. Qualitative Research, 5(2), 167-179.

Cassiman, B., Di Guardo, M., \& Valentini, G. (2010). Organizing links with science: Cooperate or contract?: A project-level analysis. Research Policy, 39(7), 882-892.

Chase, S. E. (2011). Narrative inquiry: Still a field in the making. In N. K. Denzin \& Y. S. Lincolon (Eds.), The sage handbook of qualitative research (pp. 421-434). Thousand Oaks, CA: Sage.

Chatterjee, D., \& Sankaran, B. (2015). Commercializing academic research in emerging economies: Do organizational identities matter? Science and Public Policy, Advance Access, 1-15.

Chia, R. (2000). Discourse analysis as organizational analysis. Organization, 7(3), 513 518.

Chreim, S., Williams, B. E., \& Hinings, C. R. (2007). Interlevel influences on the reconstruction of professional role identity. Academy of Management Journal, 50(6), 1515-1539. 
Clark, W. C., \& Dickson, N. M. (2003). Sustainability science: The emerging research program. Proceedings of the National Academy of Sciences of the United States of America, 100(14), 8059-8061.

Clarkson, M. B. E. (1995). A stakeholder framework for analyzing and evaluating corporate social performance. Academy of Management Review, 20(1), 92-117.

Clegg, S. R., Vieira da Cunha, J., \& Pina e Cunha, M. (2002). Management paradoxes: A relational view. Human Relations, 55(5), 483-503.

Cohen, L., Duberley, J., \& McAuley, J. (1999). Fuelling discovery or monitoring productivity: Research scientists' changing perceptions of management. Organization, 6(3), 473-497.

Cohen, W. M., Nelson, R. R., \& Walsh, J. P. (2002). Links and impacts: The influence of public research on industrial R\&D. Management Science, 48(1), 1-23.

Collins, E., \& Kearins, K. (2010). Delivering on sustainability's global and local orientation. Academy of Management Learning \& Education, 9(3), 499-506.

Constas, M. A. (1992). Qualitative analysis as a public event: The documentation of category development procedures. American Educational Research Journal, 29(2), 253-266.

Cooper, M. H. (2009). Commercialization of the university and problem choice by academic biological scientists. Science, Technology, \& Human Values, 34(5), 629653.

Corley, K. G., \& Gioia, D. A. (2011). Building theory about theory building: What constitutes a theoretical contribution? Academy of Management Review, 36(1), 1232 .

Cornelissen, J. P. (2012). Sensemaking under pressure: The influence of professional roles and social accountability on the creation of sense. Organization Science, 23(1), 118-137.

Cramer, J., Jonker, J., \& van der Heijden, A. (2004). Making sense of corporate social responsibility. Journal of Business Ethics, 55, 215-222.

Creswell, J. W., \& Miller, D. L. (2000). Determining validity in qualitative inquiry. Theory Into Practice, 39(3), 124-130.

Crossley, J. (2013, March 6, 2013). Scientists collaborate long term, The Dominion Post.

Crown Ownership Monitoring Unit. (2012). Owner's expectations manual. Retrieved July 7, 2014, 2015, from http://www.treasury.govt.nz/commercial/publications/guidance/ownersexpectations-manual/ 
Crown Research Institute Taskforce. (2010). How to enhance the value of New Zealand's investment in Crown Research Institutes: Report of the Crown Research Institute Taskforce. Retrieved August 15, 2014, from http://www.msi.govt.nz/assets/MSI/CRI/Report-of-the-Crown-Research-InstituteTaskforce.pdf

Cunliffe, A., \& Coupland, C. (2012). From hero to villain to hero: Making experience sensible through embodied narrative sensemaking. Human Relations, 65(1), 63-88.

Currie, G., \& Brown, A. D. (2003). A narratological approach to understanding processes of organizing in a UK hospital. Human Relations, 56(5), 563-586.

Daellenbach, U., \& Davenport, S. (2004). Establishing trust during the formation of technology alliances. Journal of Technology Transfer, 29, 187-202.

Davenport, S., \& Bibby, D. (2007). Contestability and contested stability: Life and times of CSIRO's New Zealand cousins, the Crown Research Institutes. Innovation: Management, Policy \& Practice, 9(2), 181-191.

Davenport, S., Davies, J., \& Grimes, C. (1999). Collaborative research programmes: Building trust from difference. Technovation, 19, 31-40.

Denison, D., Hooijberg, R., \& Quinn, R. E. (1995). Paradox and performance: Toward a theory of behavioral complexity in managerial leadership. Organization Science, 6, 524-540.

Denzin, N. K., \& Lincoln, Y. S. (Eds.). (1994). Handbook of qualitative research. Thousand Oaks, CA: Sage.

Dervin, B. (2003). Given a context by any other name: Methodological tools for taming the unruly beast. In B. Dervin, L. Foreman-Wernet \& E. Lauterbach (Eds.), Sensemaking methodology reader: Selected writings of Brenda Dervin (pp. 111-132). Cresskill, N.J.: Hampton Press.

DiMaggio, P. J., \& Powell, W. W. (1983). The iron cage revisited: Institutional isomorphism and collective rationality in organizational fields. American Sociological Review, 48(2), 147-160.

Duberley, J., Cohen, L., \& Mallon, M. (2006). Constructing scientific careers: Change, continuity and context. Organization Studies, 27(8), 1131-1151.

Dubois, A., \& Gadde, L. E. (2002). Systematic combining: An abductive approach to case research. Journal of Business Research, 55(7), 553-560.

Dutton, J. E., Dukerich, J. M., \& Harquail, C. V. (1994). Organizational images and member identification. Administrative Science Quarterly, 39, 239-263.

Ellis, N., \& Ybema, S. (2010). Marketing identities: Shifting circles of identification in interorganizational relationships. Organization Studies, 31(3), 279-305. 
Elmes, M., \& King, K. (2012). Moral sensemaking through digital storytelling. Journal of Business Ethics Education, 9, 259-280.

Empson, L. (2013). My affair with the "other": Identity journeys across the researchpractice divide. Journal of Management Inquiry, 22(2), 229-248.

Epstein, M. J. (2008). Making sustainability work: Best practices in managing and measuring corporate social, environmental, and economic impacts. Sheffield: Greenleaf.

Etzkowitz, H. (1998). The norms of entrepreneurial science: Cognitive effects of the new university-industry linkages. Research Policy, 27, 823-833.

Evans, G., \& Durant, J. (1995). The relationship between knowledge and attitudes in the public understanding of science in Britain. Public Understanding of Science, 3, 5774.

Fahy, D., \& Nisbet, M. C. (2011). The science journalist online: Shifting roles and emerging practices. Journalism, 12(7), 778-793.

Fassin, Y., \& Van Rossem, A. (2009). Corporate governance in the debate on CSR and ethics: Sensemaking of social issues in management by authorities and CEOs. Corporate Governance, 17(5), 573-593.

Fraser, E. D. G., Dougill, A. J., Mabee, W. E., Reed, M., \& McAlpine, P. (2006). Bottom up and top down: Analysis of participatory processes for sustainability indicator identification as a pathway to community empowerment and sustainable environmental management. Journal of Environmental Management, 78, 114-127.

Garud, R., \& Gehman, J. (2012). Metatheoretical perspectives on sustainability journeys: Evolutionary, relational and durational. Research Policy, 41, 980-995.

Gauchat, G. (2011). The cultural authority of science: Public trust and acceptance of organized science. Public Understanding of Science, 20(6), 751-770.

Geels, F. W. (2010). Ontologies, socio-technical transitions (to sustainability), and the multi-level perspective. Research Policy, 39, 495-510.

Geels, F. W., Hekkert, M. P., \& Jacobsson, S. (2008). The dynamics of sustainable innovation journeys. Technology Analysis \& Strategic Management, 20(5), 521536.

Gibbons, M. (1999). Science's new social contract with society. Nature, 402(6761), C81C84.

Gibbs, D. (2009). Sustainability entrepreneurs, ecopreneurs and the development of a sustainable economy. Greener Management International, Winter(55), 63-78. 
Gioia, D. A., \& Chittipeddi, K. (1991). Sensemaking and sensegiving in strategic change initiation. Strategic Management Journal, 12, 433-448.

Gioia, D. A., Schultz, M., \& Corley, K. G. (2000). Organizational identity, image, and adaptive instability. Academy of Management Review, 25(1), 63-81.

Given, L. M. (2008). The Sage encyclopedia of qualitative research methods. Los Angeles, CA: Sage.

Gladwin, T. N., Kennelly, J. J., \& Krause, T. S. (1995). Shifting paradigms for sustainable development: Implications for management theory and research. Academy of Management Review, 20(4), 874-907.

Glenna, L. L., Welsh, R., Ervin, D., Lacy, W. B., \& Biscotti, D. (2011). Commercial science, scientists' values, and university biotechnology research agendas. Research Policy, 40(7), 957-968.

Glynn, M. A. (2000). When cymbals become symbols: Conflict over organizational identity within a symphony orchestra. Organization Science, 11(3), 285-298.

Gotsi, M., Andriopoulos, C., Lewis, M. W., \& Ingram, A. (2010). Managing creatives: Paradoxical approaches to identity regulation. Human Relations, 63(6), 781-805.

Goven, J. (2006). Processes of inclusion, cultures of calculation, structures of power: Scientific citizenship and the Royal Commission on Genetic Modification. Science, Technology \& Human Values, 31(5), 565-598.

Grant, A. M., Dutton, J. E., \& Rosso, B. D. (2008). Giving commitment: Employee support programs and the prosocial sensemaking process. Academy of Management Journal, 51(5), 898-918.

Gregory, R., \& Keeney, R. L. (1994). Creating policy alternatives using stakeholder values. Management Science, 40(8), 1035-1048.

Grifoni, P., Guzzo, T., \& Ferri, F. (2014). Environmental sustainability and participatory approaches: The case of Italy. Journal of Sustainable Development, 7(3), 1-12.

Guba, E. G., \& Lincoln, Y. S. (1994). Competing paradigms in qualitative research. In N. K. Denzin \& Y. S. Lincoln (Eds.), Handbook of qualitative research (pp. 105-117). Thousand Oaks, CA: Sage.

Hackett, E. J. (2005). Essential tensions: Identity, control, and risk in research. Social Studies of Science, 35(5), 787-826.

Hahn, T., Figge, F., Pinkse, J., \& Preuss, L. (2010). Trade-offs in corporate sustainability: You can't have your cake and eat it. Business Strategy and the Environment, 19(4), 217-229. 
Hahn, T., Pinkse, J., Preuss, L., \& Figge, F. (2015). Tensions in corporate sustainability: Towards an integrative framework. Journal of Business Ethics, 127(2), 297-316.

Hahn, T., Preuss, L., Pinkse, J., \& Figge, F. (2014). Cognitive frames in corporate sustainability: Managerial sensemaking with paradoxical and business case frames. Academy of Management Review, 39(4), 463-487.

Heinze, T., \& Kuhlmann, S. (2008). Across institutional boundaries? Research collaboration in German public sector nanoscience. Research Policy, 37, 888-899.

Hirsch Hadorn, G., Bradley, D., Pohl, C., Rist, S., \& Wiesmann, U. (2006). Implications of transdisciplinarity for sustainability research. Ecological Economics, 60(1), 119128.

Holstein, J. A., \& Gubrium, J. F. (1994). Phenomenology, ethnomethodology, and interpretive practice. In N. K. Denzin \& Y. S. Lincoln (Eds.), Handbook of qualitative research (pp. 262-272). Thousand Oaks, CA: Sage.

Holt, R., \& Cornelissen, J. P. (2014). Sensemaking revisited. Management Learning, $45(5), 525-539$.

Humphreys, M., Ucbasaran, D., \& Lockett, A. (2012). Sensemaking and sensegiving stories of jazz leadership. Human Relations, 65(1), 41-62.

Humphries, M., \& Brown, A. D. (2002). Narratives of organizational identity and identification: A case study of hegemony and resistance. Organization Studies, 23(3), 421-447.

Ibarra, H. (1999). Provisional selves: Experimenting with image and identity in professional adaptation. Administrative Science Quarterly, 44, 764-791.

Jain, S., George, G., \& Maltarich, M. (2009). Academics or entrepreneurs? Investigating role identity modification of university scientists involved in commercialization activity. Research Policy, 38, 922-935.

Jamali, D., Mirshak, R, Yianni, M., \& Abdallah, H. (2011). Strategic partnerships, social capital and innovation: Accounting for social alliance innovation. Business Ethics: A European Review, 20(4), 375-391.

Jarzabkowski, P., Le, J., \& Van de Ven, A. H. (2013). Responding to competing strategic demands: How organizing, belonging, and performing paradoxes coevolve. Strategic Organization, 11(3), 245-280.

Jay, J. (2013). Navigating paradox as a mechanism of change and innvovation in hybrid organizations. Academy of Management Journal, 56(1), 137-159.

Jonker, J., \& Nijhof, A. (2006). Looking through the eyes of others: Assessing mutual expectations and experiences in order to shape dialogue and collaboration between business and NGOs with respect to CSR. Corporate Governance, 14(5), 456-466. 
Kaiser, M. (2014). The integrity of science - Lost in translation? Best Practice \& Research Clinical Gastroenterology, 28, 339-347.

Karreman, D., \& Alvesson, M. (2001). Making newsmakers: Conversational identity at work. Organization Studies, 22, 59-89.

Kelsey, J. (1997). The New Zealand experiment: A world model for structural adjustment? Auckland, New Zealand: Auckland University Press.

Ketola, T. (2007). A holistic corporate responsibility model: Integrating values, discourses, and actions. Journal of Business Ethics, 80(3), 419-435.

Klag, M., \& Langley, A. (2013). Approaching the conceptual leap in qualitative research. International Journal of Management Reviews, 15, 149-166.

Kosmala, K., \& Herrbach, O. (2006). The ambivalence of professional identity: On cynicism and jouisance in audit firms. Human Relations, 59(10), 1393-1428.

Krishna, V. V. (2014). Changing social relations between science and society: Contemporary challenges. Science, Technology \& Society, 19(2), 133-159.

Kubie, L. S. (1960). Some unsolved problems of the scientific career. In M. R. Stein, A. J. Vidich \& D. M. White (Eds.), Identity and Anxiety: Survival of the person in mass society (pp. 241-268). New York, USA: The Free Press.

Lam, A. (2007). Knowledge networds and careers: Academic scientists in industryuniversity links. Journal of Management Studies, 44(6), 1467-6486.

Lam, A. (2010). From 'Ivory Tower Traditionalists' to 'Entrepreneurial Scientists'? Academic scientists in fuzzy university-industry boundaries. Social Studies of Science, 40(2), 307-340.

Lam, A. (2011). What motivates academic scientists to engage in research commercialization: 'Gold', 'ribbon' or 'puzzle'? Research Policy, 40(10), 13541368 .

Larsen, M. T. (2011). The implications of academic enterprise for public science: An overview of the empirical evidence. Research Policy, 40(1), 6-19.

Lawrence, P. R., \& Lorsch, J. W. (1967). Differentiation and integration in complex organizations. Administrative Science Quarterly, 12(1), 1-47.

Lawrence, R. J., \& Despres, C. (2004). Futures of transdisciplinarity. Futures, 36, 397405.

Le Ber, M. J., \& Branzei, O. (2010). (Re)forming strategic cross-sector partnerships: Relational processes of social innovation. Business \& Society, 49(1), 140-172. 
Leitch, S., \& Davenport, S. (2005). The politics of discourse: Marketization of the New Zealand science and innovation system. Human Relations, 58(7), 891-912.

Leitch, S., \& Davenport, S. J. (2007). Strategic ambiguity as a discourse practice: The role of keywords in the discourse on 'sustainable' biotechnology. Discourse Studies, 9(1), 43-61.

Leitch, S., Motion, J., Merlot, E., \& Davenport, S. (2014). The fall of research and rise of innovation: Changes in New Zealand science policy discourse. Science and Public Policy, 41(1), 119-130.

Lewis, G. J., \& Stewart, N. (2003). The measurement of environmental performance: An application of Ashby's law Systems Research and Behavioral Science, 20, 31-52.

Lewis, M. W. (2000). Exploring paradox: Towards a more comprehensive guide. Academy of Management Review, 25(4), 760-776.

Lewis, M. W., Andriopoulos, C., \& Smith, W. K. (2014). Paradoxical leadership to enable strategic agility. California Management Review, 56(3), 58-77.

Lewis, M. W., \& Smith, W. K. (2014). Paradox as a metatheoretical perspective: Sharpening the focus and widening the scope. Journal of Applied Behavioral Science, 50(2), 127-149.

Locke, K. D., Golden-Biddle, K., \& Feldman, M. S. (2008). Making doubt generative: Rethinking the role of doubt in the research process. Organization Science, 19(6), 907-918.

Louis, M. (1980). Surprise and sensemaking: What newcomers experience in entering unfamiliar organizational settings. Administrative Science Quarterly, 25(2), 226251.

Low, B., \& Johnston, W. (2012). Emergent technologies, network paradoxes, and incrementalism. Journal of Business Research, 65, 821-828.

Luscher, L. S., \& Lewis, M. W. (2008). Organizational change and managerial sensemaking: Working through paradox. Academy of Management Journal, 51(2), 221-240.

Luscher, L. S., Lewis, M. W., \& Ingram, A. (2006). The social construction of organizational change paradoxes. Journal of Organizational Change Management, 19(4), 491-502.

Maclean, M., Harvey, C., \& Chia, R. (2012). Sensemaking, storytelling and the legitimization of elite business careers. Human Relations, 65(1), 17-40.

Maitlis, S. (2005). The social processes of organizational sensemaking. Academy of Management Journal, 48(1), 21-49. 
Maitlis, S., \& Christianson, M. (2014). Sensemaking in organizations: Taking stock and moving forward. Academy of Management Annals, 8(1), 57-125.

Maitlis, S., \& Lawrence, T. B. (2007). Triggers and enablers of sensegiving in organizations. Academy of Management Journal, 50(1), 57-84.

Maitlis, S., \& Sonenshein, S. (2010). Sensemaking in crisis and change: Inspiration and insights from Weick (1988). Journal of Management Studies, 47(3), 551-580.

Maitlis, S., Vogus, T. J., \& Lawrence, T. B. (2013). Sensemaking and emotion in organizations. Organizational Psychology Review, 3(3), 222-247.

Mallon, M., Duberley, J., \& Cohen, L. (2005). Careers in public sector science: Orientations and implications. $R \& D$ Management, 35(4), 395-407.

Mantere, S., Schildt, H. A., \& Sillince, J. A. (2012). Reversal of strategic change. Academy of Management Journal, 55(1), 172-196.

Margolis, J. D., \& Walsh, J. P. (2003). Misery loves companies: Rethinking social initiatives by business. Administrative Science Quarterly, 48, 268-305.

Mariappanadar, S. (2014). Stakeholder harm index: A framework to review work intensification from the critical HRM perspective. Human Resource Management Review, 24, 313-329.

Markard, J., Raven, R., \& Truffer, B. (2012). Sustainability transitions: An emerging field of research and its prospects. Research Policy, 41, 955-967.

McAuley, J., Duberley, J., \& Cohen, L. (2000). The meaning professionals give to management . . . and strategy. Human Relations, 53(1), 87-116.

McIntyre, J. (1998). Consideration of categories and tools for holistic thinking. Systemic Practice and Action Research, 11(2), 105-126.

Michaud, V. (2013). Business as a pretext? Managing social-economic tensions on a social enterprise's website.M@n@gement, 16(3),294-331.

Midgley, G., \& Reynolds, M. (2004). Systems/operational research and sustainable development: Towards a new agenda. Sustainable Development, 12, 56-64.

Miles, M. B., \& Huberman, A. M. (1994). Qualitative data analysis (2nd ed.). Thousand Oaks, CA: Sage.

Miller, D. (1993). The architecture of simplicity. Academy of Management Review, 18(1), 116-138.

Miller, T. R. (2013). Constructing sustainability science: Emerging perspectives and research trajectories. Sustainability Science, 8, 279-293. 
Ministry of Business Innovation \& Employment. (2014). Crown Research Institutes. Get Connected. Retrieved March 24, 2015, from http://www.msi.govt.nz/getconnected/crown-research-institutes/2015-cri-toolkit/section-4/\#no-surprises-policy

Mora-Valentin, E. M., Montoro-Sanchez, A., \& Guerras-Martin, L. A. (2004).

Determining factors in the success of $R \& D$ cooperation agreements between firms and research organizations. Research Policy, 33, 17-40.

Morgan, G. (1997). Images of organization. Thousand Oaks, CA: Sage.

Motion, J., \& Doolin, B. (2007). Out of the laboratory: Scientists' discursive practices in their encounters with activists. Discourse Studies, 9(1), 63-85.

Mumford, M. D., Connelly, S., Brown, R. P., Murphy, S. T., Hill, J. H., Antes, A. L., . . Devenport, L. D. (2008). A sensemaking approach to ethics training for scientists: Preliminary evidence of training effectiveness. Ethics \& Behavior, 18(4), 315-339.

Nelkin, D. (1977). Scientists and professional responsibility: The experience of American ecologists. Social Studies of Science, 7, 75-95.

Nonaka, I., Toyama, R., \& Konno, N. (2000). SECI, Ba and leadership: A unified model of dynamic knowledge creation. Long Range Planning, 33(1), 5-34.

O'Leary, R., Gerard, C. M., \& Choi, Y. (2012). The skill set of the successful collaborator. Public Administration Review, 72(51), 570-583.

Office of the Auditor-General. (2013). Crown Research Institutes: Results of the 2011/2012 audits. Retrieved February 5, 2015, from http://www.oag.govt.nz/2013/cri-audits/docs/crown-research-institutes-audits.pdf

Ong, B. K. (2012). Grounded theory method (GTM) and the abductive research strategy (ARS): A critical analysis of their differences. International Journal of Social Research Methodology, 15(5), 417-432.

Pache, A., \& Santos, F. (2010). When worlds collide: The internal dynamics of organizational responses to conflicting institutional demands. Academy of Management Review, 35(3), 455-476.

Papachroni, A., Heracleous, L., \& Paroutis, S. Organizational ambidexterity through the lens of paradox theory: Building a novel research agenda. Journal of Applied Behavioral Science, Published online before print October 10, 2014. doi: $10.1177 / 0021886314553101$

Patton, M. Q. (2002). Qualitative research \& evaluation methods (3rd ed.). Thousand Oaks, CA: Sage.

Pearlson, K. E., \& Saunders, C. S. (2001). There's no place like home: Managing telecommuting paradoxes. Academy of Management Executive, 15(2). 
Poole, M. S., \& Van de Ven, A. H. (1989). Using paradox to build management and organization theories. Academy of Management Review, 14(4), 562-578.

Pratt, M. G., Rockmann, K. W., \& Kaufmann, J. B. (2006). Constructing professional identity: The role of work and identity earning cycles in the customization of identity among medical residents. Academy of Management Journal, 49(2), 235262.

Prenkert, F. (2006). A theory of organizing informed by activity theory: The locus of paradox, sources of change, and challenges to management. Journal of Organizational Change Management, 19(4), 471-490.

Putnam, L. L., Myers, K. K., \& Gailliard, B. M. (2013). Examining the tensions in workplace flexibility and exploring options for new directions. Human Relations, 66(12), 1-28.

Quinn, J. B. (1980). Strategies for change: Logical incrementalism. Homewood, IL: Irwin.

Quinn, J. B. (1982). Managing strategies incrementally. OMEGA - The International Journal of Management Science, 10(6), 613-627.

Quinn, R. E. (1988). Beyond rational management: Mastering the paradoxes and competing demands of high performance. San Francisco: Jossey-Bass.

Quinn, R. E., \& Cameron, K. S. (Eds.). (1988). Paradox and Transformation: A framework for viewing organization and management. Cambridge, MA: Ballinger.

Rama, D., Milano, B. J., Salas, S., \& Liu, C.-H. (2008). CSR implementation: Developing the capacity for collective action. Journal of Business Ethics, 85, 463-477.

Ramarajan, L. (2014). Past, present and future research on multiple identities: Toward an intrapersonal network approach. Academy of Management Annals, 8(1), 589-659.

Ramirez, G. A. (2012). Sustainable development: Paradoxes, misunderstandings and learning organizations. The Learning Organization, 19(1), 58-76.

Rasche, A., \& Behnam, M. (2009). As if it were relevant: A systems theoretical perspective on the relation between science and practice. Journal of Management Inquiry, 18(3), 243-255.

Redclift, M. (2005). Sustainable development (1987-2005): An oxymoron comes of age. Sustainable Development, 13(4), 212-227.

Rees, W. (2010). What's blocking sustainability? Human nature, cognition, and denial. Sustainability: Science, Practice, \& Policy, 6(2), 13-25.

Ridder, H. G., Hoon, C., \& McCandless Baluch, A. (2014). Entering a dialogue:

Positioning case study findings towards theory. British Journal of Management, 25(2), 373-387. 
Roche, M. M. (1993). Public Good Science Fund: Crown Research Institutes and the restructuring of State science research in New Zealand. New Zealand Geographer, $49(1), 42-45$.

Roper, J., \& Schoenberger-Orgad, M. (2011). State-owned enterprises: Issues of accountability and legitimacy. Management Communication Quarterly, 25(4), 693 709 .

Rosso, B. (2014). Creativity and constraints: Exploring the role of constraints in the creative processes of research and development teams. Organization Studies, 35(4), 551-585.

Rouleau, L. (2005). Micro-practices of strategic sensemaking and sensegiving: How middle managers interpret and sell change every day. Journal of Management Studies, 42(7), 1413-1441.

Royal Society of New Zealand. (2012, 18 October 2012). Royal Society of New Zealand Code of Professional Standards and Ethics. Retrieved March 19, 2015, from http://www.royalsociety.org.nz/organisation/about/code/

Sandberg, J., \& Tsoukas, H. (2011). Grasping the logic of practice: Theorizing through practical rationality. Academy of Management Review, 36(2), 338-360.

Sanz-Menendez, L., \& Cruz-Castro, L. (2003). Coping with environmental pressures: Public research organisations responses to funding crises. Research Policy, 32, 1293-1308.

Schwandt, T. A. (1994). Constructivist, interpretivist approaches. In N. K. Denzin \& Y. S. Lincoln (Eds.), Handbook of qualitative research (pp. 118-137). Thousand Oaks, CA: Sage.

Science Media Centre. (2015). Crown Research Institutes. Retrieved January 21, 2015, from http://www.sciencemediacentre.co.nz/science-in-nz/crown-research-institutes/

Science New Zealand. (2012). Science \& Innovation that benefits New Zealand: Briefing to incoming ministers. Wellington, New Zealand: Science New Zealand.

Science New Zealand. (2013). Who we are. About Science New Zealand. Retrieved April 16, 2013, from http://www.sciencenewzealand.org/About-Science-New-Zealand

Science New Zealand. (2014). Advancing ideas, delivering results: Briefing for incoming ministers. Wellington, NZ: Science New Zealand.

Seager, T. P. (2008). The sustainability spectrum and the sciences of sustainability. Business Strategy and the Environment, 17, 444-453. 
Seitanidi, M. M., Koufopoulos, D. N., \& Palmer, P. (2010). Partnership formation for change: Indicators for transformative potential in cross sector social partnerships. Journal of Business Ethics, 94(1), 139-161.

Selsky, J. W., \& Parker, B. (2011). Platforms for cross-sector social partnerships: Prospective sensemaking devices for social benefit. Journal of Business Ethics, 94(1), 21-37.

Senge, P., Smith, B., Kruschwitz, N., Laur, J., \& Schley, S. (2008). The necessary revolution: How individuals and organizations are working together to create a sustainable world. London: Nicholas Brealey.

Seo, M. G., Putnam, L. L., \& Bartunek, J. M. (2004). Dualities and tensions of planned organizational change. In M. S. Poole \& A. H. Van de Ven (Eds.), Handbook of Organizational Change and Innovation (pp. 73-107). New York: Oxford University Press.

Sharma, A., \& Kearins, K. (2010). Interorganizational collaboration for regional sustainability: What happens when organizational representatives come together? Journal of Applied Behavioral Science, 47(2), 168-203.

Sharma, G., \& Good, D. (2013). The work of middle managers: Sensemaking and sensegiving for creating positive social change. Journal of Applied Behavioral Science, 49(1), 95-122.

Shove, E., \& Walker, G. (2010). Governing transitions in the sustainability of everyday life. Research Policy, 39, 471-476.

Simpson, B., \& Hibbert, P. (2008). Tradition and identity change in public sector science organizations. International Journal of Public Administration, 31(9), 1110-1126.

Sluss, D. M., \& Ashforth, B. E. (2007). Relational identity and identification: Defining ourselves through work relationships. Academy of Management Review, 32(1), 932.

Small, B., \& Mallon, M. (2007). Science, society, ethics, and trust: Scientists' reflections on the commercialization and democratization of science. International Studies of Management \& Organization, 37(1), 103-124.

Smith, K., \& Berg, D. (1987a). Paradoxes of group life. San Francisco, CA: Jossey-Bass.

Smith, K., \& Berg, D. (1987b). A paradoxical conception of group dynamics. Human Relations, 40(10), 633-657.

Smith, W. K. (2014). Dynamic decision making: A model of senior leaders managing strategic paradoxes. Academy of Management Journal, 57(6), 1592-1623.

Smith, W. K., Besharov, M., Wessels, A., \& Chertok, M. (2012). A paradoxical leadership model for social entrepreneurs: Challenges, leadership skills, and pedagogical tools 
for managing social and commercial demands. Academy of Management Learning \& Education, 11(3), 463-478.

Smith, W. K., \& Lewis, M. W. (2011). Toward a theory of paradox: A dynamic equilibrium model of organizing. Academy of Management Review, 36(2), 381403.

Smith, W. K., \& Lewis, M. W. (2012). Leadership skills for managing paradoxes. Industrial \& Organizational Psychology, 5(2), 227-231.

Smith, W. K., \& Tushman, M. L. (2005). Managing strategic contradictions: A top management model for managing innovation streams. Organization Science, 16(5), $522-536$.

Snow, D. A., Rochford, E. B., Worden, S. K., \& Benfold, R. D. (1986). Frame alignment processes, micromobilization, and movement participation. American Sociological Review, 51(4), 464-481.

Sonenshein, S. (2010). We're changing or are we? Untangling the role of progressive, regressive, and stability narratives during strategic change implementation. Academy of Management Journal, 53(3), 477-512.

Steiner, S., \& Posch, A. (2006). Higher education for sustainability by means of transdisciplinary case studies: An innovative approach for solving complex, realworld problems. Journal of Cleaner Production, 14, 877-890.

Stevens, P. (2012). Towards an ecosociology. Sociology, 46(4), 579-595.

Strauss, A., \& Corbin, J. (1994). Grounded theory methodology: An overview. In N. K. Denzin \& Y. S. Lincoln (Eds.), Handbook of qualitative research (pp. 273-285). Thousand Oaks, CA: Sage.

Stryker, S., \& Burke, P. J. (2000). The past, present, and future of an identity theory. Social Psychology Quarterly, 64(4), 284-297.

The New Zealand Association of Scientists. (2005). There is a better way: Eight recommendations on the science system in New Zealand. Retrieved June 4, 2013, from http://www.scientists.org.nz/files/page/2010/07/nzasdp2005.pdf.

Thompson, L., Gilding, M., \& Spurling, T. H. (2011). The paradox of public science and global business: CSIRO, commercialisation and the national system of innovation in Australia. Innovation: Management, Policy \& Practice, 13(3), 327-340.

Tosey, P. (2005). The Hunting of the Learning Organization: A Paradoxical Journey. Management Learning, 36(3), 335-352.

Tracey, P., Phillips, N., \& Jarvis, O. (2011). Bridging institutional entrepreneurship and the creation of new organizational forms. Organization Science, 22, 60-80. 
Tracy, S. (2004). Dialectic, contradiction, or double bind? Analyzing and theorising employee reactions to organizational tension. Journal of Applied Communication Research, 32(2), 119-146.

Valente, M. (2012). Theorizing firm adoption of sustaincentrism. Organization Studies, 33(4), 563-591.

Van der Byl, C. A., \& Slawinski, N. (2015). Embracing tensions in corporate sustainability: A review of research from win-wins and trade-offs to paradoxes and beyond. Organization \& Environment, 28(1), 54-79.

Van Maanen, J., Sorensen, J. B., \& Mitchell, T. R. (2007). The interplay between theory and method. Academy of Management Review, 32, 1145-1154.

Vince, R., \& Broussine, M. (1996). Paradox, defense and attachment: Accessing and working with emotions and relations underlying organizational change. Organization Studies, 17, 1-21.

Waddock, S., \& McIntosh, M. (2011). SEE Change: Making the transition to a sustainable enterprise economy. Sheffield: Greenleaf.

Weber, K., \& Glynn, M. A. (2006). Making sense with institutions: Context, thought and action in Karl Weick's theory. Organization Studies, 27(11), 1639-1660.

Weick, K. E. (1979). The social psychology of organizing (2nd ed.). Reading, MA: Addison-Wesley.

Weick, K. E. (1989). Theory construction as disciplined imagination. Academy of Management Review, 14(4), 516-531.

Weick, K. E. (1995). Sensemaking in organizations. Thousand Oaks, CA: Sage.

Weick, K. E. (2007). The generative properties of richness. Academy of Management Journal, 50, 14-19.

Weick, K. E. (2012). Organized sensemaking: A commentary on processes of interpretive work. Human Relations, 65(1), 141-153.

Weick, K. E., \& Roberts, K. H. (1993). Collective mind in organizations: Heedful interrelating on flight decks. Administrative Science Quarterly, 38, 357-381.

Weick, K. E., Sutcliffe, K. M., \& Obstfeld, D. (1999). Organizing for high reliability: Processes of collective mindfulness. Research in Organizational Behavior, 21, 81123.

Weick, K. E., Sutcliffe, K. M., \& Obstfeld, D. (2005). Organizing and the process of sensemaking. Organization Science, 16(4), 409-421. 
Weisenfled, U. (2009). Serendipity as a mechanism of change and its potential for explaining change processes. Management Revue, 20(2), 138-148.

Welsh, R., Glenna, L., Lacy, W., \& Biscotti, D. (2008). Close enough but not too far: Assessing the effects of university-industry research relationships and the rise of academic capitalism. Research Policy (37), 1854-1864.

Whittemore, A. (2013). Finding sustainability in conservative contexts: Topics for conversation between American conservative elites, planners and the conservative base. Urban Studies, 50(4), 1-18.

Willis, J. W. (2007). Foundations of qualitative research: Interpretive and critical approaches. Thousand Oaks, CA: Sage.

Wisker, G. (2008). The postgraduate research handbook (2nd ed.). Basingstoke, UK: Palgrave Macmillan.

World Commission on Environment and Development. (1987). Our common future. Oxford: Oxford University Press.

Worley, C. G., Feyerherm, A. E., \& Knudsen, D. (2010). Building a collaboration capability for sustainability: How Gap Inc. is creating and leveraging a strategic asset. Organizational Dynamics, 39, 325-334.

Wrzesniewski, A., \& Dutton, J. E. (2001). Crafting a job: Revisioning employees as active crafters of their work. Academy of Management Review, 26(2), 179-201.

Yarime, M., Trencher, G., Mino, T., Scholz, R. W., Olsson, L., Ness, B., . . Rotmans, J. (2012). Establishing sustainability science in higher education institutions: Towards an integration of academic development, institutionalization, and stakeholder collaborations. Sustainability Science, 7(Supplement 1), 101-113.

Zabusky, S. E., \& Barley, S. R. (1997). "You can't be a stone if you're cement": Reevaluating the emic identities of scientists in organizations. Research in Organizational Behavior, 19, 361-404.

Zilber, T. B. (2007). Stories and the discursive dynamics of institutional entrepreneurship: The case of Israeli high-tech after the bubble. Organization Studies, 28, 1035-1054. 


\section{Appendices}

Appendix I: Crown Research Institutes Act 1992 (Part 1, Section 5)

Appendix II: Interview schedule

Appendix III: Letter of introduction (organisations)

Appendix IV: Information sheet (participants)

Appendix V: Consent form 


\section{Appendix I \\ Crown Research Institutes Act 1992 (Part 1, Section 5)}

\section{Principles of operation ${ }^{1}$}

(1) Every Crown Research Institute shall, in fulfilling its purpose, operate in accordance with the following principles:

(a) that research undertaken by a Crown Research Institute should be undertaken for the benefit of New Zealand:

(b) that a Crown Research Institute should pursue excellence in all its activities:

(c) that in carrying out its activities a Crown Research Institute should comply with any applicable ethical standards:

(d) that a Crown Research Institute should promote and facilitate the application of-

(i) the results of research; and

(ii) technological developments:

(e) that a Crown Research Institute should be a good employer as required by section 118 of the Crown Entities Act 2004:

(f) that a Crown Research Institute should be an organisation that exhibits a sense of social responsibility by having regard to the interests of the community in which it operates and by endeavouring to accommodate or encourage those interests when able to do so.

(2) Every Crown Research Institute shall, in fulfilling its purpose, operate in a financially responsible manner so that it maintains its financial viability.

(3) For the purposes of subsection (2), a Crown Research Institute is financially viable if-

(a) regardless of whether or not it is required to pay dividends to the Crown, the activities of the Crown Research Institute generate, on the basis of generally accepted accounting principles, an adequate rate of return on shareholders' funds; and

(b) the Crown Research Institute is operating as a successful going concern.

${ }^{1}$ Crown Research Institutes Act 1992, No. 47. (1992). Retrieved from http://www.legislation.govt.nz/act/public/1992/0047/latest/DLM265144.html. 


\section{Appendix II \\ Interview Schedule}

Introductory questions:

1. What is your role within this organisation? How long have you worked here?

2. What information, if any, have you received on your organisation's corporate responsibility policy or sustainability philosophy since joining the organisation? How do you see it yourself?

3. What involvement have you personally had with any external organisations or groups concerned with matters of sustainability?

Questions generally relevant to sustainability:

4. What does 'sustainability' mean to you?

5. CRIs have special responsibilities under the CRI Act 1992 to conduct their affairs in a socially responsible manner. How does this policy resonate with you, as a scientist? What implications, if any, does it have in terms of your dayto-day activities?

6. As a research scientist, how do you view the relationship between the corporate sector, wider society, and the natural environment?

Questions relevant to managing sustainability

7. What is your experience of working with business on issues of sustainability? What prompted your involvement? What was your role?

8. What are some of the key challenges and rewards you see in working with business on issues of sustainability?

9. In what ways can organisational or group dynamics influence such research programmes?

10. How do you see your organisation's role evolving when it comes to dealing with business on issues of sustainability? Is this the best way forward/what ought to happen?

11. In what ways, if any, has your engagement with colleagues and clients on issues of sustainability influenced the way you feel about your role as a research scientist? 


\section{Appendix III \\ Letter of Introduction}

\section{Dear Scientist}

As part of my PhD studies at Victoria University of Wellington, I am exploring the role of the public research scientist in the corporate sustainability agenda. I am seeking your permission to include some of the scientists employed by your organisation in my study.

The aim of my research is to contribute to understanding the dynamics that guide scientists in their interactions with others as they engage with business on issues of sustainability. This will include the ways in which they interpret, navigate, and identify with their role, and how they see this role evolving. It is anticipated that the findings will shed light on how different worldviews of organising and action are enabling or constraining the development of an externally productive and internally fulfilling role for the public research scientist in the corporate sustainability agenda.

Central to the success of this study is the participation of scientists who have experience with one or more commercial contracts with a focus on sustainability. The nature of this involvement may range from behind-the-scenes laboratory work to participation in team decision-making, and/or direct collaboration with a corporate client. If you are interested, I would be happy to provide you with a summary of findings on completion of this project. Each participant will also be offered a summary of findings.

If your organisation takes part in this study, interviews will be conducted with a selection of staff who individually agree to participate. These interviews would take approximately 60 minutes, and be scheduled at a time convenient to participants. If possible, it would be helpful to be provided with names of staff with relevant experience who may be invited to participate in the study. Your organisation would be one of four organisations I would include in my research.

My research follows all the guidelines of Victoria University's Human Ethics Committee. Participation is entirely voluntary and participants are free to pull out at any stage prior to final analysis of data (date). Neither the organisations nor the individual participants who take part in this study will be identified in the reporting. Data gathered will be held securely in password protected files and a locked filing cabinet, and access will be restricted to me and my supervisors.

If you would like to meet to discuss any aspect of this project, please let me know. Alternatively, you are welcome to contact one of my supervisors. 
Researcher: Mary Ashby

PhD Student

Victoria Management School

Victoria University of Wellington

P O Box 600, Wellington 6140

Mobile: $\mathrm{xxx}$

Email: mary.ashby@vuw.ac.nz

Supervisors: Dr Sally Riad

Professor Sally Davenport

Victoria Management School

Victoria Management School

Victoria University of Wellington Victoria University of Wellington

P O Box 600, Wellington 6140

P O Box 600, Wellington 6140

Phone: 044635079

Phone: 044635144

Email: sally.riad@vuw.ac.nz

Email: sally.davenport@ vuw.ac.nz 


\title{
Appendix IV \\ Information Sheet
}

\author{
Information for Research Participants
}

\section{Overview}

As part of my $\mathrm{PhD}$ studies at Victoria University of Wellington, I am exploring the role of the public research scientist in the corporate sustainability agenda. The aim of my research is to contribute to understanding the dynamics that guide scientists in their interactions with others as they engage with business on issues of sustainability. This will include the ways in which they interpret, navigate, and identify with their role in relation to sustainability, and how they see this role evolving. It is anticipated that the findings will shed light on different worldviews of organising and action that enable or constrain the development of an externally productive and internally fulfilling role for the public research scientist in the corporate sustainability agenda.

Central to the success of this study is the participation of scientists who have experience with one or more commercial contracts, directly or indirectly linked to an issue of sustainability. The nature of this involvement may range from behind-the-scenes laboratory work to participation in team decision-making, and/or direct collaboration with a corporate client. Although your organisation has agreed to be included in this research, you are under no obligation to participate. Approval has been granted by the Victoria University Human Ethics Committee to proceed with this project.

\section{What is involved?}

- I am looking for a range of views, a variety of different experiences and opinions, from scientists who agree to talk with me.

- I will be asking about your opinions of corporate sustainability generally, and specific experiences you have had in your role as a scientist with regard to issues of sustainability.

- Interviews are expected to take about one hour; with your permission, they will be recorded. 


\section{How is research material handled?}

- Confidentiality will be maintained during and after the research study. Quotes from individuals will be used, but the organisation's name and the participants' names will not be mentioned; pseudonyms will be used instead. While every effort will be placed to ensure confidentiality, participants should be aware that their past or present profile within the organisation could link them to the information provided.

- When the research is completed, a summary of findings will be made available for you upon your request.

- A participant may withdraw themselves or any information they have provided by 31 October 2011 (when data collection is completed in your organisation) without having to give reasons. Data collected from the participant will be removed from all records.

- The data collected will be securely held, and access will be restricted to me and my supervisors.

The findings of this study will be of value to your organisation and other organisations concerned with corporate sustainability. If you have any queries about this study, please do not hesitate to ask. Contact details are below.

\section{Researcher:}

Mary Ashby

$\mathrm{PhD}$ Student

Victoria Management School

Victoria University of Wellington

P O Box 600, Wellington 6140

Mobile: $x x x$

Email: mary.ashby@vuw.ac.nz

\section{Supervisors:}

$\begin{array}{ll}\text { Dr Sally Riad } & \text { Professor Sally Davenport } \\ \text { Victoria Management School } & \text { Victoria Management School } \\ \text { Victoria University of Wellington } & \text { Victoria University of Wellington } \\ \text { P O Box 600, Wellington 6140 } & \text { P O Box 600, Wellington 6140 } \\ \text { Phone: 04 463 5079 } & \text { Phone: 04 463 5144 } \\ \text { Email: } \text { sally.riad@ vuw.ac.nz } & \text { Email: } \text { sally.davenport@ vuw.ac.nz }\end{array}$




\section{Appendix V \\ Consent Form}

\section{Participant Consent Form}

I have been given and have understood an explanation of this research project. I have had an opportunity to ask questions and have them answered to my satisfaction. I understand that I may withdraw myself or any information I have provided by 31 October 2011 (before data collection is completed within my organisation) without having to give reasons.

$\square \quad$ I agree to the use of the recorder during the interview (please tick if you agree)

$\square \quad$ I would like to receive a summary of the findings of this research (please tick if interested)

I have read and understood the above and agree to participate in this study.

\section{Participant}

Name:

Organisation:

Signature:

Date:

Additional comments (optional)

I wish to be identified by the following position descriptor: 